\title{
A landscape-scale assessment of Holocene fire regime controls in south-eastern
} British Columbia, Canada

\author{
by \\ Colin John Courtney Mustaphi
}

\begin{abstract}
A thesis submitted to the Faculty of Graduate and Postdoctoral Affairs in partial fulfillment of the requirements for the degree of
\end{abstract}

\author{
Doctor of Philosophy \\ in \\ Earth Sciences
}

Carleton University

Ottawa, Ontario

(C) 2013

Colin J. Courtney Mustaphi 


\begin{abstract}
Multiple vegetation and forest fire history records were established by analyzing Holocene-aged lake sediment stratigraphies collected across a vegetation and elevation gradient in southeast British Columbia, Canada. The stratigraphies were dated using radiometric techniques, ${ }^{210} \mathrm{~Pb}$ and ${ }^{14} \mathrm{C}$ dating, and tephrochronology and were examined to understand the spatial controls of forest fires and how those controls varied in importance throughout the Holocene in response to orbital geometry variations, climatic change, forest composition changes, and fuel abundance within the watersheds. Local conditions have been shown to be important controls of fire activity in the region, but can be overridden by other broad-scale factors such as climate. Aspect was shown to be an important spatial control of fire frequencies at mid elevation Engelmann spruce-subalpine fir forests. At subalpine elevations, fuel abundance within the catchment was important in explaining millennial to centennial scale fire frequencies. When investigating past biomass burning, the analysis of macroscopic charcoal morphologies permits a more nuanced analysis of the temporal variability in fuel sources and taphonomic processes in a watershed. This study contributes to our knowledge of the varying spatial controls at the landscape scale of Holocene forest fires in mountainous southeastern British Columbia, to understand the influence of local and broad-scales controls of biomass burning and to the analysis of sediment-charcoal morphologies.
\end{abstract}




\section{Table of Contents}

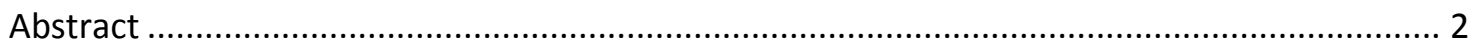

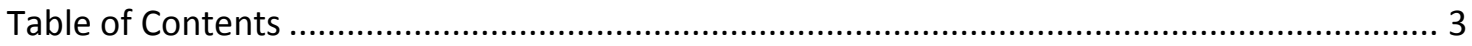

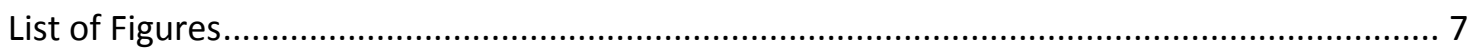

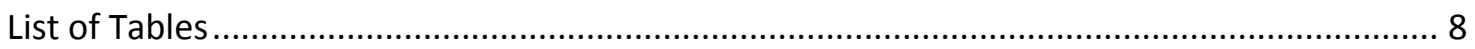

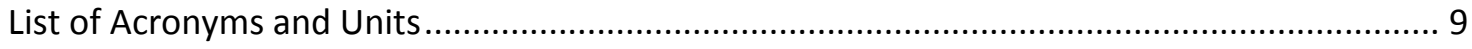

Preface

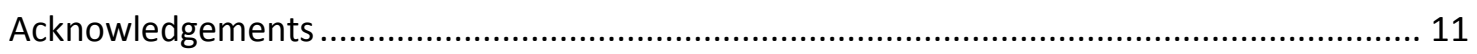

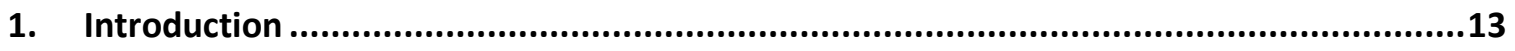

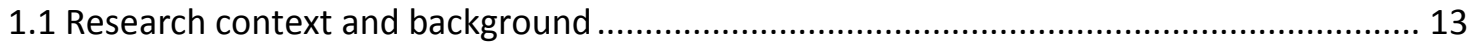

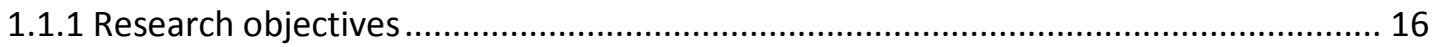

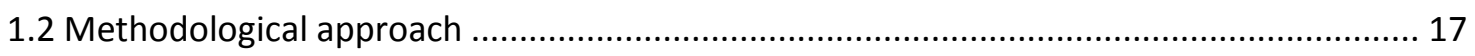

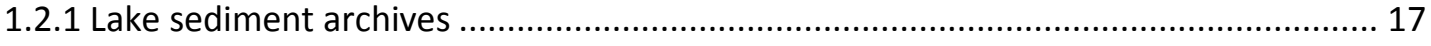

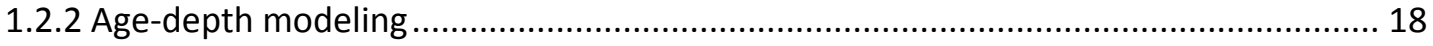

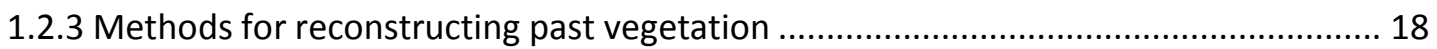

1.2.4 Methods for reconstructing past forest fire activity ............................................... 19

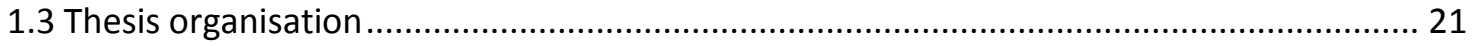

2. Varying influence of climate and aspect as controls of montane forest fire regimes during the late Holocene, south-eastern British Columbia, Canada....................................................22

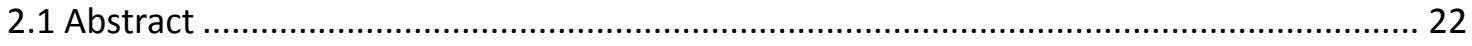

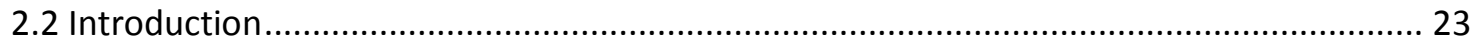

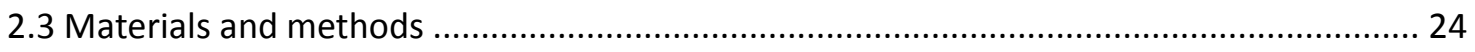

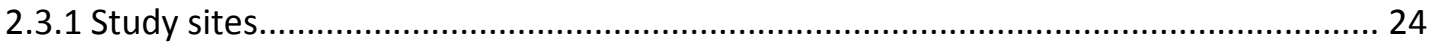

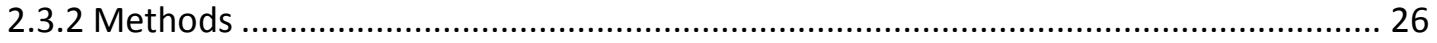

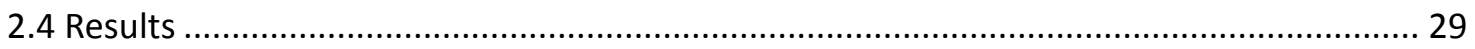

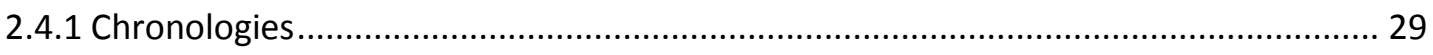

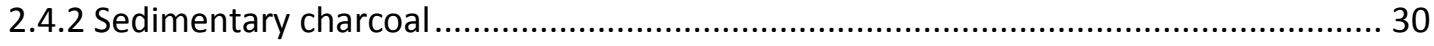

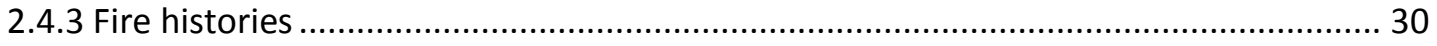

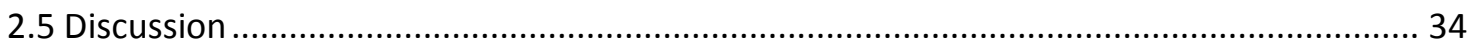

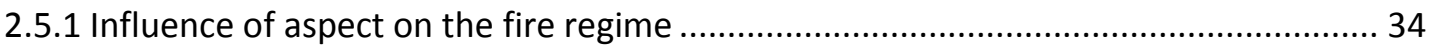

2.5.2 Millennial-scale variability of fire frequency ............................................................. 37 


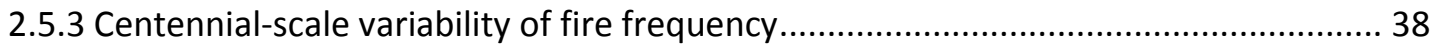

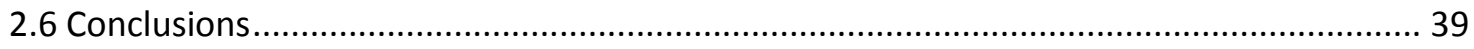

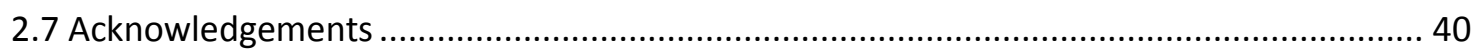

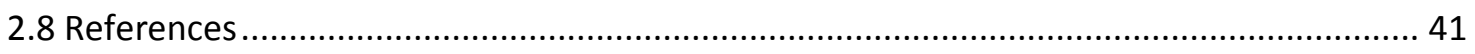

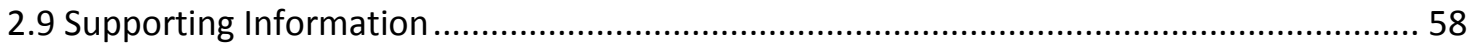

3. Holocene climate-fire-vegetation interactions at a subalpine watershed in southeastern

British Columbia, Canada ................................................................................................59

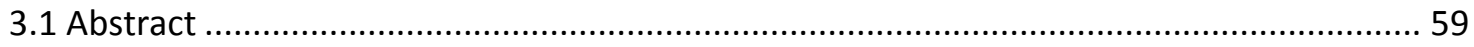

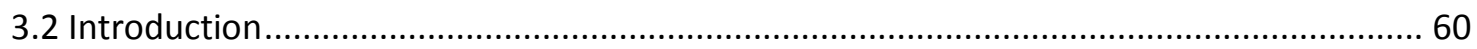

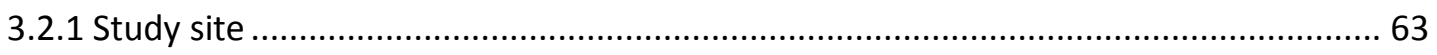

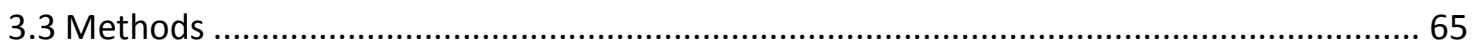

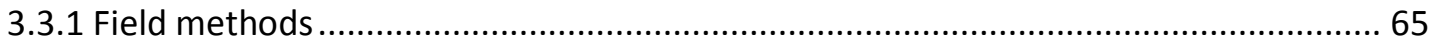

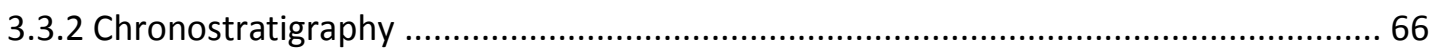

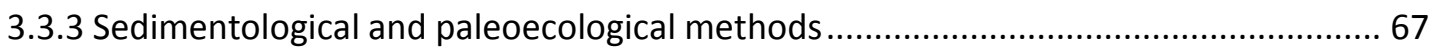

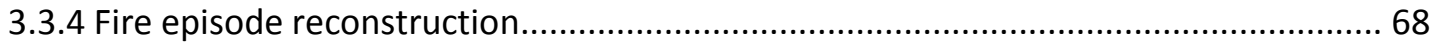

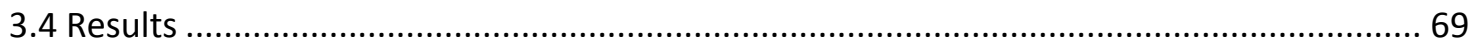

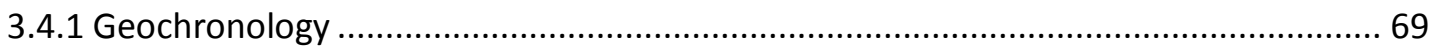

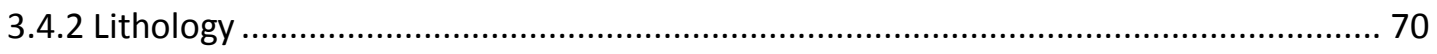

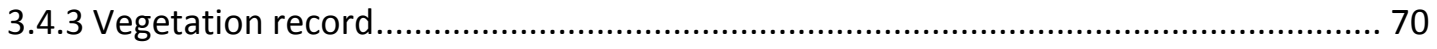

3.4.4 Macroscopic charcoal record and fire-episode reconstruction ................................. 72

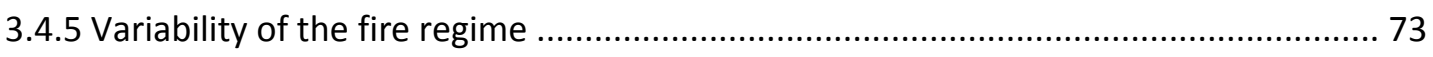

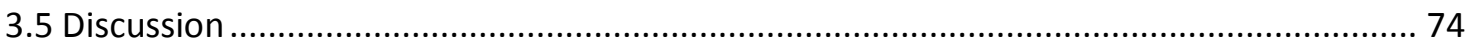

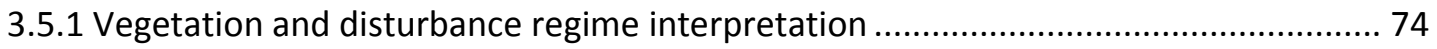

3.5.2 Comparison with other Holocene Engelmann spruce forest records ......................... 79

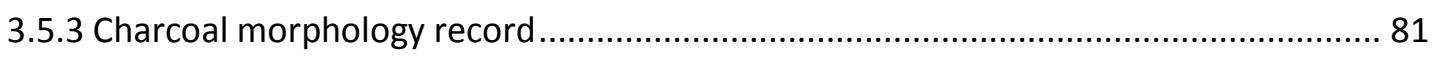

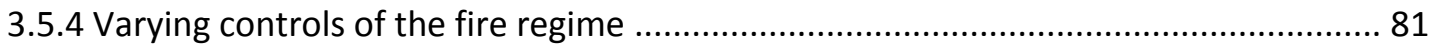

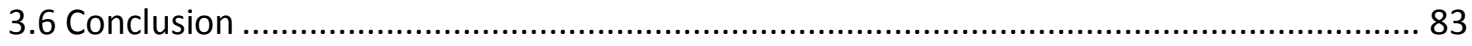

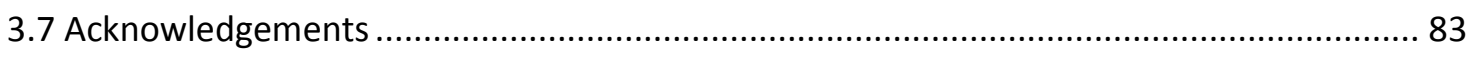

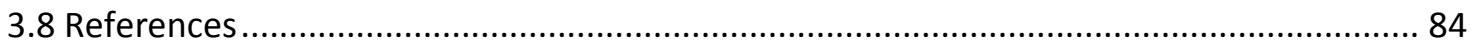

4. A 7500-year record of climate-fire-vegetation interactions at a mountain valley site, southeast British Columbia, Canada ................................................................................. 103

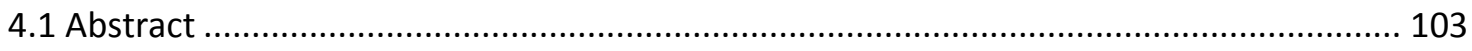




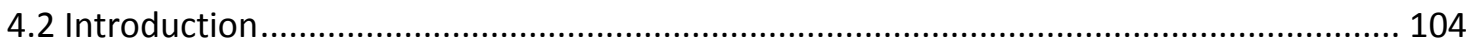

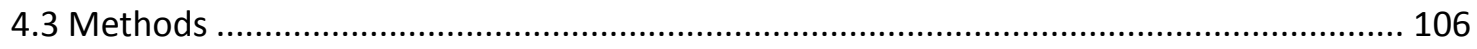

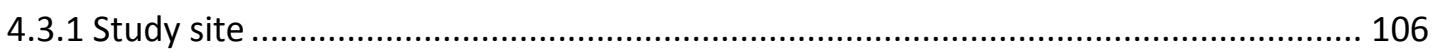

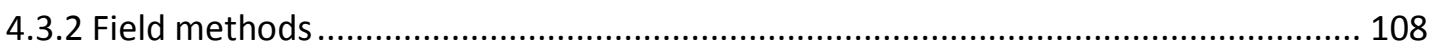

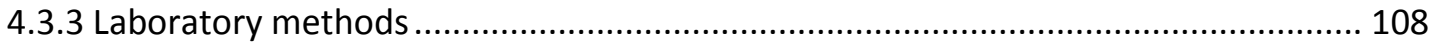

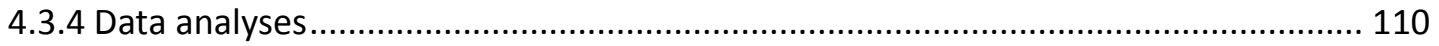

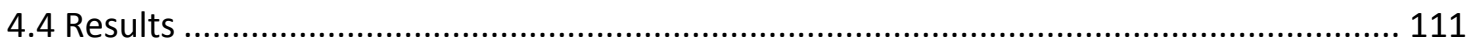

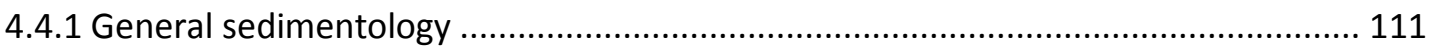

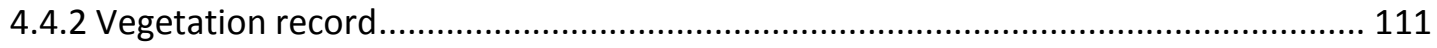

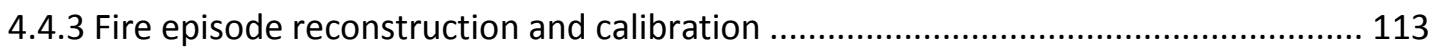

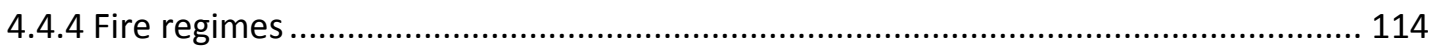

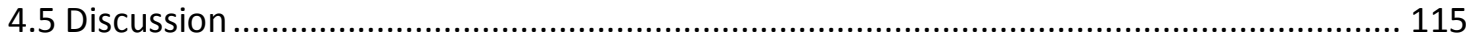

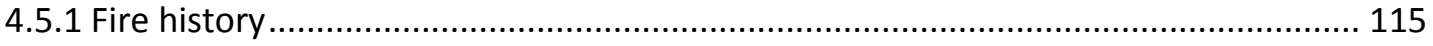

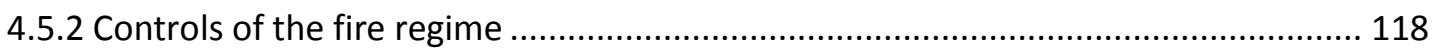

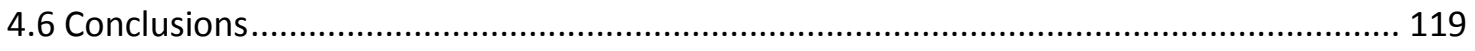

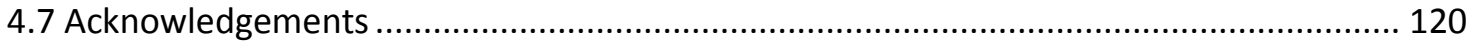

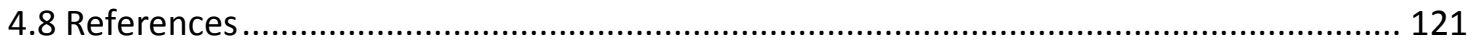

\section{A classification for macroscopic charcoal morphologies found in Holocene lacustrine}

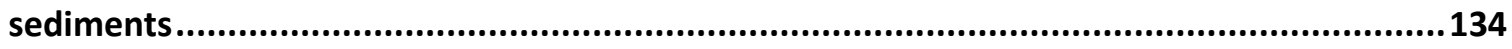

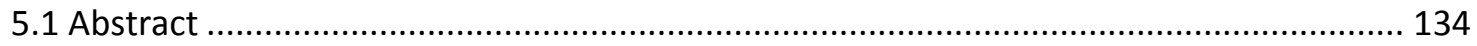

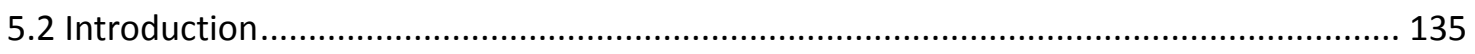

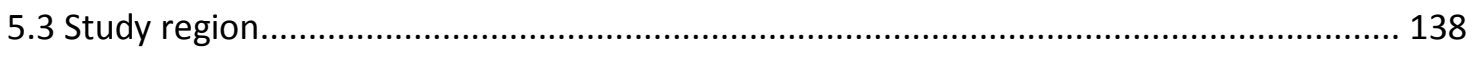

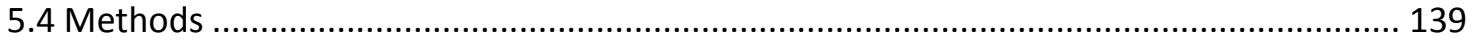

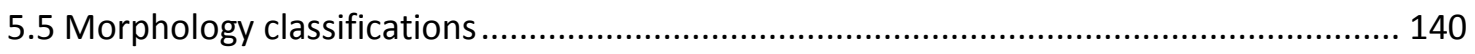

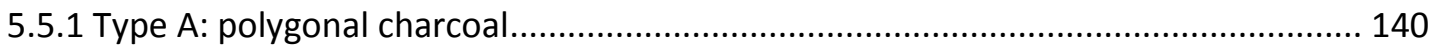

5.5.2 Type B: ortho-angular polygons and polyhedra (blocky shaped).............................. 141

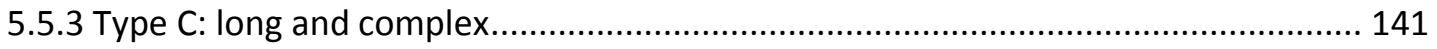

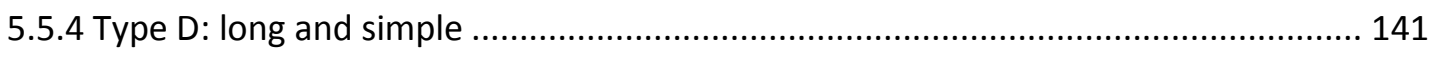

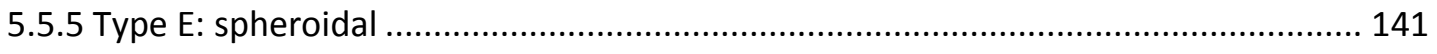

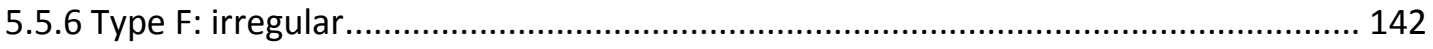

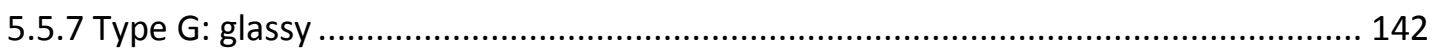

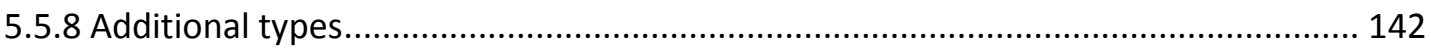




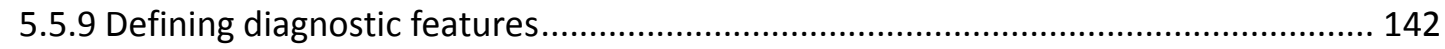

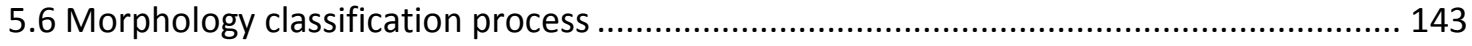

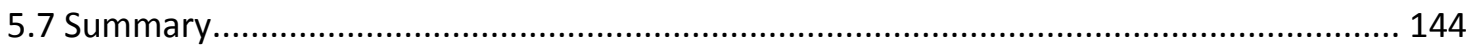

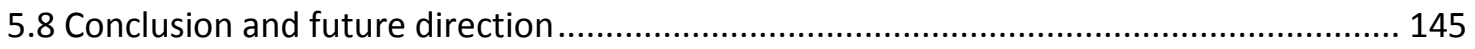

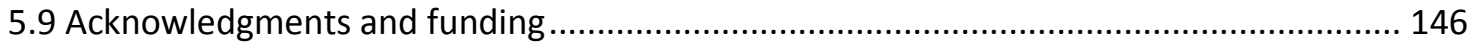

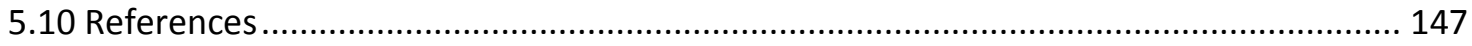

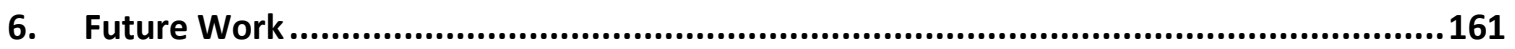

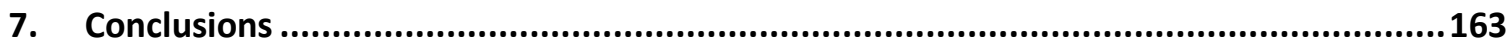

References cited in the Introduction and Conclusion chapters ..........................................164

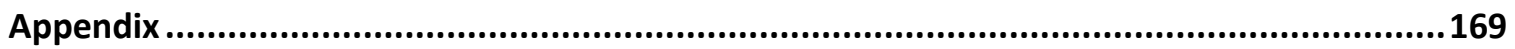

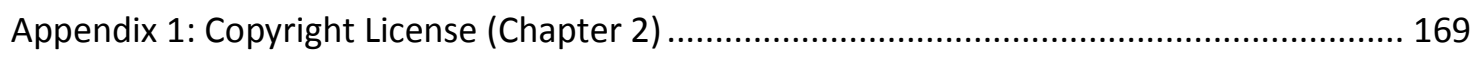

Appendix 2: NELO3 spline and BACON age-depth models ................................................ 170 


\section{List of Figures}

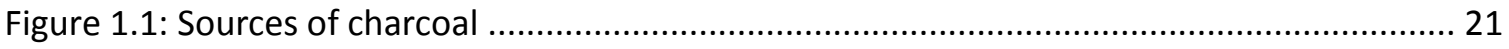

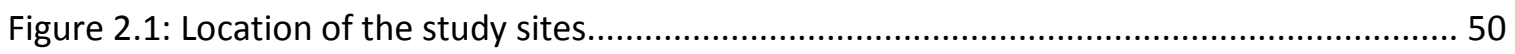

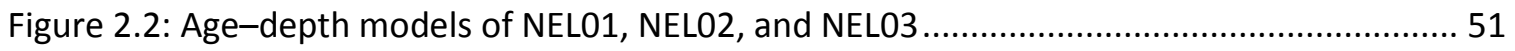

Figure 2.3: Fire reconstructions from 5 lake sediment stratigraphies ........................................ 52

Figure 2.4: Bivariate $L$-function analyses between fire histories at each lake site ...................... 54

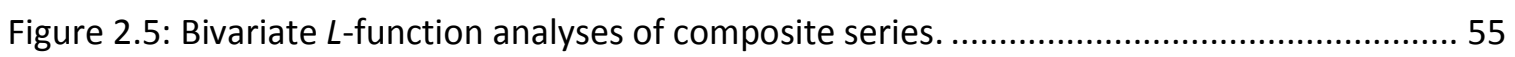

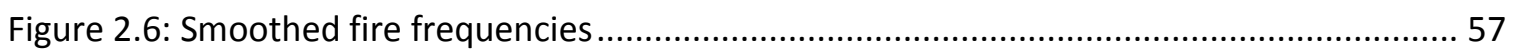

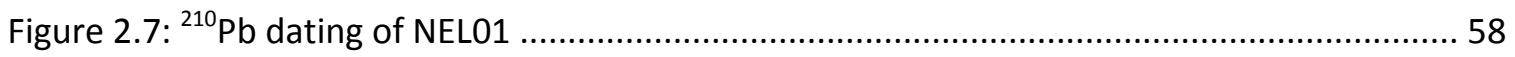

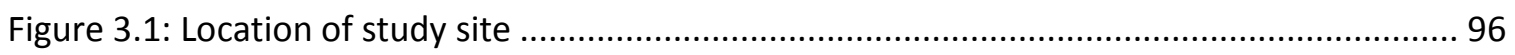

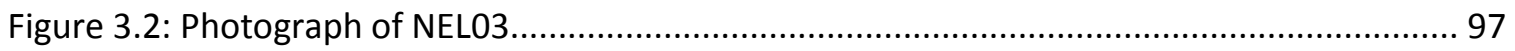

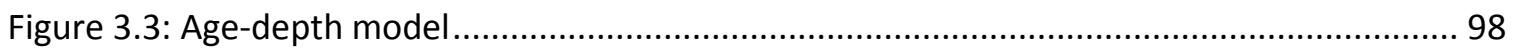

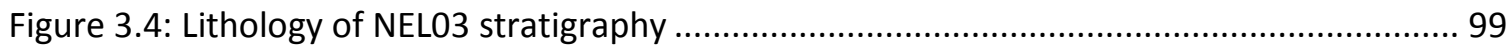

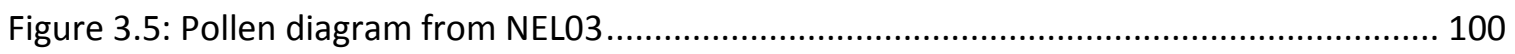

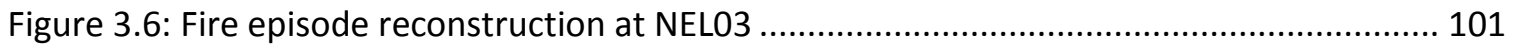

Figure 3.7: Holocene vegetation and disturbance history .................................................. 102

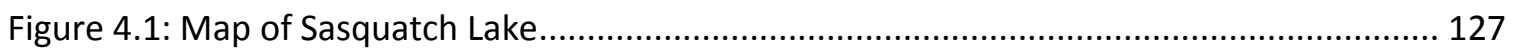

Figure 4.2: General sedimentology of Sasquatch Lake ........................................................ 128

Figure 4.3: Holocene pollen spectra of the Sasquatch Lake sediment stratigraphy.................. 129

Figure 4.4: Summary of known fire information near Sasquatch Lake .................................... 130

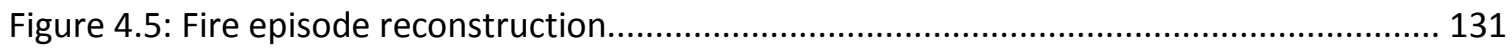

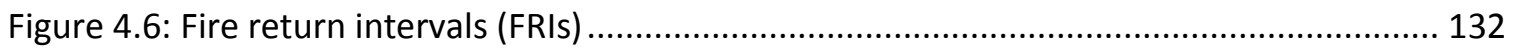

Figure 4.7: Holocene vegetation and disturbance history ................................................... 133

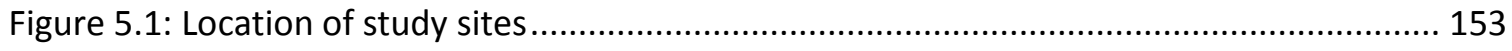

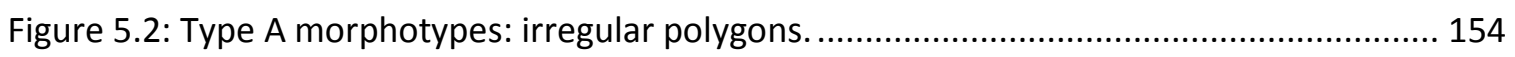

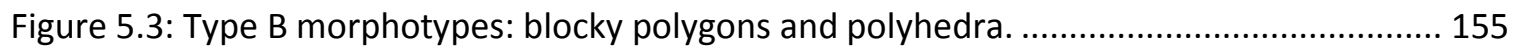

Figure 5.4: Type C morphotypes: long with complex features. ............................................. 156

Figure 5.5: Type D to G morphotypes: long and simple, spheroidal, irregular, and glassy......... 157

Figure 5.6: Classification key for sedimentary macroscopic charcoal morphology analysis....... 158

Figure 5.7: Photographs of charcoal produced from burning of known fuels........................... 159

Figure 5.8: Photographs of charcoal found in lake sediments ................................................. 159 


\section{List of Tables}

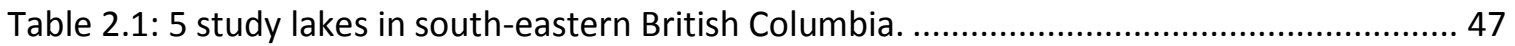

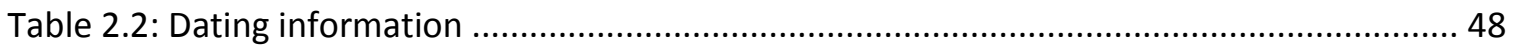

Table 2.3: Summary statistics of fire episode reconstruction ................................................... 49

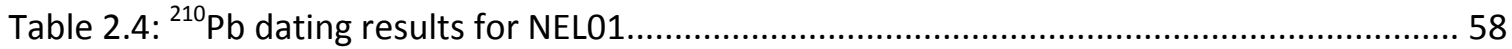

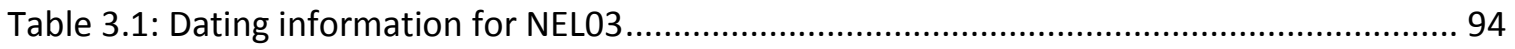

Table 3.2: Total and morphotype charcoal accumulation rates (CHAR) ................................... 95

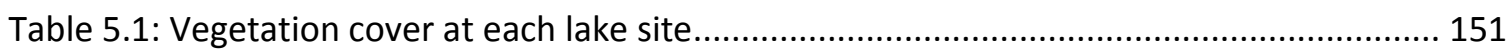

Table 5.2: Decision process for charcoal and charcoal morphology identification ..................... 152 


\section{List of Acronyms and Units}

$\begin{array}{ll}\text { a (unit) } & \text { annus (year) } \\ \text { AD } & \text { Anno Domini } \\ \text { AMS } & \text { accelerator mass spectroscopy } \\ \text { BP } & \text { Before Present (CE 1950) } \\ \text { bCHAR } & \text { background charcoal accumulation rate (pieces cm }{ }^{-2} \mathrm{yr}^{-1} \text { ) } \\ \text { cal a BP, cal. yr BP } & \text { calibrated years Before Present (CE 1950) } \\ \text { CE } & \text { Common Era } \\ \text { CHAR } & \left.\text { charcoal accumulation rate (pieces } \mathrm{cm}^{-2} \mathrm{yr}^{-1}\right) \\ \text { CNFDB } & \text { Canadian National Fire Database } \\ \text { CONISS } & \text { constrained incremental sums of squares cluster analysis } \\ \text { CRS } & \text { constant rate of supply (modelled }{ }^{210} \mathrm{~Pb} \text { dates) }^{-1} \\ \text { CUPL } & \text { Carleton University Paleoecological Laboratory } \\ \text { CWFIS } & \text { Canadian Wildland Fire Information System } \\ \text { ESSF } & \text { Engelmann spruce-subalpine fir } \\ \text { FRI } & \text { fire return interval } \\ \text { ICH } & \text { interior cedar-hemlock } \\ \text { LIA } & \text { Little Ice Age } \\ \text { LOWESS } & \text { locally weighted (regression) and scatterplot smoothing } \\ \text { Ma } & \text { megaannum (million years ago) } \\ \text { MCA } & \text { Medieval Climate Anomaly } \\ \text { mFRI } & \text { median fire return interval } \\ \text { PEARL } & \text { Paleoecological Environmental Assessment and Research } \\ \text { RSI } & \text { Laboratory (Queen's University, Kingston, Canada) } \\ \text { SNI } & \text { regime shift index } \\ & \text { signal-to-noise index }\end{array}$




\section{Preface}

This integrated article format thesis dissertation comprises four chapters that have been submitted to peer-reviewed scientific journals. The overall workload for this dissertation took this form: Dr. Michael F.J. Pisaric (MFJP) and Colin J. Courtney Mustaphi (CJCM) conceived the studies and led the fieldwork; CJCM collected the data and conducted the data analyses with oversight from MFJP and suggestions from Dr. Timothy Patterson; CJCM ideated the manuscripts; and CJCM and MFJP co-authored the writing. Each chapter has been edited and modified from the submitted versions for formatting and figure and table numbering.

A version of Chapter 2 was published in the Journal of Biogeography and was reproduced with permission from John Wiley and Sons (license in Appendix 1).

Colin J. Courtney Mustaphi and Michael F.J. Pisaric. Varying influence of climate and aspect as controls of montane forest fire regimes during the late Holocene, southeastern British Columbia, Canada. Journal of Biogeography, Volume 40, Issue 10, pages 1983-1996. DOI: 10.1111/jbi.12143

CJCM and MFJP conceived the study; MFJP and CJCM led the field work; CJCM led the data collection and data analysis; and CJCM and MFJP led the writing.

A version of Chapter 3 was accepted to Quaternary Research as

Colin J. Courtney Mustaphi and Michael F.J. Pisaric. Holocene climate-fire-vegetation interactions at a subalpine watershed in southeastern British Columbia, Canada.

CJCM and MFJP conceived the study; MFJP and CJCM led the field work; CJCM led the data collection and data analysis; and CJCM and MFJP led the writing.

Chapter 4 was submitted to the International Journal of Wildland Fire as Colin J. Courtney Mustaphi and Michael F.J. Pisaric. A 7500-year record of climatefire-vegetation interactions at a mountain valley site, southeast British Columbia, Canada.

CJCM and MFJP conceived the study; MFJP and CJCM led the field work; CJCM led the data collection and data analysis; and CJCM and MFJP led the writing.

Chapter 5 was submitted to Progress in Physical Geography as

Colin J. Courtney Mustaphi and Michael F.J. Pisaric. A classification for macroscopic charcoal morphologies found in Holocene lacustrine sediments. 
CJCM conceived the study; MFJP and CJCM led the field work; CJCM led the data collection and data analysis; and CJCM and MFJP led the writing.

Some additional material, mainly from work done alongside Chapters 2-4, was contributed to a multi-author study submitted to Quaternary International titled

Jesse L. Morris, Colin J. Courtney Mustaphi, Vachel A. Carter, Jennifer Watt, Kelly Derr, Michael F.J. Pisaric, R. Scott Anderson, and Andrea Brunelle. How do bark beetle remains in lake sediments correspond to severe outbreaks? A review of published and ongoing work.

JLM conceived the study, all others provided field- and lab-based information and all contributed to writing.

\section{Acknowledgements}

This work would not have been possible without the efforts of other researchers and those who helped in the laboratory. I am indebted to my supervisor and co-author of each thesis chapter; Michael Pisaric, and to the co-primary investigators of the original project proposal and outline who have continually guided and been involved in these projects from the onset of my involvement: Lori D. Daniels, Ze'ev Gedalof, and Rosemary Sherriff. I am also indebted to Timothy Patterson for co-supervising my work in the department. This project was successful because of the great sedimentary records collected in the field with the help of Michael Pisaric, Lori D. Daniels, Ze'ev Gedalof, Eugénie Paul-Limoges, and Joelle Perreault. The fruit of the labour of a number of volunteers and Ontario Work-Study Program students can be seen in the results chapters; I would like to thank: Danielle E. Paull, Kerry-Lynn Robillard, Joss Williams, Ronan M. Drysdale, Robert Q. Wu, Luke Charlebois, Alexa D'Addario, Carly Ladd, Alex Laudadio, Rachael Young, Sonam Drakto, Evan Rundle, and Namdar Moazzami, whose efforts helped add more data to the studies. Thanks also to the support and discourse held with my fellow labmates and colleagues; notably, Trevor Porter, Jesse Vermaire, Joshua Thienpont, Jennifer Korosi, Peter Jones, Carley Crann, Andrew Macumber, Lisa Neville, Matthew Ladd, Ramin Deison, Joanna Northover, and Matthew Peros. Much of this work has built off of ideas and studies by Eric Da Silva, John H. Nesbitt, Vesta Mather, Hélène Marcoux, Gregory A. Greene, and Raphaël D. Chavardès. Additional input and discussions with other researchers proved extremely fruitful, so I would like to thank the following people for their time: Daniel Gavin, Phil Higuera, William "Bill” A. Patterson, Emily Heyerdahl, Mitchell Power, Brent Wolfe, Rolland Hall, Reinhard Pienitz, Martin Simard, and Konrad Gajewski. For help with getting through the bureaucratic university machine (across two departments) I would like to extend a warm thank you to Elsie Clement, Sheila Thayer, and Brian Cousens, and to my main Loeb Building lab colleagues: Elyn and Mike Humphreys, Murray Richardson, Quang Ngo, and David 
Bertram (retired). I also thank Emma Davis for reviewing the book end chapters of this document. All errors, omissions, and other issues are solely my own.

Special thanks to those who have written reference letters for me: Ian D. Clark, Konrad Gajewski, Matthew Peros, and Michael Pisaric. As well as a big thank you to Michel Gaulin and the examination committee; Fred Michel, Ian Clark, Murray Richardson, Tim Patterson, Michael Pisaric, as well as to Kathryn Addison and to Tim Cathcart-Black, Michael Jary and Martin Bostock, who arranged the teleconference.

I would also like to thank family and friends for their support throughout the four years undertaken to complete these studies. Thanks to my parents Elizabeth and Phil, and my siblings Damien and Stacie Courtney Mustaphi for all of their strong support. Thank you to the Canadian public for financing public research that is relevant both to multiple stakeholders throughout society and upholds our collective, sustained direction of examining our interaction with the Earth (and beyond) to inform our stewardship. Additional financial support crucially came twice from the Department of Earth Sciences Dr. George A. Jeletzky Memorial Award.

Detailed acknowledgements were included in each manuscript chapter. As with any endeavour; I would like to acknowledge and thank all of those whose work these contributions were borne and built from. And last but not least, I thank the editors and reviewers of the journals where these papers have been submitted to - these efforts have always benefitted myself and produced improved scientific documents.

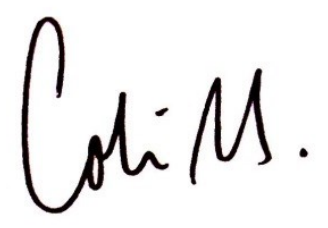

Colin J. Courtney Mustaphi

15 December 2013, York, UK 


\section{Introduction}

\subsection{Research context and background}

Lake sediment stratigraphies are an important terrestrial archive of environmental variability that can be used to understand how ecosystems have responded to natural and anthropogenic influences at multiple spatial and temporal scales. The accumulated sediments in lake basins preserve physical, chemical and biological information that can be quantified and analyzed through the conceptual framework of uniformitarianism and superposition of sedimentary beds. Sedimentological and paleoecological indicators preserved in lake sediments provide high-resolution records of past environmental ontogeny from the intra-catchment scale to the global scale. In many cases, mid-latitude lakes in Canada provide post-glacial Holocene records that are useful for examining environmental changes at annual to millennial resolutions.

Examining the natural variability and complex interactions occurring at various spatiotemporal scales is crucial in order to understand how future global climate change will affect fire regimes across the landscape (Whitlock et al., 2010; Hessl, 2011). Empirical studies of natural historic fire regimes form our understanding of how the current landscape evolved, how the major influences and drivers of environmental changes interacted, and how ecosystems responded to gradual changes and punctuated perturbations over millennial time periods. These quantitative studies constrain models of how forests and fire regimes will be affected by continued climatic changes and anthropogenic influences and are critical to informing human-environment policy and sustainable management strategies (Gavin et al., 2007; Smol, 2008). 
Conditions for the occurrence of fire on Earth were achieved during the Paleozoic Era 540-250 million years ago (Ma). Since the first records of fire appeared in the geologic record, fire has continued to be an important component of many ecosystems leading to similar adaptations amongst different species and across different biomes (Moritz et al., 2005). An individual fire event relies upon four variables: an ignition, fuel, oxygen, and a chain reaction to propagate the burn (Pyne et al, 1996; Agee, 1997; Scott, 2000). At a global scale, the frequency of ignitions, fuel abundance, distribution, and conditions, and the concentration of atmospheric oxygen have all varied through geologic time and have affected fire regimes (Scott and Glasspool, 2006). Terrestrial plants were first evident in the fossil record during the Silurian Period (450-400 Ma), while the first evidence of terrestrial plants burning was found in a limited number of sedimentary deposits from the Late Silurian (420-400 Ma) and again during the Late Devonian Period (400-350 Ma), and was not widespread until the Early Carboniferous Period (350-300 Ma; Scott, 2000; 2009; 2010; Scott and Glasspool, 2006). The burning of terrestrial biomass has since driven many important processes such as evolution, adaptation, influences on community structure, nutrient cycling, slope stability, soil formation, atmospheric composition, and human history. Since the Middle Pleistocene, fire was increasingly domesticated by hominids leading to anthropogenic alteration of wildfire regimes (James, 1989; Rolland, 2004; Bowman et al., 2011). The relative importance of various controls on fire regimes are not static through time (Gedalof, 2011) making it necessary to develop numerous long term paleoecological records to fully characterise and understand the variability of climate-fire-vegetation interactions. 
The complex interactions between the controls of fire operate at multiple temporal and spatial scales resulting in a patchy occurrence over the landscape (Whitlock et al., 2010). Broadly, these controls can be characterized as top-down (climatic) and bottom-up (local) controls. Top-down controls include climate and meteorological conditions that can homogenize fire regimes over large regions by overriding the importance of local factors. Climate variability over short (annual) to long (millennial) time scales drives fire regimes directly by controlling moisture and energy budgets and indirectly through climatic-mediation of vegetation assemblages, vegetation abundance and density, and fuel accumulation. At shorter time scales, fire weather strongly influences lightninginduced ignitions and the probability and spread of fire. Alternatively, bottom-up controls are those that exist locally and are inherent to or develop on the land surface. Bottom-up influences of the fire regime include vegetation types and density, fuel connectivity, interaction between other abiotic and biotic disturbances, aspect, topographic relief, soil moisture and other local site factors. The relative importance of each control of fire varies over small and large spatial scales and through time in response to climatic and natural and anthropogenic ecosystem changes (Heyerdahl et al., 2001; Gavin et al., 2003; Gedalof, 2011).

Quantitative records of decadal- to millennial-scale fire regimes can be established through the analysis of lake sediment records (Whitlock and Larsen, 2001). Multiple records are needed to assess the natural variability of fire regimes and to understand the spatial controls of fire regimes (Heyerdahl et al., 2001; 2007; Hallett and Anderson, 2010; Courtney Mustaphi and Pisaric, 2013). Lake sediment records provide 
high-resolution records of fire occurrence within the local watershed through the analysis of macroscopic charcoal (Conedera et al., 2009). Vegetation histories are developed using micropaleontological techniques and the analysis of plant macroremains (Bennett and Willis, 2001; Birks, 2001; MacDonald, 2001). Examining fire and vegetation histories with independent records of paleoclimate and biomass burning trends is useful for determining the long-term controls of fire by assessing the coherence of the fire records.

\subsubsection{Research objectives}

Wildfires are one of the most important disturbances in boreal and mixed-conifer forests that influence landscape-scale dynamics of the ecosystem (Lindgren and Lewis, 1997). To examine the relative importance of the controls of fire throughout out the Holocene, this study aims to:

1) Develop multiple robust Holocene-aged proxy-based records of vegetation and wildfire geohistories using paleoecological indicators preserved in lake sediment stratigraphies.

2) Analyse multiple sites across environmental gradients to examine the relative importance and spatiotemporal variability of the environmental influences of wildfire occurrence by making use of new and published paleoclimatic and paleoecological records. 
3) Advance the methods commonly used in the reconstruction of sediment-based forest fire geohistories through macroscopic charcoal analyses by developing and assessing the utility of detailed charcoal morphological analysis. Develop a morphological classification by observing the preserved sedimentary charcoal at the study sites and perform experimental biomass burning to begin to characterize charcoal fuel sources.

\subsection{Methodological approach}

\subsubsection{Lake sediment archives}

The accumulation of undisturbed sediment sequences in depositional environments provides an opportunity to qualitatively and quantitatively study the ontogeny and variability of past geological and biological processes. Examining lacustrine sediments on Quaternary landscapes provides detailed information about past environmental conditions at an annual to millennial resolution. Lake sediment core sequences can be collected from a platform deployed on the lake and extracting the sediment through a series of drives using a coring device. By analysing the remains of flora preserved within the lake sediments, such as pollen, stomata, and charcoal, a detailed understanding of the vegetation-fire interactions can be assessed for a given watershed. Geochronologies can be established through many relative and absolute methods; for the studies here, tephrochonology and the radiometric methods of ${ }^{210} \mathrm{~Pb}$ and ${ }^{14} \mathrm{C}$ dating are used to establish chronologies. 


\subsubsection{Age-depth modeling}

Precise chronological control is important to all paleoenvironmental research and for this dissertation a number of techniques were used to establish robust chronologies. Radiometric techniques were used to date some of the upper sediments and Holoceneaged sediments. The recent sediments were dated using ${ }^{210} \mathrm{~Pb}$ (Appleby, 2001) at the Paleoecological Environmental Assessment and Research Laboratory (PEARL), Queen's University, Kingston, Canada. Accelerator mass spectroscopy (AMS) radiocarbon dating was performed on small quantities of organic detritus found in the lake sediments at Beta Analytic Inc., Miami, Florida, USA. Multiple volcanoes in the Cascadian Volcanic Arc experienced highly explosive eruptions during the Holocene and provided a wellestablished regional tephrochronology (Foit et al., 2004). Identification of the conspicuous felsic ashfall deposits in the lake sediment stratigraphies provides chronological constraints with a high degree of certainty. Advances in age modeling using Bayesian statistics develops realistic models because this approach makes full use of the uncertainty associated with calibrating radiocarbon ages (Reimer et al., 2009; Blaauw and Christen, 2011). The combination of these dating techniques allows robust age-depth models to be developed for high-resolution interpretations of the paleoenvironmental histories.

\subsubsection{Methods for reconstructing past vegetation}

Past vegetation assemblages can be inferred through the analysis of subfossil plant remains preserved in lake sediments, such as pollen (Fægri and Iversen, 1989; Bennett and Willis, 2001), stomata analysis (MacDonald, 2001), and macroremains such as 
needles, seeds, and cones (Birks, 2001). The analysis of each proxy has particular strengths and weaknesses. Pollen is preserved in vast quantities in many depositional environments and is highly resistant to degradation, yet the fossil record is heavily biased toward anemophilous taxa and the complexity of wind transportation in mountainous environments can lead to pollen records that reflect regional vegetation assemblages rather than local watershed compositions (Solomon and Silkworth, 1986). Stomata and macroremains are deposited near the source plants and reflect vegetation composition of the immediate watershed and can be used to constrain palynostratigraphy and record initial and sustained local presence of taxa. The abundance of stomata varies and can be quite low compared to pollen abundances. Vegetation assemblages vary due to climatic, geomorphic, edaphic, and biotic influences, and knowledge of this variability is important to understand climate-fire-vegetation interactions at local and larger spatial scales.

\subsubsection{Methods for reconstructing past forest fire activity}

The role of fire in the evolution of an ecosystem on annual to millennial timescales can be investigated using fire proxies preserved in sedimentary stratigraphies (Whitlock and Larsen, 2001; Gavin et al, 2007; Conedera et al, 2009). Lake sediments provide high resolution millennial scale archives that are longer than observational and dendrochronological studies (Gavin et al., 2007; Whitlock et al., 2010). One indicator of historical fire events is the occurrence of charcoal in sediments, produced from the incomplete burning of biomass, which can be quantified and analysed to produce fire history records (Fig. 1.1). Macroscopic charcoal, generally $>100 \mu \mathrm{m}$ in diameter, is predominantly derived from local fires proximal to the lake (Clark, 1988; Gavin et al., 
2003; Lynch et al, 2004; Peters and Higuera, 2007; Higuera et al., 2007); although, longdistance transport of macroscopic charcoal has been observed during fires with intense convection (Pisaric, 2002; Tinner et al., 2006). Once macroscopic charcoal has been tallied, a decomposition of each quantitative charcoal record separates a varying background component and a peak component. Background charcoal reflects changes to the abundance of terrestrial biomass (Marlon et al., 2006), burning rates, and erosion, within the catchment (Higuera et al., 2007), and the peak component represents past fire episodes. The most common approach to decomposing millennial-scale fire records are facilitated by CharAnaysis software and related methods (Higuera, 2009; Higuera et al., 2009; 2010; Kelly et al., 2011). This software establishes varying background charcoal accumulation rates and identifies peaks which represent fire episodes. The fire dates inferred from the lake sediment records can be calibrated to known fire dates from observational and dendrochronological studies to increase the certainty and robustness of the reconstruction (Higuera et al., 2005; 2011). By analysing multiple records, information about the variability of fire frequency and inferences about the relative importance of the spatial controls acting upon the fire regime can be better understood (Heyerdahl et al., 2001; 2007; Gavin et al., 2006; Hallett and Anderson, 2010; Courtney Mustaphi and Pisaric, 2013). 


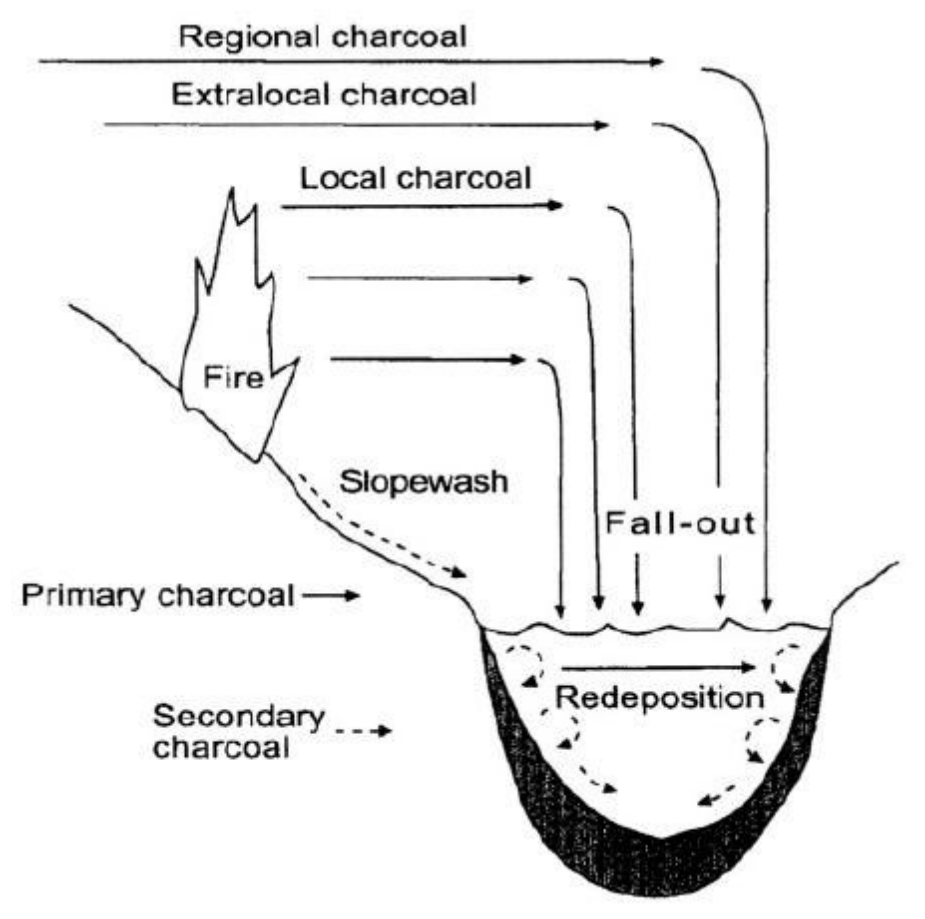

Figure 1.1: Sources of charcoal from region and watershed into a lake (Whitlock and Larsen, 2001).

\subsection{Thesis organisation}

The format of this thesis is as follows: Chapter 1 has described the overall approach and methodological context for the use lake sediment stratigraphies to examine and interpret paleoecological changes during the late Quaternary. Chapter 2 investigates the spatial controls on fire regimes in the West Kootenays over the past 5000 years. Chapters 3 and 4 further analyze the stratigraphy, vegetation, and fire regimes, at two sites over the full Holocene. Chapter 5 assembles some observational classifications of charcoal morphologies found in the lake sediments. Experimental burning of various biomass fuels adds to the interpretation of fuel sources for the charcoal morphologies. Chapter 6 describes some ongoing studies related to this thesis work and Chapter 7 presents the conclusions. 


\section{Varying influence of climate and aspect as controls of montane forest fire regimes during the late Holocene, south-eastern British Columbia, Canada}

\subsection{Abstract}

Top-down (climatic) controls of fire occurrence are expected to homogenize fire regimes in a given area over long (millennial) temporal scales. Previous investigations in southeastern British Columbia have shown that bottom-up (local site) factors can override long-term climate as a dominant control. Here, we examine the interactions between fire regime controls using five 5000-year-long lake sediment records. All lakes are located in separate watersheds within a $550-\mathrm{km}^{2}$ region of Engelmann spruce-subalpine fir forest in the Columbia Mountains, British Columbia, Canada. Sedimentary macroscopic $(>150 \mu \mathrm{m})$ charcoal analysis was used to produce local fire history records. Fire events were identified by decomposing the charcoal concentration series using the program CHARANALYSIS. We analysed the temporal coherence of the reconstructed fire events and the distributions of the fire return intervals at all sites and pooled sites by their northfacing or south-facing aspect. Since $5000 \mathrm{cal}$. yr BP, fire frequency was highest between 4250 and $2750 \mathrm{cal}$. yr BP and lowest from $750 \mathrm{cal}$. yr BP to the present. Median fire return intervals were shorter on the warmer and drier south-facing slopes (135-190 years) and longer on the cooler and moister north-facing slopes (226-241 years). Significant synchrony existed between sites with similar aspect, but no synchrony was found at sites with opposing aspect, providing evidence for the importance of bottom-up controls. Smoothed fire frequencies suggested that the influence of aspect varied throughout the period and that the importance of aspect could be overridden by other controls. The asynchrony between sites with opposite aspects suggests that local conditions for fire are important spatial controls on the fire regime. Aspect is an important bottom-up control of fire regimes in mid-elevation forests and its influence varies through time. The variability of climate-fire-vegetation interactions in the region needs to be investigated to understand the importance of top-down and bottom-up controls.

Key words: Aspect, British Columbia, charcoal, disturbance, fire regime, Kootenays, lake sediments, Holocene, synchrony, wildfire 


\subsection{Introduction}

Future fire projections suggest that a warming climate will increase the frequency and severity of fires in boreal Canada, and the area burned (Flannigan et al., 2009). Forest fires are an important ecological disturbance within the subalpine forests of southern British Columbia (Johnson, 1992). Fire regimes influence stand composition and age, and affect soil and slope processes at multiple spatial and temporal scales. Socioeconomically, wildfires threaten life and infrastructure, interrupt resource-based economic activities, and negatively affect air and water quality. Quantitative records of centennial-scale and millennial-scale fire regimes can be established through the analysis of lake sediment records (Whitlock \& Larsen, 2001), and are crucial to our understanding of climate-fire-vegetation interactions and ecosystem responses to future climate variability and anthropogenic influences. There have been a number of studies analysing long-term fire regimes in south-eastern British Columbia (Gavin et al., 2006; 2007; Hallett \& Hills, 2006), but, due to the complex topography, ecology and climate of this region, the conclusions of these studies suggest that more sites are required to understand regional variability across this region (Bowman et al., 2011; Daniau et al., 2012; Power et al., 2012).

Climatic variability is a top-down control of wildfire occurrence through its influence on moisture and energy budgets at multiple temporal and spatial scales. Large fires in British Columbia are associated with persistent blocking ridges that reduce fuel moisture and occur more frequently during positive modal phases of the Pacific-North America circulation pattern (Johnson \& Wowchuk, 1993). Although fires can occur during any given year, widespread fires are more probable after warm springs followed 
by warm and dry summers, consistent with positive El Niño-Southern Oscillation and Pacific Decadal Oscillation phases (Heyerdahl et al., 2008; Trouet et al., 2010), and modulated at multidecadal scales by teleconnections over the Atlantic Ocean (Kitzberger et al., 2007). Bottom-up controls - including fuel type and topography - interact with meteorological conditions affecting fuel drying and the ignition, spread and extinction of fire (Lertzman \& Fall, 1998; Macias Fauria et al., 2011). The relative importance of topdown and bottom-up controls varies over multiple temporal and spatial scales (Heyerdahl et al., 2001; Gavin et al., 2003; Gedalof, 2011). There is, therefore, a need to develop long-term fire history records to fully capture the effects of past climate and vegetation variability and to accurately define the fire regime of an area (Whitlock et al., 2010).

This study describes 5000-year fire histories reconstructed from macroscopic charcoal preserved in sediments from five lakes: three previously unpublished sites and two published (Gavin et al., 2006) from the Columbia Mountains (Fig. 2.1). We present a regional-scale $\left(550 \mathrm{~km}^{2}\right)$ data set of reconstructed fires that covers a large environmental gradient to evaluate the relative importance of fire-regime controls (Heyerdahl et al., 2001). By analysing a number of sites within similar vegetation assemblages and across a gradient of elevation and aspect, the relative importance of interacting top-down and bottom-up controls of fire activity and their impacts on the landscapes can be examined.

\subsection{Materials and methods}

\subsubsection{Study sites}

To provide the best historical charcoal records, small lakes with simple bathymetries, narrow littoral zones, and little to no inflow or outflow, were targeted for sampling (Fig. 
2.1, Table 2.1; Whitlock and Millspaugh, 1996). NEL01 (all lake names are unofficial) is a small $(0.86 \mathrm{ha})$ and relatively deep lake $\left(Z_{\max }=9.0 \mathrm{~m}\right)$ located in a south-facing watershed in the Selkirk Mountains. NEL01 is situated in the Engelmann sprucesubalpine fir (ESSF) biogeoclimatic zone (BCVRI, British Columbia Vegetation Resources Inventory) and has a small ephemeral stream flowing out of it. The surrounding forests are dominated by Engelmann spruce (Picea engelmannii Parry ex Engelm.), subalpine fir [Abies lasiocarpa (Hook.) Nutt.], and lesser amounts of western hemlock [Tsuga heterophylla (Raf.) Sarg.], western red-cedar (Thuja plicata Donn ex D. Don), lodgepole pine (Pinus contorta var. latifolia Engelm. ex S. Watson), and western larch (Larix occidentalis Nutt.). Sasquatch Lake (NEL02) is small (2 ha) and moderately deep $\left(Z_{\max }=4.6 \mathrm{~m}\right)$, and is located in a narrow valley surrounded by interior cedar-hemlock (ICH) forests composed of western red-cedar and western hemlock. The slopes above the lake are dominated by ESSF forests. The lake is situated in a T-shaped valley junction, with surrounding mountain slopes facing many directions. NEL03 is a small ( 0.35 ha), shallow $\left(Z_{\max }=2.4 \mathrm{~m}\right)$, subalpine lake, with a small inflow and outflow, located at the head of a north-north-east trending valley. The lake is within ESSF forest, dominated by subalpine fir, subalpine larch (Larix lyallii Parl.), Engelmann spruce, and occasional whitebark pine (Pinus albicaulis Engelm.). Rockslide and Cooley Lakes are south-facing and north-facing, respectively, and are surrounded by ESSF forests dominated by subalpine fir and Engelmann spruce, with some western hemlock, western red-cedar, western white pine (Pinus monticola Douglas ex D. Don), Douglas-fir [Pseudotsuga menziesii (Mirb.) Franco], and western larch near Cooley Lake (Fig. 2.1; Gavin et al., 2006). 
Recent disturbance patterns suggest a stand-replacing disturbance interval of 150350 years for ESSF and ICH forests (Pollack et al., 1997; Wong et al., 2004; Gavin et al., 2006). Modern forests had become established in the Columbia Mountains by $4500-4000$ cal. yr BP (Hebda, 1995) and regional expansion of T. plicata and T. heterophylla indicate that mid-elevation sites may have become more mesic during this period (Gavin et al., 2006). The relative stability of the dominant vegetation assemblages in the region allows us to investigate top-down versus bottom-up controls of fire occurrence.

\subsubsection{Methods}

During the summers of 2009 and 2010, lake sediment cores were collected from the central basins of NEL01, NEL02 and NEL03. In order to collect intact sediment-water interfaces, the uppermost sediments were collected using a large-diameter Glew gravity corer deployed from a boat. Sediment cores were extruded using a vertical extruder (Glew et al., 2001) at contiguous $0.25-\mathrm{cm}$ intervals from 0 to $15 \mathrm{~cm}$ depth, and at $0.5-\mathrm{cm}$ intervals to the base. Deeper sediments were collected in 1-m drives using a $5-\mathrm{cm}$ diameter Livingstone piston corer (Wright et al., 1984). Piston cores were extruded, wrapped in plastic and aluminium foil, and then shipped and stored at $c .4{ }^{\circ} \mathrm{C}$. Coring ceased at NEL01 at $323.5 \mathrm{~cm}$ below the water-sediment interface, at NEL02 at $531.5 \mathrm{~cm}$, and at $351.5 \mathrm{~cm}$ at NEL03.

Sediment ages were established using radiometric methods and an established regional tephrochronology (Foit et al., 2004). The upper sediments of NEL01 were ${ }^{210} \mathrm{~Pb}$ dated at the Paleoecological Environmental Assessment and Research Laboratory, Queen's University, Kingston, ON, Canada, and accelerator mass spectrometry (AMS) 
radiocarbon dating was performed at Beta Analytic, Miami, FL, USA. Two felsic ashfall deposits were conspicuous in NEL01 and NEL03, the younger being the Mount Saint Helens Wn tephra (Mullineaux, 1996), dated to 468-469 cal. yr BP (Yamaguchi, 1983, 1985), which was identified at a similar sediment depth at Cooley and Rockslide Lakes (Foit et al., 2004). The deeper and thicker tephra was interpreted as the Mazama O tephra (Bacon, 1983) dated to $7627 \pm 150$ cal. yr BP (Zdanowicz et al., 1999). NEL03 contained a redeposited layer of Mazama $\mathrm{O}$ tephra, which had also been observed in the Rockslide Lake record (Gavin et al., 2006). The thick tephra deposits were treated as nearinstantaneous events, and the layers were removed from the age-depth series to create an adjusted age-depth series. Radiocarbon dates were calibrated using IntCal09 (Reimer et al., 2009). Age-depth models were produced using the weighted averages of the age probability densities (Telford et al., 2004) and modelled with cubic spline functions, weighted by the inverse of the average $2 \sigma$ radiocarbon error range. In the case of NEL02, a more flexible spline was needed to preserve a monotonic age-depth relationship caused by a rapid sedimentation event within the uppermost sediments, probably initiated by a proximal landslide near the lake.

Contiguous $1-\mathrm{cm}^{3}$ subsamples of homogeneous sediment were removed and soaked in a metaphosphate solution (Bamber, 1982) for at least $24 \mathrm{~h}$ and then wet-sieved through a $150-\mu \mathrm{m}$ mesh. The remaining material was transferred to a Petri dish and the number of macroscopic charcoal pieces was tallied (Whitlock \& Larsen, 2001) under a Nikon SMZ800 stereoscope (6-40× magnification). Sediment macroscopic charcoal concentrations (pieces $\mathrm{cm}^{-3}$ ) were converted to charcoal accumulation rates (CHAR; pieces $\mathrm{cm}^{-2} \mathrm{yr}^{-1}$ ) and analysed using the program CHARANALYSIS (Higuera et al., 2009). 
To balance variable sedimentation rates among all sites, raw charcoal concentrations were resampled at 12-year intervals to create an interpolated CHAR series for peak analysis, as this interval was very near the median sampling interval at each site. The varying background CHAR was estimated using a LOWESS smoother (Cleveland, 1979) that is robust to outliers, over a 500 -year window that adequately captured centennialscale variability and would not be strongly biased by high-magnitude peaks (Gavin et al., 2006). CHAR peaks, locally defined within 500-year windows, were obtained by subtracting the background CHAR component from the interpolated CHAR series and identified through a noise cut-off probability at the 99th percentile, established by a Gaussian mixture model (Higuera et al., 2010). Minimum charcoal concentrations within a 75 -year period prior to a peak with a probability $<5 \%$ of coming from the same Poisson distribution as the associated peak were retained as significant peaks (Higuera, 2009; Higuera et al., 2010). The identified CHAR peaks represented fire episodes of one or more large fires that occurred in the lake catchment within a 12-year period. The tally of fire events within the window sizes of 1000,500 and 200 years were smoothed by a tricube weighting over the given window size, to create smoothed fire frequencies using the program K1D (Long et al., 1998; Gavin et al., 2006; Higuera, 2009; Hallett \& Anderson, 2010).

Synchrony in the timing of fire episodes between each lake site was calculated using a bivariate Ripley's $K$ function in K1D (Ripley, 1977; Gavin et al., 2006). Reconstructed fire-episode years for each lake were compared to one another by calculating an $L$-function, $L_{\mathrm{AB}}(t)$, where the $K$-function gives the number of events in record B occurring within a time window $(t)$ of each event in record A, and was then 
converted to an $L$-function for visualisation by stabilising the mean and variance over $t$. The $95 \%$ confidence interval envelopes were estimated by 1000 iterations of circularly randomizing one record (Gavin et al., 2006). Fire return interval distributions from each of the five sites were fitted with Weibull models using maximum-likelihood techniques. All Weibull-estimated distributions passed a one-sample Kolmogorov-Smirnov (KS) goodness-of-fit test at $P>0.10$ (NEL01, NEL02, NEL03 and Cooley Lake) or $P>0.05$ (Rockslide Lake). Weibull median fire return intervals were derived (mFRI; GrissinoMayer, 1999) with 95\% confidence intervals, estimated from 1000 bootstrapped samples. Fire return intervals (FRIs) were also pooled into a group with sites with south-facing (NEL01, NEL02 and Rockslide Lake) or north-facing aspect (NEL03 and Cooley Lake). Both two-sample Kolmogorov-Smirnov (KS) tests and likelihood-ratio tests (LRT; Higuera et al., 2009) were used to examine whether the null hypotheses were true, that each site pairing of FRIs, sites versus the pooled series, and between the north and south pooled series, came from the same underlying distributions.

\subsection{Results}

\subsubsection{Chronologies}

Dating results and age-depth models are presented in Table 2.2 \& Fig. 2.2 and Appendix S1 in Supporting Information. One AMS radiocarbon date from NEL01 was rejected because it appeared to be redeposited, degraded wood fragments (Fig. 2.2, Table 2.2). Visual inspection of the cores from NEL02 revealed no conspicuous signs of disturbances, but the age-depth model and location of the site at the bottom of a narrow valley suggested a more variable sedimentation rate than the other sites (Figs $2.1 \& 2.2$ ). 
The dating appeared to be robust, even without tephra marker beds, as the pollen profile indicated that Tsuga heterophylla arrived by c. 4500 cal. yr BP, consistent with regional interpretations (Rosenberg et al., 2003; Gavin et al., 2006).

\subsubsection{Sedimentary charcoal}

Charcoal concentration was greatest at NEL02 (median, 34.0; range, 0-252 pieces $\mathrm{cm}^{-3}$ ), slightly lower at NEL03 (median, 32.5; range, 1-369 pieces $\mathrm{cm}^{-3}$ ), and lowest at NEL01 (median, 23.0; range, $0-220$ pieces $\mathrm{cm}^{-3}$; Table 2.3). NEL02 also had the highest charcoal accumulation rate (CHAR; median, 1.7; range, 0-23 pieces $\mathrm{cm}^{-2} \mathrm{yr}^{-1}$ ), followed by NEL03 (median, 1.1; range, $0-11$ pieces $\mathrm{cm}^{-2} \mathrm{yr}^{-1}$ ), and NEL01 (median, 1.0; range,

$0-8$ pieces $\mathrm{cm}^{-2} \mathrm{yr}^{-1}$ ). When all five sites were considered, Cooley Lake had the highest CHAR values (median, 4.0 pieces $\mathrm{cm}^{-2} \mathrm{yr}^{-1}$ ) and Rockslide Lake had the lowest (median, 0.6 pieces $\left.\mathrm{cm}^{-2} \mathrm{yr}^{-1}\right)$.

\subsubsection{Fire histories}

The reconstructed fire histories represented an area fire return interval, as the fire signal was that of all or part of each catchment. Each CHAR record showed distinct peaks above a variable background rate (Fig. 2.3, Table 2.3) and high signal-to-noise index values (SNI; Kelly et al., 2011). All global SNI values were above three (Table 2.3), although NEL02 had several short periods of low local SNI values that should be interpreted cautiously (SNI < 3; Fig. 2.3).

Rockslide Lake recorded the most fire events $(n=35$; Table 2.3) and Cooley Lake recorded the fewest $(n=21)$. These values differed slightly from those reported by Gavin 
et al. (2006), because those authors resampled at 10-year intervals and used a global threshold value to identify peaks. Specifically, 33 and 23 fires were originally detected at Rockslide and Cooley Lakes, respectively. Known fire dates, established through firescar studies in stands near or at lower elevations than the lake catchments, were presented with the most recent reconstructed fire episodes of NEL01 and NEL03, being well represented within \pm 4 years of dendrochronological fire scar dates (Fig. 2.3; Nesbitt, 2010). Additional known large fire dates, established through gridded fire scar sampling near NEL03, showed good agreement \pm 6 years of a reconstructed fire date (Greene, 2011). Canopy trees near NEL02 established discontinuously within the past $c$. $120-370$ years to form an uneven-aged canopy with a single undated fire-scarred snag, and the stand was interpreted as experiencing low-to-moderate severity fires. The best calibration between known fires and inferred fires from the sedimentary record was from a site c. $5 \mathrm{~km}$ down-valley that burned 10 years prior to the most recent inferred fire date at NEL02 (Nesbitt, 2010). These known fire dates provided evidence of mixed-severity and high-severity fires occurring near the lake sites and agree with inferred fire dates from the lake sediments.

A weak negative correlation between site elevation and number of fires was not significant $(r=-0.34, P=0.58)$, but sites with a south-facing aspect (NEL01, NEL02 and Rockslide Lake) burned more often (27-35 fires) than north-facing sites (21 and 22 fires at Cooley Lake and NEL03, respectively). Consequently, the median fire return intervals (mFRI) were significantly shorter at south-facing sites (135-190 years) than at north-facing sites (226-241 years; Fig. 2.3, Table 2.3). Fire return interval distributions at all sites passed a one-sample KS goodness-of-fit test $(P>0.10$; Higuera, 2009), so 
Weibull models were applied. KS and LR tests on all pairwise comparisons of sites suggested that sites with shared aspect tended to have similar fire return interval distributions over the past 5000 years, and that sites with differing aspects had different distributions. For example, the south-facing sites NEL01 and NEL02 shared a similar fire return interval distribution, that can be seen quantitatively by the Weibull distribution estimate (Fig. 2.3) and by KS test results $(P=0.99)$. Rockslide Lake was also southfacing and NEL01 and Rockslide Lake had similar distributions $(P=0.57)$, as did NEL02 and Rockslide Lake $(P=0.58)$. NEL03 and Cooley Lake were on north-facing aspects and had similar fire return interval distributions $(P=0.99)$. Pairwise combinations of sites with different aspects had significantly different distributions ( $P=0.003$ to 0.17$)$, although NEL03 showed no difference from NEL01 or NEL02 $(P=0.40$ and 0.47$)$. Likelihood-ratio test (LRT) results were similar, but generally weaker. For example, the results suggested that the only significantly different $(\alpha=0.05)$ distribution was between Rockslide Lake and NEL03 and Cooley Lake ( $P<0.009 ; 10,000$ iterations).

Overall, there was a tendency for sites with a common aspect to have exhibited synchronous fire activity, and sites with opposed aspect to be asynchronous. The results of the bivariate Ripley's $K$ function analyses (Fig. 2.4) indicated that south-facing sites showed significant synchrony at multi-centennial to millennial time-scales. Records from different aspects suggested independence and some asynchrony over similar time windows (e.g. NEL01 versus NEL03, compared to NEL02 versus NEL03; Fig. 2.4). Owing to the resampling of the original fire records of Rockslide and Cooley Lakes at 12-year intervals, the results of independence between these sites (Gavin et al., 2006) were not reproduced here, and instead significant asynchronous patterns were identified. 
This is likely to be due to the resampling, but maintained the assumption that each fire episode contained one or more fires and allowed comparisons between all sites.

FRIs were pooled (Higuera et al., 2009) into two populations: one group with south-facing sites (NEL01, NEL02 and Rockslide Lake), and another with north-facing sites (NEL03 and Cooley Lake). Based on LRT results (Higuera et al., 2009), we rejected the null hypothesis that the Weibull-modelled distributions of the pooled north-facing and south-facing composite sites came from the same distribution $(P<0.01$; KS test results were similar). Comparison of the Weibull-modelled FRIs from the north-facing sites NEL03 and Cooley Lake - with the south-facing composite suggested that each came from a different distribution $(P<0.10$ and $P<0.05$, respectively). Comparison of the north-facing composite with each south-facing site - NEL01, NEL02 and Rockslide Lake - suggested that each came from a different distribution $(P<0.10$ for the comparisons of NEL01 and NEL02 with the composite, and $P<0.001$ for Rockslide Lake). These results were robust whether NEL02 was included or excluded from the pooled south-facing composite. A comparison of these composite series using a bivariate Ripley's $K$ function suggested that the fire activity between north and south slopes exhibited independence, with significant asynchrony centred at 900-year scales ( $t=450$; Fig. 2.5 inset). If NEL02 was excluded from the south aspect group, which limited the comparison to mid-to-high elevation ESSF sites in watersheds with opposing aspect, there were 15 significant asynchronous windows (580-1580 years; Fig. 2.5).

Smoothed fire frequencies showed strong qualitative agreement at each site within the south-facing and north-facing groups (Fig. 2.6) and the south-facing sites tended to have a higher number of fires overall per 1000 years. NEL02 deviated slightly from other 
south-facing sites at 2250 and 3150 cal. yr BP. Overall, the highest fire frequencies occurred between 2750 and 4250 cal. yr BP, and the lowest occurred during the past $c$. 750 years. Throughout the entire record, fire frequency at sites with southern aspects decreased while its frequency at sites with northern aspects slightly increased. The degree of coherence between the smoothed fire frequencies at centennial-scale windows between each pooled group varied throughout the late Holocene (Fig. 2.6d). From 5000 to 4250 cal. yr BP, and again from 1500 to 700 cal. yr BP, fire frequencies on north-facing and south-facing aspects had an inverse relationship, but during the periods of 4250-1500 cal. yr BP and 700 cal yr. BP - present, both pooled groups covaried. Removal of NEL02 from the south-facing composite did very little to affect the variability over all window lengths. These results were unaffected, even if fire dates during the 20th century (AD 1900 to present) were omitted from the analysis, as these fires may have reflected intensification of anthropogenic activity in the region (Agee, 1993; Pearkes, 2002; Bowman et al., 2011).

\subsection{Discussion}

\subsubsection{Influence of aspect on the fire regime}

Since 5000 cal. yr BP, the lake sediment records from montane ESSF and ICH forests in the Columbia Mountains of British Columbia suggest that fires were most frequent at south-facing sites (Table 2.3, Fig. 2.3). This indicates the importance of aspect in mountainous regions as a bottom-up control of fire by influencing the radiation and thermal and moisture conditions of the fuels. Climate and weather conditions interacted with aspect and affected the thermal and moisture budget, directly influenced vegetation 
and fuel conditions, and synchronized fire occurrence across some watersheds (Heyerdahl et al., 2001; Gavin et al., 2003). Centennial-scale and millennial-scale fire occurrence was synchronous among sites with similar aspect. Much of the independence of fire activity at most time windows may be explained by the relative importance of local site factors, such as vegetation type, fuel connectivity and topography.

Fire occurrence between the composite series of north-facing sites and of southfacing sites was asynchronous at time-scales of 580-1480 years (Fig. 2.5), which suggests that aspect was an important influence of fire activity. The tendency towards asynchronous fires was probably due to aspect-driven variation in fuel moisture conditions - where conditions for fire have been much more frequent on south-aspect watersheds - and the major fire barrier (the Kootenay River system) impeding the spread of fire to the adjacent slopes. Conditions for large fires on north-facing watersheds were met in extreme dry years when fires may preferentially burn through dense forests and not past the major fire barrier, but tend to burn up-slope, away from the south-facing slopes in the region.

Based on dendrochronological records of fire scars and stand ages, at low to midelevations within the same study area, mixed- and high-severity fire regime sites had similar times since last fire, regardless of aspect. North-facing sites $(n=6)$ had not burned in 104-159 years and south-facing sites $(n=3)$ had experienced 116-146 years since the last fire (Nesbitt, 2010). The dendrochronological analysis of fire history at nearby sites suggested lower FRIs than those reconstructed from the sedimentary charcoal records. This discrepancy is probably because low- to mid-elevation forests in this region are dominated by low-to-moderate severity fire regimes (Nesbitt, 2010). It is 
more difficult to analyse low-to-moderate severity fire regimes using sedimentary charcoal records, because these records are more effective at capturing signals from highseverity fires, which produce greater amounts of charcoal. Additionally, the different time-scales analysed by the tree-ring study (c. 300 years) versus the lake sediment charcoal analysis (5000 years) may also contribute to the different reconstructed FRIs (Whitlock et al., 2010), and the spatial resolution also differs. Thus, the charcoal records were reconstructing a maximum FRI, and small-area fire events within the catchment or low-intensity fires may not be captured in the sediment record. Also, the more mesic conditions that normally typify higher subalpine environments, especially around a lake (Jungen, 1980), may inhibit low-severity and high-frequency fires but be overridden by high-severity, low-frequency fires during extreme dry years, contributing to longer fire return intervals at higher elevation sites.

Despite the lack of importance of aspect at lower elevations in our study area (Nesbitt, 2010), the spatial variation of fire frequency with aspect is a common feature in western North America (Taylor \& Skinner, 1998, 2003). In the drier montane spruce forests of the East Kootenays, aspect was shown to be an important control on fire frequency, where south-facing sites burned more frequently, although there was a strong vegetation difference among sites with xerophilic ponderosa pine and Engelmann spruce dominance on south-facing and north-facing slopes, respectively (Da Silva, 2009). In the Stein Valley of the interior of southern British Columbia, aspect was an important control of fire frequency at low-elevation forests with overstoreys dominated by ponderosa pine or Douglas-fir (Heyerdahl et al., 2007). Vegetation type also varied with aspect in the Stein Valley, with fuels on southern aspects being more conducive to the spread of fire. 
In the Blue Mountains of Washington and Oregon, dendroecological evidence over the past $c .400$ years shows that fire frequency varied with aspect at mid-elevation sites that are codominated by Abies and Pseudotsuga, where a significant barrier to fire spread existed between each topographic facet. Aspect was not significantly correlated with fire frequencies on gentle landscapes or where topographic facets interdigitated and allowed fires to spread (Heyerdahl et al., 2001).

\subsubsection{Millennial-scale variability of fire frequency}

Through the late Holocene, decreasing insolation could have influenced fire frequencies at millennial time-scales. At south-facing sites, fire frequency has tended to decrease since 4500 cal. yr BP (Fig. 2.6b), attributed to decreased summer insolation during the late Holocene (Berger \& Loutre, 1991). Decreased solar radiation directly affected fuel conditions, affected the moisture budget following snow-melt, shortened the fire season, and reduced the probability of extremely dry conditions (Hayes, 1942) relative to the early Holocene. Slope, aspect, latitude and orbital geometry interacted to determine the amount of radiation a given watershed received and influenced the moisture balance. The influence of these bottom-up factors seemed to be more important during the period earlier period (2500-5000 cal. yr BP) because the synchrony was higher than during the latter period (Fig. 2.5c, 2.6b).

Changing vegetation may also affect fire frequencies at millennial time-scales. Engelmann spruce and subalpine fir dominated the watersheds, but some variation existed as there was some young lodgepole pine and older red-cedar and hemlock at NEL01, a large portion of uneven-aged subalpine larch at NEL03 with understorey 
shrubs, and minor amounts of other conifers near Cooley Lake (Gavin et al., 2006). NEL02 was proximally dominated by red-cedar and western hemlock, but the immediate up-slope forest was dominated by dense Engelmann spruce and subalpine fir. Regardless of these slight variations in vegetation assemblages, the influence of aspect persisted.

A transition at $2500 \mathrm{cal}$. yr BP, evident at centennial to millennial scales, showed decreased fire frequency at south-facing sites and a slight increase at north-facing sites. The cause of this divergent pattern is unclear, but it may have been influenced by local site factors and minor changes to regional climate (Fig. 2.6b-d). For example, the expansion of Tsuga heterophylla, attributed to increased precipitation during the late Holocene (Rosenberg et al., 2003), may have affected the vegetation and/or fuel conditions of north-facing and south-facing aspects differently, leading to increased large fires on south-facing sites and little change to north-facing sites. This unexpected result deserves further research.

\subsubsection{Centennial-scale variability of fire frequency}

The relative importance of decadal- to centennial-scale climate variability on fire activity may have increased during the latter half of the record (Gavin et al., 2006) and increased the asynchrony between the records from different aspects (Fig. 2.5c). Chironomidinferred temperature reconstructions from south-eastern British Columbia broadly indicated climate cooling and reduced millennial-scale variability during the late Holocene (Rosenberg et al., 2004; Chase et al., 2008). Glacial advances also indicated climate cooling in the Rocky Mountain region since c. 3300 cal. yr BP (Osborn \& Karlstrom, 1988; Luckman et al., 1993) and more recently during the Little Ice Age 
(LIA; c. 750 cal. yr BP to c. 1850 CE; Luckman, 2000). During the Medieval Climate Anomaly (MCA; 1000-750 cal. yr BP), summer temperatures were warmer and winter precipitation was higher in the Pacific Northwest (Steinman et al., 2012), and fire frequencies were moderately high at most sites (Fig. 2.6b,d), although they continued to decrease at long-term scales at south-facing sites (Fig. 2.6b,c). Generally, warmer conditions would have led to rapid melting of snowpacks and more severe drying throughout the summer, promoting conditions for fire, especially on south-facing slopes (Fig. 2.5d). During the LIA, summer temperatures and levels of winter precipitation were lower, and the composite fire frequency at all sites was very low, with only Cooley Lake having frequent fires at this time (Fig. 2.6a,d).

\subsection{Conclusions}

Over the past 5000 years, fire regimes in the Columbia Mountain forests of south-eastern British Columbia have been influenced by bottom-up controls such as aspect. Multiple fire histories at sites situated in different watersheds with similar aspect had a tendency to be more coherent across centennial and millennial time-scales. This analysis has identified higher fire frequencies on south-facing sites during the late Holocene and a tendency towards synchronous fires between sites that shared similar aspect. Comparison of pooled sites based on aspect showed an asynchronous relationship. Complex interactions between top-down climate and bottom-up controls have caused the relative importance of these controls to vary, and additional fire records from nearby watersheds may be needed to fully analyse their relative importance in this area. Future work should investigate the relative importance of top-down and bottom-up controls through time 
using longer records, covering major climate and vegetation variations, with an emphasis on explaining the processes and mechanisms by which these controls interact at various temporal and spatial scales. To improve our understanding of the spatial variation of long term historical fire regimes and the controls that drive them, additional long-term fire records from across the landscape are needed (Heyerdahl et al., 2001). This information would be widely important to defining baseline ecological conditions and discerning natural and anthropogenic changes to these forested landscapes. As urban centres in the interior of British Columbia continue to expand into the wildland-urban interface, the need to understand long-term variability of fire regimes and how fire responds to vegetation, land use and climate change at various temporal and spatial scales will become increasingly important.

\subsection{Acknowledgements}

We thank Ze'ev Gedalof, Eugénie Paul-Limoges, Joelle T. Perreault and Lori D. Daniels for assisting in the field, and Kerry-Lynn Robillard, Ronan M. Drysdale, Joss Williams, Namdar Moazzami, Sonam Drakto and Danielle E. Paull for assistance in the laboratory. Thanks to Phil Higuera for our use of ChARANALYSIS and likelihood-ratio test script, as well as to Dan Gavin for our use of K1D and charcoal data. Important insights came from discussions with Gregory A. Greene, Raphaël D. Chavardès and William A. Patterson. We also thank Jesse C. Vermaire, L.D. Daniels and Z. Gedalof for commenting on drafts of this manuscript. The suggestions by an anonymous referee, Daniel Gavin and Doug Hallett vastly improved this paper. This study was funded by the Natural Sciences and Engineering Research Council of Canada (NSERC) Supplemental Strategic Grant program and a NSERC Discovery grant to M.F.J.P., and a Jeletzky Memorial Award to C.J.C.M. 


\subsection{References}

Agee, J.K. (1993) Fire ecology of Pacific Northwest forests. Island Press, Washington, DC.

Bacon, C.R. (1983) Eruptive history of Mount Mazama and Crater Lakes Caldera, Cascade Range, U.S.A. Journal of Volcanology and Geothermal Research, 18, 57-115.

Bamber, R.N. (1982) Sodium hexametaphosphate as an aid in benthic sample sorting. Marine Environmental Research, 7, 251-255.

Berger, A. \& Loutre M.F. (1991) Insolation values for the climate of the last 10 million years. Quaternary Sciences Reviews, 10, 297-317.

Bowman, D.M.J.S., Balch, J., Artaxo, P., Bond, W.J., Cochrane, M.A., D’Antonio, C.M., DeFries, R., Johnston, F.H., Keeley, J.E., Krawchuk, M.A., Kull, C.A., Mack, M., Moritz, M.A., Pyne, S., Roos, C.I., Scott, A.C., Sodhi, N.S. \& Swetnam, T.W. (2011) The human dimension of fire regimes on Earth. Journal of Biogeography, 38, 22232236.

Cleveland, W.S. (1979) Robust locally weighted regression and smoothing scatterplots. Journal of the American Statistical Association, 74, 829-836.

Da Silva, E. (2009) Wildfire history and its relationship with top-down and bottom-up controls in the Joseph and Gold Creek watersheds, Kootenay Mountains, British Columbia. MSc Thesis, Department of Geography, University of Guelph, Guelph.

Daniau, A.-L., Bartlein, P.J., Harrison, S.P. et al. (2012) Predictability of biomass burning in response to climate changes. Global Biogeochemical Cycles, 26, GB4007.

Flannigan, M.D., Krawchuk, M.A., de Groot, W.J., Wotton, B.M. \& Gowman, L.M. (2009) Implications of changing climate for global wildland fire. International Journal of Wildland Fire, 18, 483-507.

Foit, F.F., Gavin, D.G. \& Hu, F.S. (2004) The tephra stratigraphy of two lakes in southcentral British Columbia, Canada and its implications for the mid-late Holocene volcanic activity at Glacier Peak and Mount St. Helens, Washington, USA. Canadian Journal of Earth Sciences, 41, 1401-1410.

Gavin, D.G., Brubaker, L.B. \& Lertzman K.P. (2003) Holocene fire history of a coastal temperate rain forest based on soil charcoal radiocarbon dates. Ecology, 84, 186-201. 
Gavin, D.G., Hu F.S., Lertzman, K. \& Corbett, P. (2006) Weak climatic control of standscale fire history during the late Holocene. Ecology, 87, 1722-1732.

Gavin, D.G., Hallett, D.J., Hu, F.S., Lertzman, K.P., Prichard, S.J., Brown, K.J., Lynch, J.A., Bartlein, P.J. \& Peterson, D.L. (2007) Forest fire and climate change in western North America: insights from sediment charcoal records. Frontiers in Ecology and the Environment, 5, 499-506.

Gedalof, Z. (2011) Climate and spatial patterns of wildfire. The landscape ecology of fire (ed. by D. McKenzie, C. Miller and D. Falk), pp. 89-115. Springer, Dordrecht.

Glew, J.R., Smol, J.P. \& Last, W.M. (2001) Sediment core collection and extrusion. Tracking environmental change using lake sediments. Vol. 1: Basin analysis, coring, and chronological techniques (ed. by W.M. Last and J.P. Smol), pp. 73-105. Kluwer Academic Publishers, Dordrecht.

Greene, G.A. (2011) Historical fire regime of the Darkwoods: quantifying the past to plan for the future. MSc Thesis, Department of Geography, University of British Columbia, Vancouver.

Grissino-Mayer, H.D. (1999) Modeling fire interval data from the American southwest with the Weibull distribution. International Journal of Wildland Fire, 9, 37-50.

Hallett, D.J. \& Anderson, R.S. (2010) Paleofire reconstruction for high-elevation forests in the Sierra Nevada, California, with implications for wildfire synchrony and climate variability in the late Holocene. Quaternary Research, 73, 180-190.

Hallett, D.J. \& Hills, L.V. (2006) Holocene vegetation dynamics, fire history, lake level and climate change in the Kootenay Valley, southeastern British Columbia, Canada. Journal of Paleolimnology, 35, 351-357.

Hayes, G.L. (1942) Differences in fire danger with altitude, aspect, and time of day. Journal of Forestry, 40, 318-323.

Hebda, R.J. (1995) British Columbia vegetation and climate history with focus on 6 ka BP. Géographie Physique et Quaternaire, 49, 55-79.

Heyerdahl, E.K., Brubaker, L.B. \& Agee, J.K. (2001) Spatial controls of historical fire regimes: a multiscale example from the interior west, USA. Ecology, 82, 660-678. 
Heyerdahl, E.K., Lertzman, K. \& Karpuk, S. (2007) Local-scale controls of a lowseverity fire regime (1750-1950), southern British Columbia, Canada. Écoscience, 14, $40-47$.

Heyerdahl, E.K., McKenzie, D., Daniels, L.D., Hessl, A.E., Littell, J.S. \& Mantua, N.J. (2008) Climate drivers of regionally synchronous fires in the inland Northwest (16511900). International Journal of Wildland Fire, 17, 40-49.

Higuera, P.E. (2009) CharAnalysis 0.9: diagnostic and analytical tools for sedimentcharcoal analysis. Available at: http://CharAnalysis.googlepages.com/.

Higuera, P.E., Brubaker, L.B., Anderson, P.M., Hu, F.S. \& Brown, T.A. (2009) Vegetation mediated the impacts of postglacial climatic change on fire regimes in the south-central Brooks Range, Alaska. Ecological Monographs, 79, 201-219.

Higuera, P.E., Gavin, D.G., Bartlein, P.J. \& Hallett, D.J. (2010) Peak detection in sediment-charcoal records: impacts of alternative data analysis methods on fire-history interpretations. International Journal of Wildland Fire, 19, 996-1014.

Johnson, E.A. (1992) Fire and vegetation dynamics: studies from the North American boreal forest. Cambridge University Press, Cambridge.

Johnson, E.A. \& Wowchuk, D.R. (1993) Wildfires in the southern Canadian Rocky Mountains and their relationship to mid-tropospheric anomalies. Canadian Journal of Forest Research, 23, 1213-1222.

Jungen, J.R. (1980) Soil resources of the Nelson map area (82F). British Columbia Soil Survey. RAB Bulletin 20, Report No. 28. Province of British Columbia, Ministry of Environment, Resource Analysis Branch. Victoria, BC.

Kelly, R.F., Higuera, P.E., Barrett, C.M. \& Hu, F.S. (2011) A signal-to-noise-index to quantify the potential for peak detections in sediment-charcoal records. Quaternary Research, 75, 11-17.

Kitzberger, T., Brown, P.M., Heyerdahl, E.K., Swetnam, T.W. \& Veblen, T.T. (2007) Contingent Pacific-Atlantic Ocean influence on multicentury wildfire synchrony over western North America. Proceedings of the National Academy of Sciences USA, 104, $543-548$. 
Lertzman, K. \& Fall, J. (1998) From forest stands to landscapes: spatial scales and the roles of disturbances. Ecological scale: theory and applications (ed. by D.L. Peterson and V.T. Parker), pp. 339-367. Columbia University Press, New York.

Long, C.J., Whitlock, C., Bartlein, P.J. \& Millspaugh, S.H. (1998) A 9000-year fire history from the Oregon Coast Range, based on a high-resolution charcoal study. Canadian Journal of Forest Research, 28, 774-787.

Luckman, B.H. (2000) The Little Ice Age in the Canadian Rockies. Geomorphology, 32, 357-384.

Luckman, B.H., Holdsworth, G. \& Osborn, G.D. (1993) Neoglacial glacier fluctuations in the Canadian Rockies. Quaternary Research, 39, 144-153.

Macias Fauria, M., Michaletz, S.T. \& Johnson, E.A. (2011) Predicting climate change effects on wildfires requires linking processes across scales. Wiley Interdisciplinary Reviews: Climate Change, 2, 99-112.

Mullineaux, D.R. (1996) Pre-1980 tephra-fall deposits erupted from Mount St. Helens, Washington. USGS Professional Paper 1563. United States Geological Survey, Washington, DC.

Nesbitt, J.H. (2010) Quantifying forest fire variability using tree rings Nelson, British Columbia 1700-Present. MSc. Thesis, University of British Columbia, Vancouver.

Osborn, G. \& Karlstrom, E.T. (1988) Holocene history of the Bugaboo Glacier, British Columbia. Geology, 16, 1015-1017.

Pearkes, E.D. (2002) Geography of memory: recovering stories of a landscape's first people. Kutenai House Press, Nelson, BC.

Pollack, J.C, Quesnel, H., Hauk, C. \& MacLean, H. (1997) A quantitative evaluation of natural age class distributions and stand replacement intervals in the Nelson Forest Region. Technical Report TR-015 Forest Sciences, Nelson Forest Region, British Columbia Ministry of Forests, Nelson, BC.

Power, M.J., Mayle, F.E., Bartlein, P.J., Marlon, J.R., Anderson, R.S., Behling, H., Brown, K.J., Carcaillet, C., Colombaroli, D., Gavin, D.G., Hallett, D.J., Horn, S.P., Kennedy, L.M., Lane, C.S., Long, C.J, Moreno, P.I., Paitre, C., Robinson, G., Taylor, Z. 
\& Walsh M. (2012) Climatic control of the biomass-burning decline in the Americas After AD 1500. The Holocene, 23, 3-13.

Reimer, P.J., Baillie, M.G.L., Bard, E. et al. (2009) IntCal09 and Marine09 radiocarbon age calibration curves, 0-50,000 years cal BP. Radiocarbon, 51, 1111-1150.

Ripley, B.D. (1977) Modelling spatial patterns. Journal of the Royal Statistical Society B, 39, 172-212.

Rosenberg, S.M., Walker, I.R. \& Mathewes, R.W. (2003) Postglacial spread of hemlock (Tsuga) and vegetation history in Mount Revelstoke National Park, British Columbia, Canada. Canadian Journal of Botany, 81,139-151.

Rosenberg, S.M., Walker, I.R., Mathewes, R.W. \& Hallett, D.J. (2004) Midge-inferred Holocene climate history of two subalpine lakes in southern British Columbia, Canada. The Holocene, 14, 258-271.

Steinman, B.A., Abbott, M.B., Mann, M.E., Stansell, N.D. \& Finney, B.P. (2012) 1,500 year quantitative reconstruction of winter precipitation in the Pacific Northwest. Proceedings of the National Academy of Sciences USA, 109, 11619-11623.

Taylor, A.H. \& Skinner, C.N. (1998) Fire history and landscape dynamics in a latesuccessional reserve, Klamath Mountains, California, USA. Forest Ecology and Management, 111, 285-301.

Taylor, A.H. \& Skinner, C.N. (2003) Spatial patterns and controls on historical fire regimes and forest structure in the Klamath Mountains. Ecological Applications, 13, 704 719.

Telford, R.J., Heegaard, E. \& Birks, H.J.B. (2004) The intercept is a poor estimate of a calibrated radiocarbon age. The Holocene, 14, 296-298.

Trouet, V., Taylor, A.H., Wahl, E.R., Skinner, C.N. \& Stephens, S.L. (2010) Fire-climate interactions in the American West since 1400 CE. Geophysical Research Letters, 37, L04702.

Whitlock, C. \& Larsen, C. (2001) Charcoal as a fire proxy. Tracking environmental change using lake sediments. Vol. 3: Terrestrial, algal, and siliceous indicators (ed. by J.P. Smol, H.J. Birks and W.M. Last), pp. 75-97. Kluwer Academic Publishers, Dordrecht. 
Whitlock, C. \& Millspaugh, S.H. (1996) Testing the assumptions of fire-history studies: an examination of modern charcoal accumulation in Yellowstone National Park, USA. The Holocene, 6, 7-15.

Whitlock, C., Higuera, P.E., McWethy, D.B. \& Briles, C.E. (2010) Paleoecological perspectives on fire ecology: revisiting the fire-regime concept. The Open Ecology Journal, 3, 6-23.

Wong, C., Sandmann, H. \& Dorner, B. (2004) Historical variability of natural disturbances in British Columbia: a literature review. FORREX-Forest Research Extension Partnership, Kamloops, BC.

Wright, H.E.J., Mann, D.H. \& Glaser, P.H. (1984) Piston corers for peat and lake sediments. Ecology, 65, 657-659.

Yamaguchi, D.K. (1983) New tree ring dates for recent eruptions of Mount St. Helens. Quaternary Research, 20, 246-250.

Yamaguchi, D.K. (1985) Tree-ring evidence for a two-year interval between recent prehistoric explosive eruptions of Mount St. Helens. Geology, 13, 554-557.

Zdanowicz, C.M., Zielinski, G.A. \& Germani, M.S. (1999) Mount Mazama eruption: Calendrical age verified and atmospheric impact assessed. Geology, 27, 621-624. 
Table 2.1: Characteristics of the 5 study lakes in south-eastern British Columbia.

\begin{tabular}{lccccc}
\hline & NEL01 & Rockslide Lake & NEL02 & NEL03 & Cooley Lake \\
\hline Coordinates & $49^{\circ} 32.5^{\prime} \mathrm{N}$, & $49^{\circ} 33.0^{\prime} \mathrm{N}$, & $49^{\circ} 41.5^{\prime} \mathrm{N}$, & $49^{\circ} 29.8^{\prime} \mathrm{N}$, & $49^{\circ} 29.5^{\prime} \mathrm{N}$, \\
& $117^{\circ} 28.0^{\prime} \mathrm{W}$ & $117^{\circ} 31.3^{\prime} \mathrm{W}$ & $117^{\circ} 184^{\prime} \mathrm{W}$ & $116^{\circ} 542^{\prime} \mathrm{W}$ & $117^{\circ} 38.7^{\prime} \mathrm{W}$ \\
Elevation (m a.s.I.) & 1520 & 1539 & 1054 & 2074 & 1515 \\
Aspect & $\mathrm{S}$ & $\mathrm{S}$ & $\mathrm{NW}-\mathrm{SE}$ valley * & $\mathrm{NNE}$ & $\mathrm{N}$ \\
& $200^{\circ}$ & $180^{\circ}$ & $330-150^{\circ}$ & $30^{\circ}$ & $25^{\circ}$ \\
Surface area (ha) & 0.86 & 3.2 & 2 & 0.35 & 4.5 \\
Max. depth (m) & 9.0 & 14.1 & 4.6 & 2.4 & 11.0 \\
Inflows & ephemeral & ephemeral & 0 & ephemeral & ephemeral \\
Outflows & 1 & 1 & 0 & 1 & 1 \\
Catchment (ha) & 62 & 107 & 120 & 36 & 86 \\
Forest type** & ESSF & ESSF & ICH & ESSF & ESSF \\
\hline
\end{tabular}

* Nearby slopes are oriented in multiple directions.

** ESSF, Engelmann spruce-subalpine fir; ICH, interior cedar-hemlock. 
Table 2.2: Uncalibrated radiocarbon ages, $2 \sigma$ calibrated ages (IntCal09), and tephrochronology used to develop age-depth relationships for 3 lake sediment stratigraphies collected in south-eastern British Columbia. Note that adjusted depths have been created by removing the tephra layer from the model.

\begin{tabular}{|c|c|c|c|c|c|c|c|}
\hline Study site & $\begin{array}{c}\text { Stratigraphic } \\
\text { depth }(\mathrm{cm})\end{array}$ & Adjusted depth (cm) & $\begin{array}{c}\text { Uncalibrated age } \\
\left({ }^{14} \mathrm{C} \text { yr BP }\right)\end{array}$ & $\begin{array}{l}{ }^{13} \mathrm{C}:{ }^{12} \mathrm{C} \text { ratio } \\
(\%)\end{array}$ & $\begin{array}{c}\text { Calibrated age } \\
\text { (cal. yr BP) }\end{array}$ & Material & $\begin{array}{l}\text { Reference or } \\
\text { lab number }\end{array}$ \\
\hline \multirow[t]{4}{*}{ NEL01 } & $24.5-25.5$ & 24.75 & & & $468-469$ & Tephra & $\mathrm{MSH} \mathrm{Wn^{a }}$ \\
\hline & $74.5-75^{\star}$ & 74.75 & $2910 \pm 40$ & -24.1 & $2946-3209$ & Wood & Beta-275054* \\
\hline & $136.5-137$ & 136.75 & $2990 \pm 30$ & -26.9 & $3075-3320$ & Plant material & Beta-314480 \\
\hline & $278.5-284.5$ & 278.5 & & & $7627 \pm 150$ & Tephra & Mazama $\mathrm{O}^{\mathrm{b}}$ \\
\hline \multirow[t]{4}{*}{ NEL02 } & $99.5-100$ & 99.75 & $190 \pm 30$ & -23.3 & $0-302$ & Wood & Beta-301978 \\
\hline & $174.5-175$ & 174.75 & $2020 \pm 30$ & -26.3 & 1892-2055 & Wood & Beta-301979 \\
\hline & $290.9-292.5$ & 291.70 & $4420 \pm 30$ & -24.8 & $4870-5266$ & Wood & Beta-314481 \\
\hline & $529-531.5$ & 530.25 & $6690 \pm 40$ & -26.4 & $7479-7621$ & Wood & Beta-314482 \\
\hline \multirow[t]{7}{*}{ NEL03 } & $27.5-28.5$ & 27.5 & & & $468-469$ & Tephra & $\mathrm{MSH} \mathrm{Wn^{a }}$ \\
\hline & $90.5-94.5$ & 90.5 & $2230 \pm 30$ & -26.0 & 2153-2335 & Wood & Beta-301980 \\
\hline & 217.5-218 & 217.5 & $5690 \pm 40$ & -23.7 & $6399-6630$ & Wood & Beta-301981 \\
\hline & 245-251.5 & & & & & Ash redeposit & \\
\hline & $266.5-293.5$ & 260.5 & & & 7477-7777 & Tephra & Mazama $\mathrm{O}^{\mathrm{b}}$ \\
\hline & $317-317.5$ & 284.5 & $7920 \pm 40$ & -24.9 & $8606-8977$ & Plant material & Beta-301982 \\
\hline & $349.5-350$ & 317 & $8600 \pm 50$ & -24.4 & $9495-9678$ & Wood & Beta-301983 \\
\hline
\end{tabular}

${ }^{\mathrm{a}}$ Yamaguchi (1983, 1985); ${ }^{\mathrm{b}}$ Zdanowicz et al. (1999); *date removed from age-depth model. 
Table 2.3: Summary of sampling, charcoal concentration, charcoal accumulation rate (CHAR), signal-to-noise indices (SNI; Kelly et al., 2011), CHAR peaks, and raw and Weibull median fire return intervals (FRIs) for each site in south-eastern British Columbia. Note the slight variations in the temporal range of each record.

\begin{tabular}{|c|c|c|c|c|c|c|}
\hline Site & & NEL01 & Rockslide Lake & NEL02 & NEL03 & Cooley Lake \\
\hline \multirow[t]{3}{*}{ Data sampling } & Record range (cal. yr BP) & $-59-5002$ & $-57-4977$ & $-59-5005$ & $-59-5005$ & $-50-5009$ \\
\hline & Median interval (years) & 14 & 12 & 6 & 15 & 12 \\
\hline & $n$ & 431 & 395 & 625 & 370 & 436 \\
\hline \multirow{4}{*}{$\begin{array}{l}\text { Charcoal concentration } \\
\text { (pieces } \mathrm{cm}^{-3} \text { ) }\end{array}$} & Mean & 32.13 & 22.62 & 38.89 & 43.13 & 103.63 \\
\hline & Median & 23.0 & 12.0 & 34.0 & 32.5 & 59.1 \\
\hline & Standard deviation & 30.9 & 30.7 & 32.5 & 42.2 & 173.2 \\
\hline & Range & $0-220$ & $0-226.5$ & $0-252$ & $1-369$ & $5.4-1836$ \\
\hline \multirow{4}{*}{ CHAR (pieces $\mathrm{cm}^{-2} \mathrm{yr}^{-1}$ ) } & Mean & 1.29 & 0.89 & 2.39 & 1.47 & 6.56 \\
\hline & Median & 0.95 & 0.59 & 1.69 & 1.13 & 3.99 \\
\hline & Standard deviation & 1.23 & 0.98 & 2.36 & 1.28 & 9.91 \\
\hline & Range & $0-7.8$ & $0-6.7$ & $0-23.2$ & $0-11.5$ & $0-89.3$ \\
\hline \multirow[t]{2}{*}{ SNI } & Range & $1.6-24.2$ & $2.0-7.8$ & $1.2-6.5$ & $2.0-9.8$ & $4.3-9.1$ \\
\hline & Global SNI & 6.0 & 7.8 & 3.4 & 6.1 & 9.1 \\
\hline \multirow[t]{3}{*}{ CHAR peaks (no.) } & $-59-5000$ yr BP & 27 & 35 & 27 & 22 & 21 \\
\hline & $-59-2500$ yr BP & 10 & 12 & 14 & 12 & 12 \\
\hline & $2500-5000$ yr BP & 17 & 23 & 13 & 10 & 9 \\
\hline \multirow[t]{3}{*}{ mFRls (years) } & $-59-5000$ yr BP & 150 & 114 & 150 & 204 & 216 \\
\hline & $-59-2500$ yr BP & 192 & 156 & 156 & 144 & 192 \\
\hline & $2500-5000$ yr BP & 144 & 96 & 144 & 228 & 228 \\
\hline \multirow[t]{3}{*}{ Weibull mFRIs (years) } & $-59-5000$ yr BP & 190 & 135 & 180 & 226 & 241 \\
\hline & $-59-2500$ yr BP & 275 & 169 & 184 & 217 & 215 \\
\hline & $2500-5000$ yr BP & 152 & 110 & 185 & 231 & 282 \\
\hline
\end{tabular}




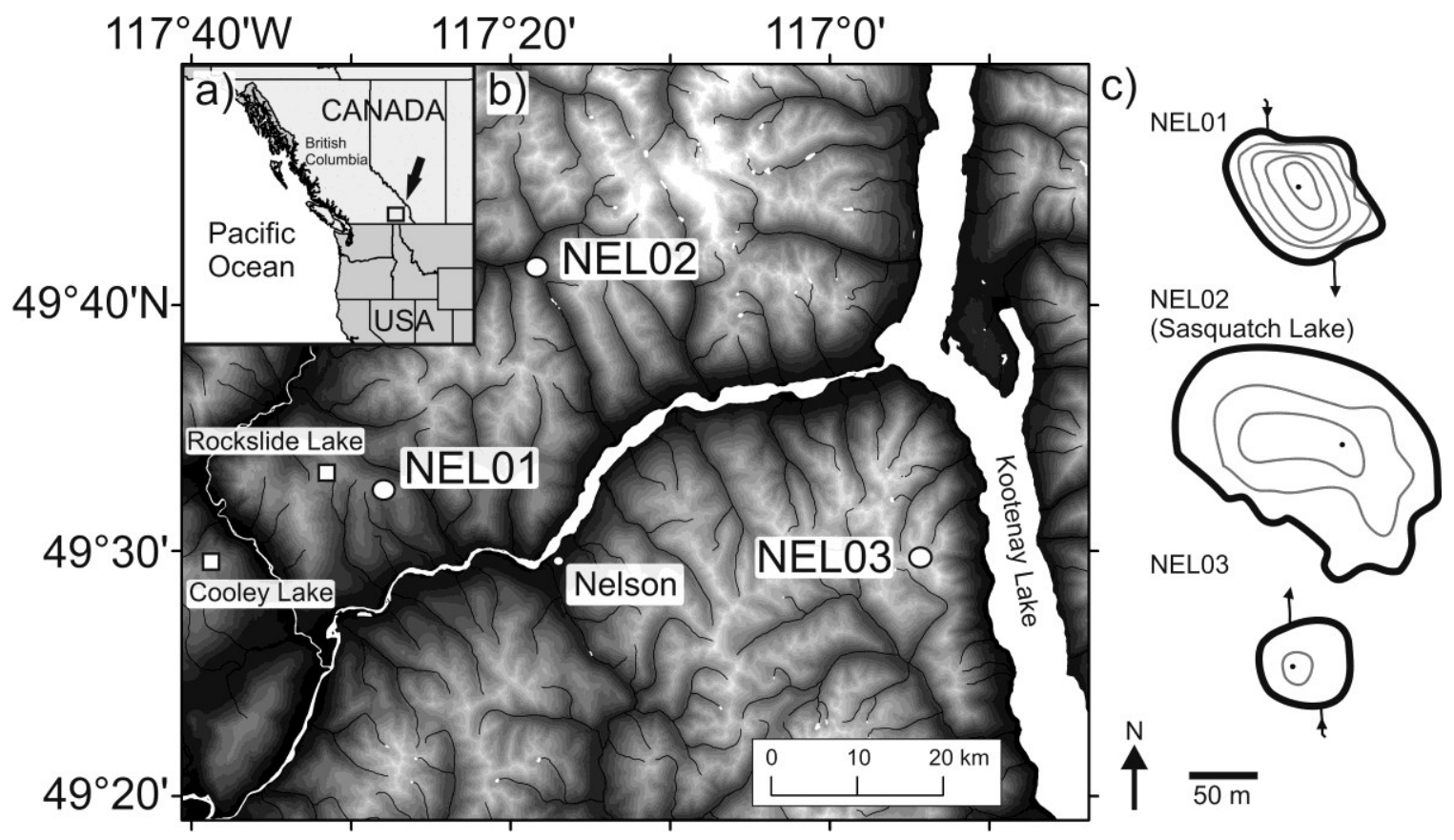

Figure 2.1: (a) Location of the study region in south-eastern British Columbia, Canada; (b) regional topography (1:50,000 digital elevation model) with study site locations (circles) and previously published lake sites (squares; Gavin et al., 2006); and (c) morphometry, bathymetry (2-m isobaths) and coring location (black circles) of each lake site, drawn to scale. Lake bathymetries were estimated by conducting 4-49 line depth soundings. 


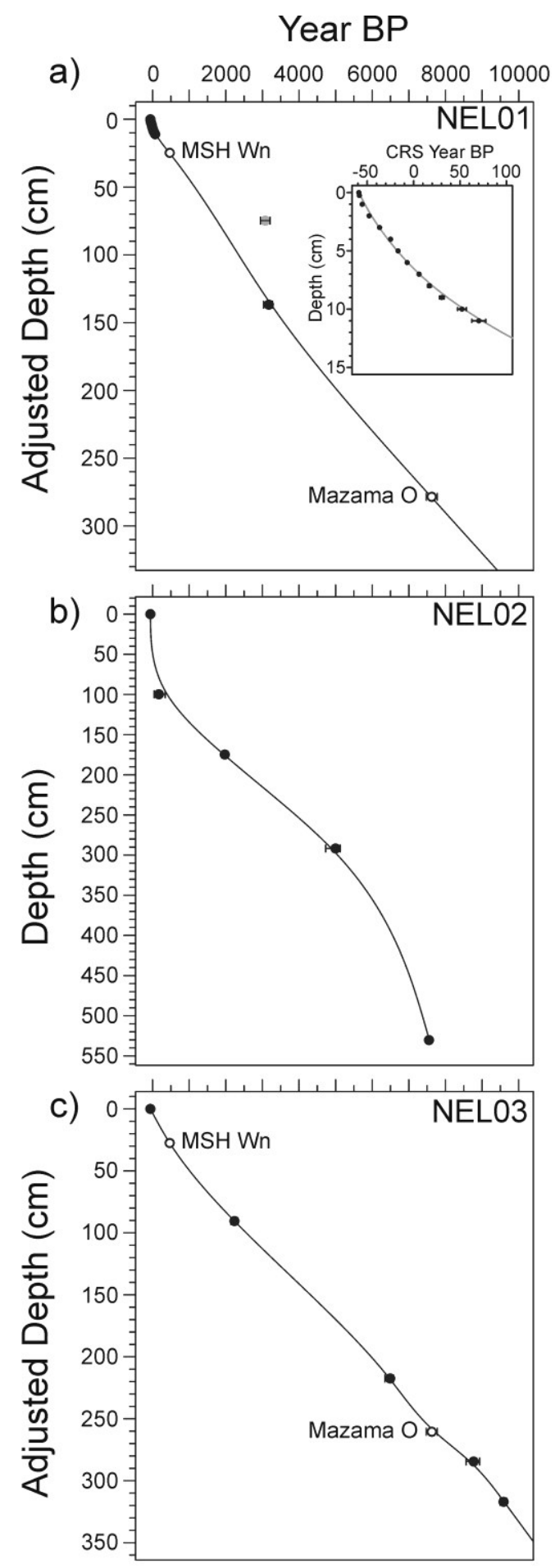

Figure 2.2: Age-depth models of 3 lake sediment stratigraphies collected in south-eastern British Columbia, Canada, using ${ }^{210} \mathrm{~Pb}$ constant rate of supply (CRS) modelled dates, accelerator mass spectrometry (AMS) radiocarbon (black circles) and tephrochronological dates (labelled open circles).(a) NEL01, modelled using a cubic smoothing spline function, $\lambda=1$ (inset shows ${ }^{210} \mathrm{~Pb}$ dating), one AMS date was rejected (grey circle); (b) NEL02, spline function with $\lambda=55$; and (c) NEL03, spline function with $\lambda=1$. Horizontal error bars show Mazama $\mathrm{O}$ (Zdanowicz et al., 1999) and $2 \sigma$ radiocarbon age ranges. Note that NEL01 and NEL03 are presented by depth adjusted for the thick instantaneously deposited tephra layers. 
a) NEL01

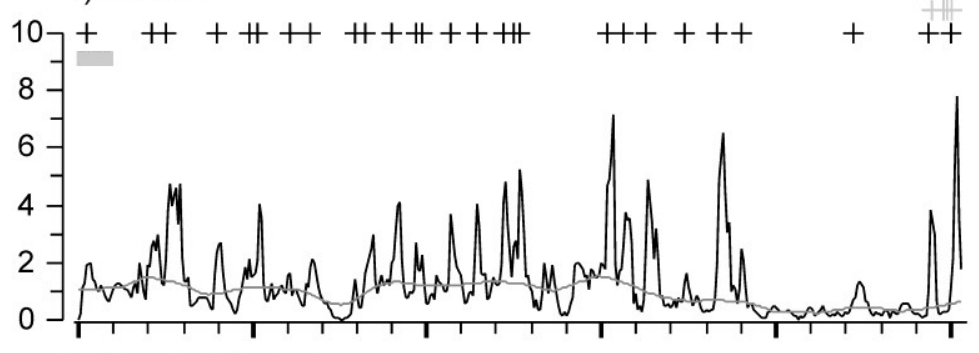

b) Rockslide Lake

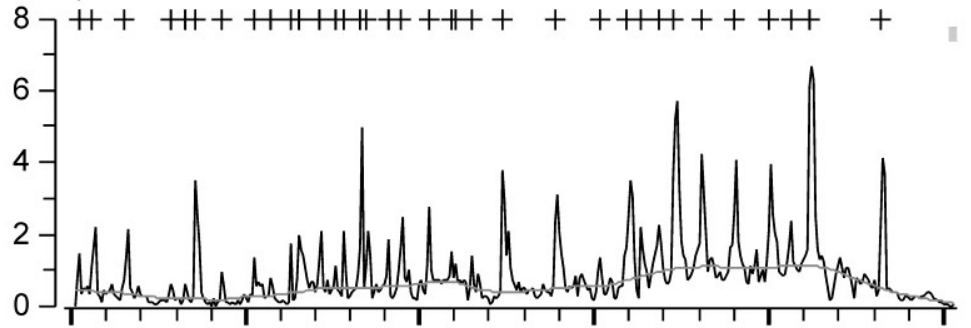

c) NELO2 (Sasquatch Lake)

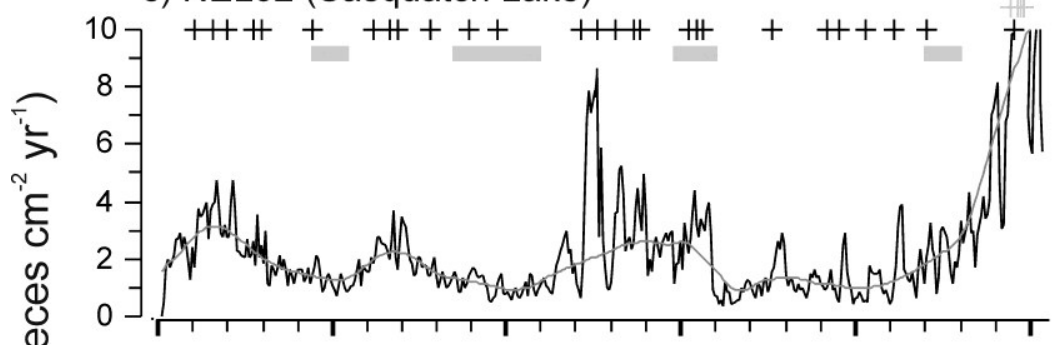

$\stackrel{-\frac{1}{2}}{2}$

$\frac{1}{4}$ d2) $+++++++++++\quad++++\#+$

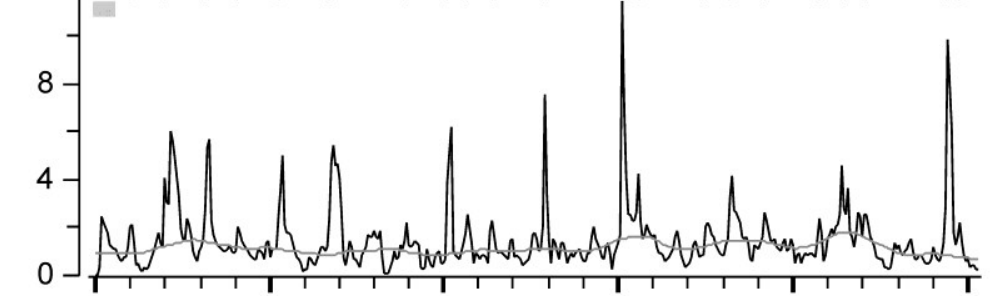

e) Cooley Lake

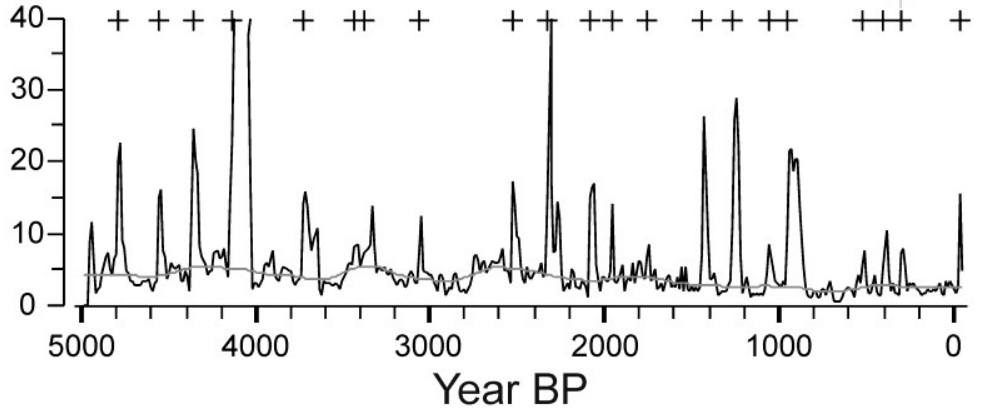

f) $-59-5000 \mathrm{yr} \mathrm{BP}$
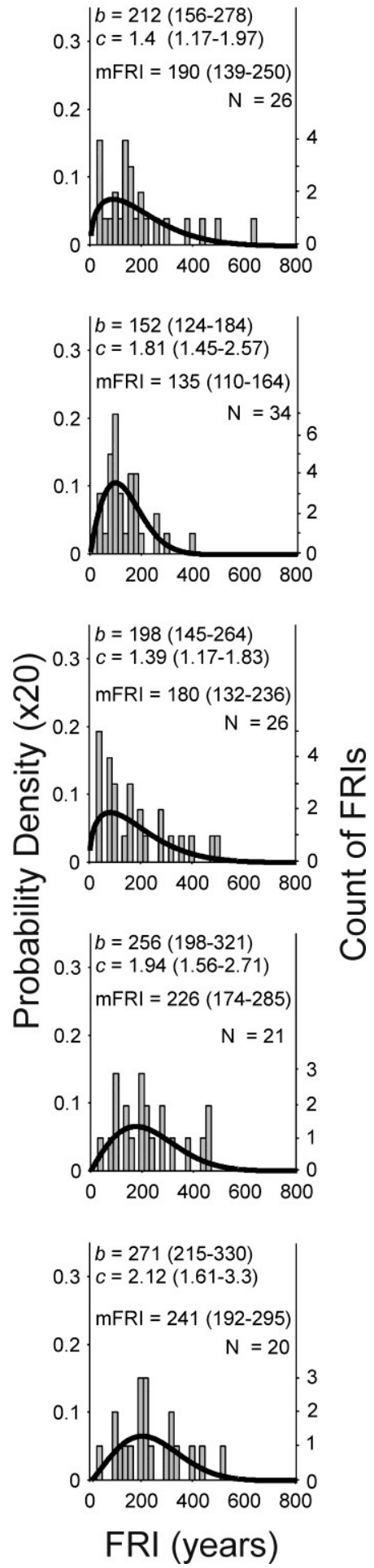

Figure 2.3: Charcoal accumulation rates (CHAR; black line) established using CHARANALYSIS from the sediments collected at south-facing sites $(\mathrm{a}-\mathrm{c}$, black labels) and north-facing sites (d-e, grey labels) in the Columbia Mountains, south-eastern British Columbia, Canada. Background CHAR (grey line) shows the varying background component of the decomposed CHAR data 
used to establish peaks in the CHAR record ('+' symbols), which represent fire events of one or more fires occurring within the lake catchment during a 12-year period. Light grey ' + ' symbols (Nesbitt, 2010) and dark grey '+' symbols (Greene, 2011) are known fire dates within 1-13 km of the lake sites, established by dendroecological methods. The known fire date for Cooley Lake was established by Gavin et al. (2006). Grey boxes below the '+' symbols indicate portions of the time series that fall below a signal-to-noise index threshold value of 3 (Kelly et al., 2011). Note that sites NEL02 and Cooley Lake (c,e) are truncated for presentation. (f) Fire return interval (FRI) distributions (grey bars) for each study site with fitted Weibull median fire return intervals (mFRI) and 95\% confidence intervals (in parentheses). Weibull $b$ and $c$ parameters are shown with $95 \%$ confidence intervals. $n$ is the number of FRIs in each record from 5000 cal. yr BP to present and $n+1$ is the number of inferred fire episodes. The counts of the FRIs are shown by the $y$-axes on the right-hand side. 

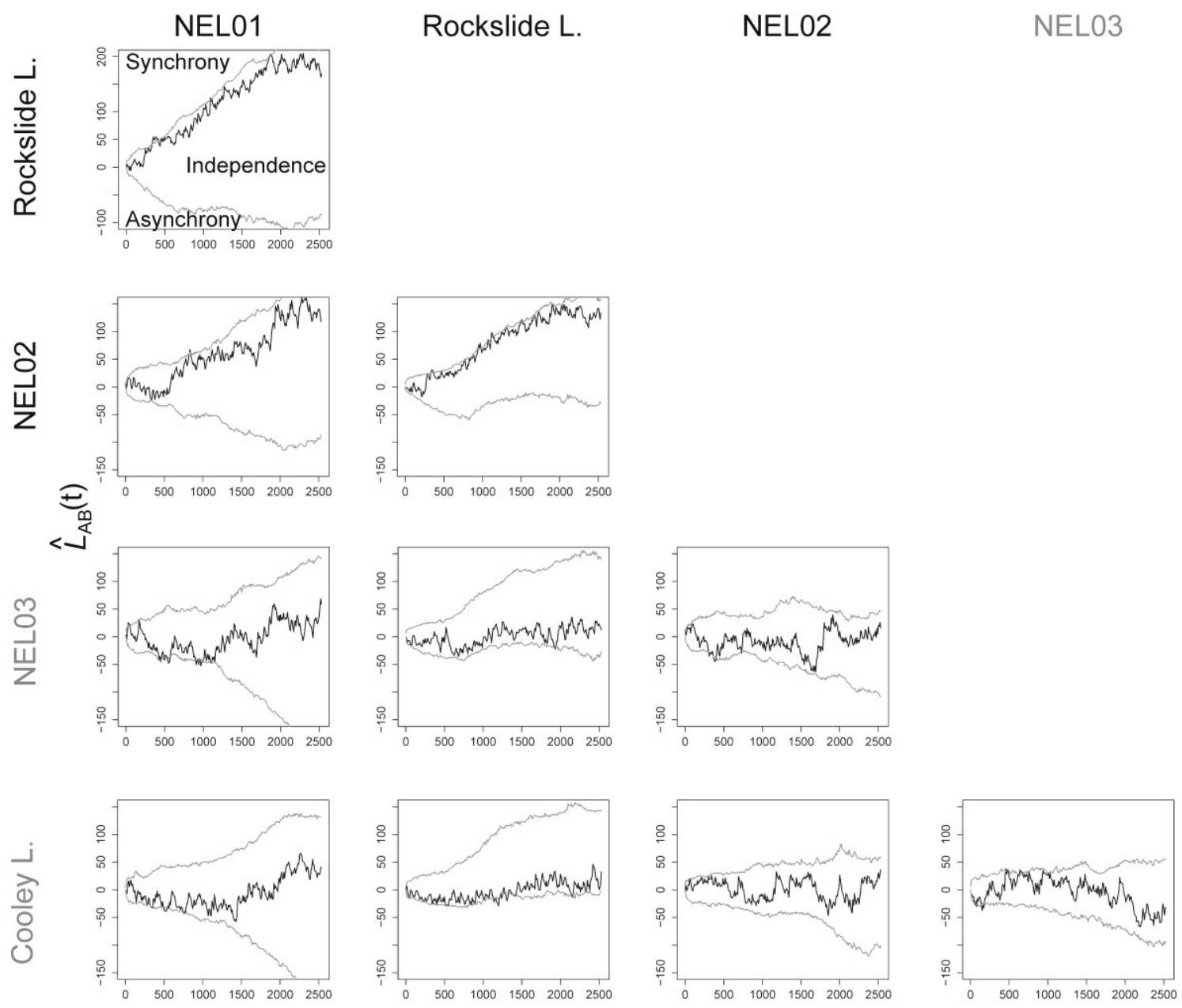

Time, $\mathrm{t}(\mathrm{yr})$

Figure 2.4: Matrix of bivariate $L$-function analyses between fire histories at each lake site, -59 to 5000 cal. yr BP. South-facing sites are labelled in black and north-facing sites are labelled in grey. The $L$-function $\left(L_{\mathrm{AB}}(t)\right)$ has been plotted at 10 -year time intervals. Where the $K$-function gives the number of events in record B occurring within a time window $(t)$ of each event in record A, and was then converted to an $L$-function for visualisation by stabilising the mean and variance over $t$. The $95 \%$ confidence interval envelopes were estimated by 1000 iterations of circularly randomizing one record (Gavin et al., 2006). 

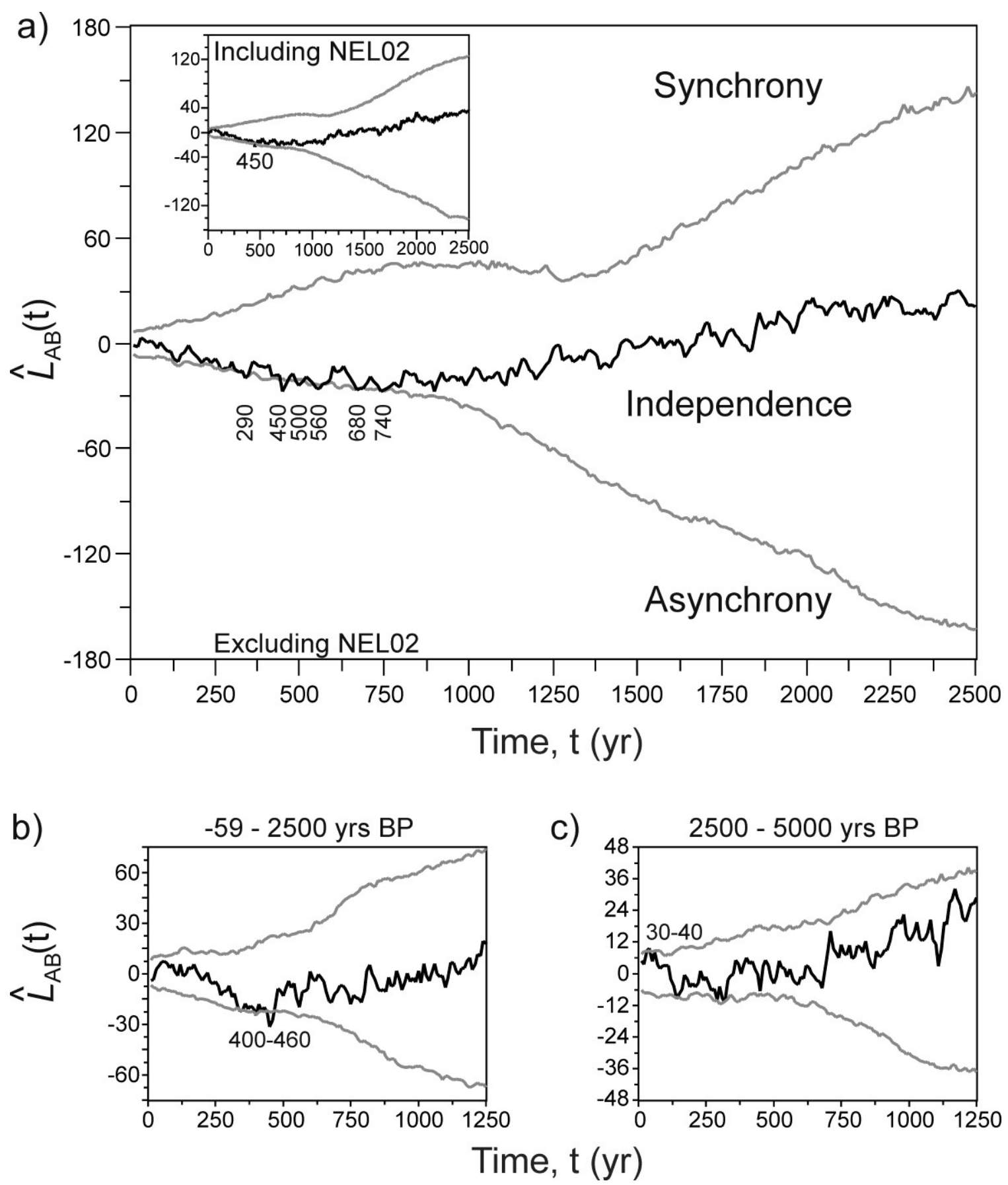

Figure 2.5: (a) $L$-function results, at 10-year time intervals, of a comparison of the north-facing and south-facing aspect composite series, with NEL02 excluded from the south-facing aspect group, with the six most significant time window lengths labelled. The inset shows significant asynchrony at the lower $L A B(t) 95 \%$ confidence interval (grey lines) at window lengths of \pm 450 years if NEL02 is included. Where the $K$-function gives the number of events in record B occurring within a time window $(t)$ of each event in record $\mathrm{A}$, and was then converted to an $L$-function for visualisation by stabilising the mean and variance over $t$. The $95 \%$ confidence interval envelopes were estimated by 1000 iterations of circularly randomizing one record (Gavin et al., 2006). The composites including NEL02 were also split into (b) $-59-2500$ cal. yr BP and (c) 2500-5000 cal. yr BP. 
a) Inferred fire episodes

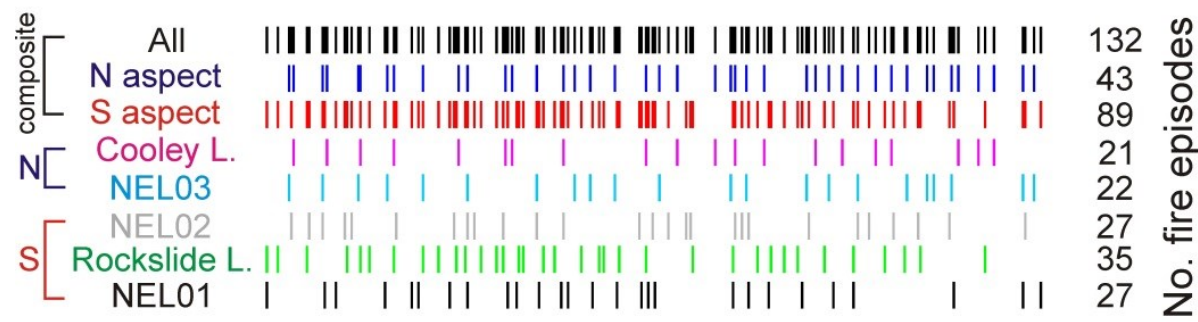

b) 1000 -year window

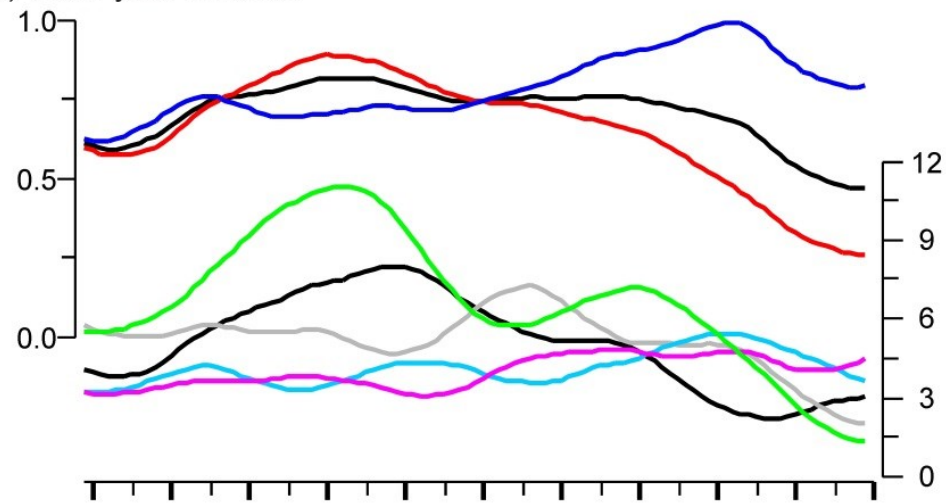

c) 500-year window

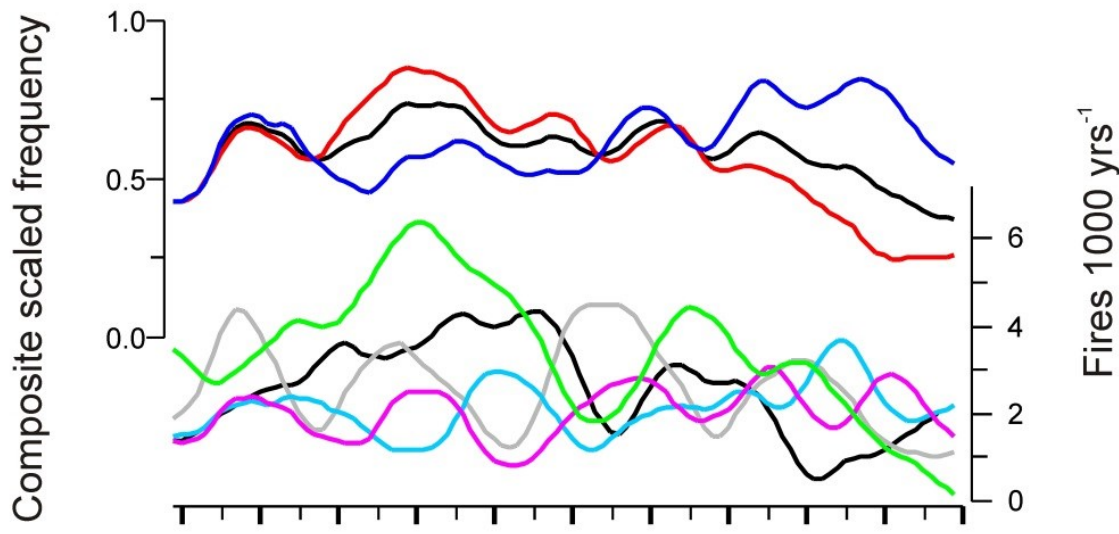

d) 200-year window

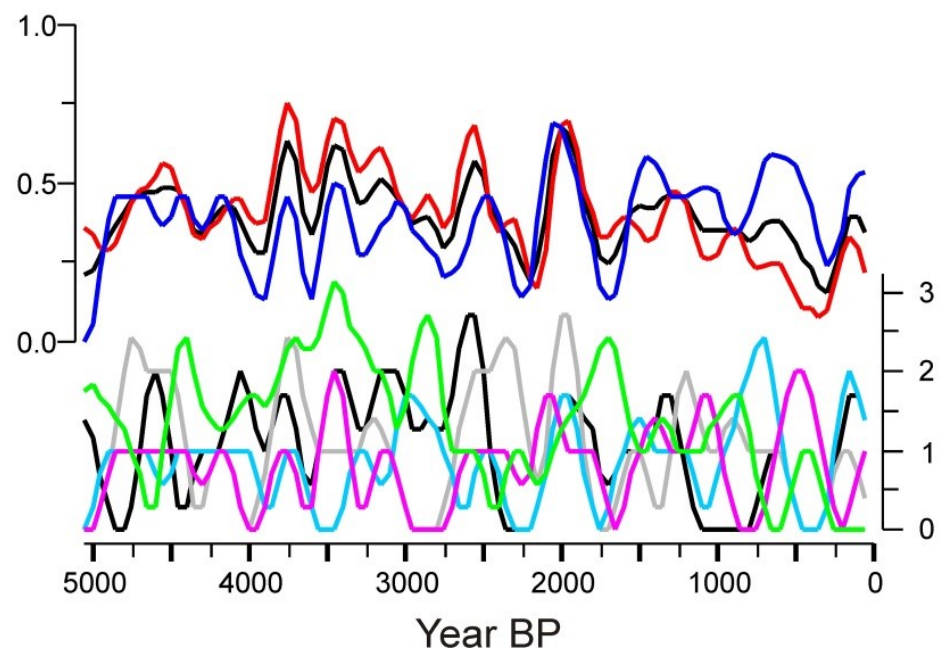


Figure 2.6: (a) Inferred fire dates and composite series of south-facing (NEL01, NEL02, and Rockslide Lake), north-facing (NEL03 and Cooley Lake) and all fire episodes. (b) The $y$-axis on the right shows fire episode frequency per 1000 years at each lake site - NEL01 (black line), NEL02 (grey line), NEL03 (cyan line), Cooley Lake (magenta line), and Rockslide Lake (green line) - calculated as the number of events with a 1000-year moving window and smoothed with a LOWESS filter. The $y$-axis on the left shows fire frequencies for the composite series of all sites (black line), south-facing sites (red line), and north-facing sites (blue line), rescaled between 0 to 1 by dividing each site record by its maximum value and averaging the sites to ensure that each site contributed equally to the variability (Gavin et al., 2006; Hallett \& Anderson, 2010). We also present similar data using (c) a 500-year window, and (d) a 200-year window, to compare millennial- and centennial-scale variability. Fire years with fire events recorded at each site in the south-facing composite are 1873 and 3673 cal. yr BP, and within the all-sites composite are $121,1165,1873,3217,3673$ and 4597 cal. yr BP. 
2.9 Supporting Information: ${ }^{210} \mathrm{~Pb}$ dating of the uppermost sediments of NELO1

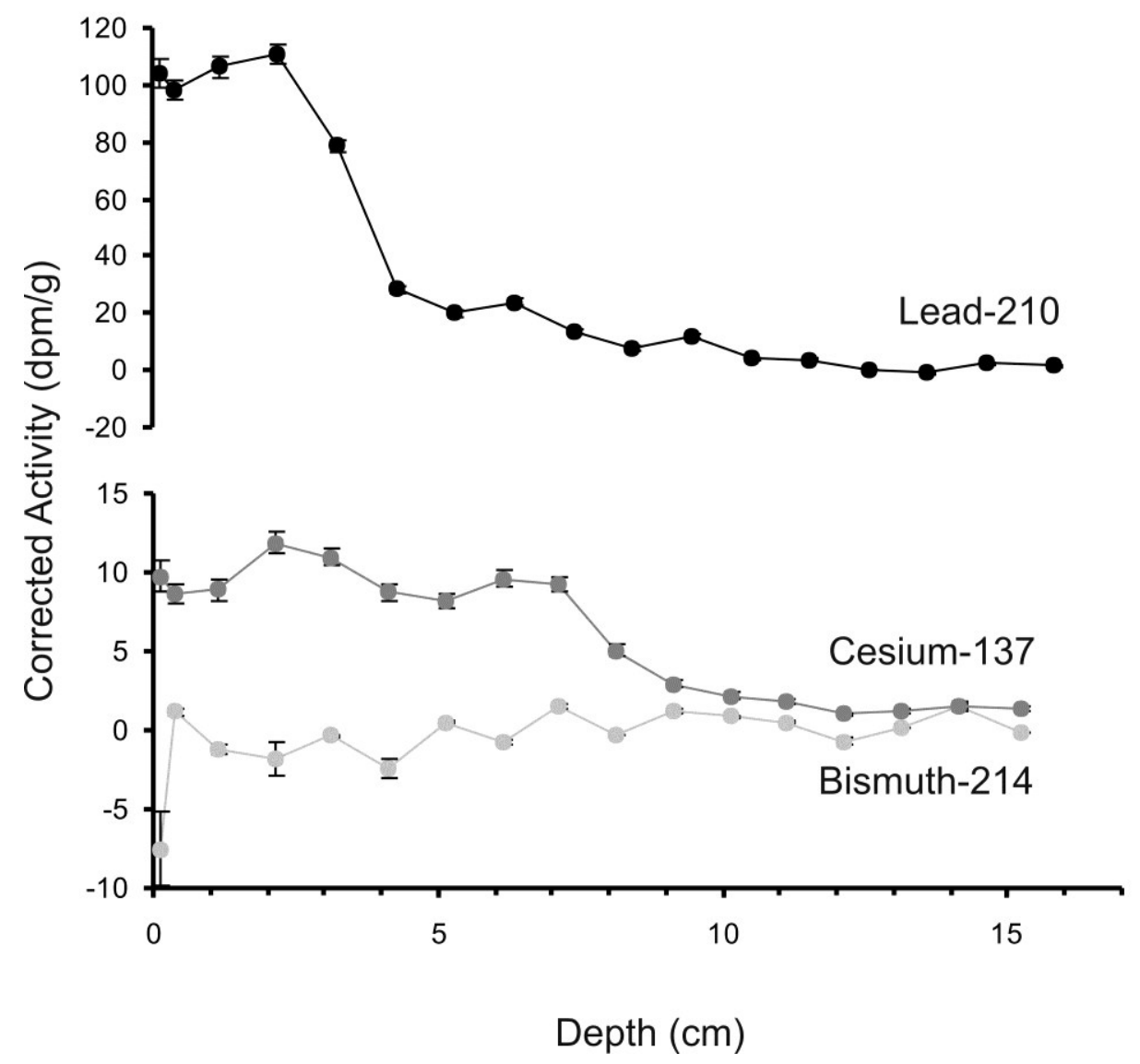

Figure 2.7: Corrected activities of ${ }^{210} \mathrm{~Pb}$ (black), ${ }^{137} \mathrm{Cs}$ (dark grey), and ${ }^{214} \mathrm{Bi}$ (light grey).

Table 2.4: Results of ${ }^{210} \mathrm{~Pb}$ constant rate of supply (CRS) modeled dates of the surface sediments from NEL01

\begin{tabular}{ccc}
\hline $\begin{array}{c}\text { Depth } \\
(\mathrm{cm})\end{array}$ & $\begin{array}{c}\text { CRS age } \\
\text { (cal. yr } \\
\text { BP })\end{array}$ & $\begin{array}{c}\text { Error } \\
( \pm \text { years })\end{array}$ \\
\hline 0 & -59.00 & 0.00 \\
0.25 & -58.52 & 0.33 \\
1 & -55.41 & 0.35 \\
2 & -47.95 & 0.39 \\
3 & -36.67 & 0.49 \\
4 & -24.80 & 0.64 \\
5 & -16.76 & 0.77 \\
6 & -6.96 & 0.98 \\
7 & 5.86 & 1.37 \\
8 & 16.94 & 1.81 \\
9 & 30.42 & 2.59 \\
10 & 52.08 & 4.67 \\
11 & 70.22 & 7.48 \\
\hline
\end{tabular}




\section{Holocene climate-fire-vegetation interactions at a subalpine watershed in southeastern British Columbia, Canada}

\subsection{Abstract}

Vegetation assemblages and associated disturbance regimes are spatially heterogeneous in mountain ecosystems throughout the world due to the complex terrain and strong environmental gradients. Given this complexity, numerous sites describing postglacial vegetation and fire histories are needed to adequately understand forest development and ecosystem responses to varying climate and disturbance regimes. To gain insight into long-term historical climate-firevegetation interactions in southeastern British Columbia, Canada, sedimentological and paleoecological analyses were performed on a sediment core recovered from a small subalpine lake. The pollen assemblages, stomata, and macroremains indicate that from 9500-7500 cal yr BP, Pinus-dominated forests occurred within the catchment and Alnus was also present. Climate was an important control of fire and fire frequency was highest at this time, peaking at 8 fires $1000 \mathrm{yr}^{-1}$, yet charcoal accumulation rates were low, indicative of low terrestrial biomass abundance. From 7500-4600 cal yr BP, Pinus decreased as Picea, Abies and Larix increased and fire frequencies decreased to 3-6 fires $1000 \mathrm{yrs}^{-1}$. Since $7500 \mathrm{cal} \mathrm{yr}$ BP the fire regime varied at a millennial scale, driven by forest biomass abundance and fuel accumulation changes. Local scale (bottom-up) controls of fire increased in relative importance since at least $6000 \mathrm{cal} \mathrm{yr} \mathrm{BP}$.

Key words: British Columbia; disturbance; charcoal; fire regime; Holocene; lake sediments; pollen; subalpine, wildfire 


\subsection{Introduction}

Fire is one of the most important abiotic disturbances to forested ecosystems, influencing stand age and composition, biodiversity, soil stability, carbon flux and biogeochemical cycling. It is critical to examine historical rates of change and the mechanisms interacting at various spatial and temporal scales to understand how future climate and vegetation changes could affect fire regimes (Whitlock et al., 2010; Hessl, 2011). Fire occurrence in mountainous regions is a patchy phenomenon due to complex interactions between top-down (climatic) and bottom-up (local) controls over multiple temporal and spatial scales. The relative importance of various controls on fire regimes are not static through time (Gedalof, 2011), highlighting the need to develop numerous long-term paleoecological records to fully understand past climate-fire-vegetation interactions. Climate variability, a top-down control, varies on short and long time scales and interacts with vegetation, fuel abundance and conditions, topography and other bottom-up control factors that affect the energy and moisture regimes across the landscape. Over long time scales, in mesic ecosystems with substantial biomass growth and accumulation, temperature is the most important control of postglacial fire activity (Daniau et al., 2012). In western North America, fire activity has increased in recent decades due to climate warming (Westerling et al., 2006) in combination with the ecological impacts caused by effective fire suppression (Marlon et al., 2012). However, how these influences affect fire regimes at high-elevation forests is less certain. Bottom-up controls, such as vegetation type and density, topography, and aspect, have also been shown to be important influences in explaining the spatial variability of fire activity in western North America (Heyerdahl et al., 2001; 2007; Gavin et al., 2006; Courtney Mustaphi and Pisaric, 2013). Lake sediment records provide a long-term perspective permitting the 
examination of Holocene fire regime variability and the relative importance of abiotic and biotic controls on past biomass burning (Whitlock and Larsen, 2001).

Records of vegetation and fire regime variability are necessary to inform land management policy and decision making (Gavin et al., 2007). Long-term fire histories need to be examined to resolve the relative importance of the interactions between top-down and bottom-up influences of fire across the heterogeneous landscape of mountainous southern British Columbia, Canada. Multiple studies have examined the long term disturbance histories of Engelmann spruce-subalpine fir (ESSF; Picea engelmannii, Abies lasiocarpa) forests in southern British Columbia, Canada (Wong et al., 2004; Gavin et al., 2006; Courtney Mustaphi and Pisaric, 2013). Previous dendroecological studies in this region have shown that pre-settlement disturbance regime intervals in wet cool ESSF forest stands range from 90-807 years and 105-508 years and that fires are the most important disturbance causing mortality over large areas (Dorner, 2001; Wong et al., 2004). Lower elevation sites within 10-40 km of the study site experience mixed severity fire regimes (Nesbitt, 2010), with stand-replacing disturbance intervals of 150-350 years for ESSF forests (Pollack et al., 1997; Wong et al., 2004). Additional Holocene records are necessary to examine the linked or cascading interrelationships between different types of disturbance, to capture the full variability of fire activity (Courtney Mustaphi and Pisaric, 2013), and to spatially-resolve the controls of fire regimes (Heyerdahl et al., 2001).

Regional synchrony of fire activity is caused by the top-down influences of climate across the Pacific Northwest (Gedalof et al., 2005). Large fires in the interior of British Columbia are associated with blocking circulation patterns resulting in prolonged high pressure systems causing fuel drying and intermittent convective thunderstorms (Johnson et al., 1990; Johnson and Wowchuk, 1993). Forests of the Kootenay region of southeastern British Columbia 
tend to burn during warm and dry years with no significant relationship with previous growing season conditions (Heyerdahl et al., 2002; Da Silva, 2009). Fires can occur in any given year, but are more likely to occur in the Pacific Northwest during regional summer drought (Trouet et al., 2010) associated, at decadal and sub-decadal time scales, with El Niño conditions (Heyerdahl et al., 2002). Climatic influences of winter snow accumulation and the rate of spring melting both have implications for the timing of the fire season. At multi-decadal scales, ocean-atmosphere interactions over the Pacific and Atlantic Oceans modulate fire activity in the Pacific Northwest (Kitzberger et al., 2007). It has also been shown, however, that local-site factors can override regional climate as the dominant influence on fire regimes at many montane study sites in the Pacific Northwest (Gavin et al., 2006; Heyerdahl et al., 2002; 2007) and that the relative influence of various top-down and bottom-up controls vary through time (Heyerdahl et al., 2001; Courtney Mustaphi and Pisaric, 2013). For example, Engelmann spruce-subalpine fir forests on north-facing slopes burn less frequently than those on south-facing slopes during the late Holocene (Steventon, 1997; Gavin et al., 2006; Courtney Mustaphi and Pisaric, 2013), with Weibull median fire return intervals of 226-241 years across north-facing watersheds and 135190 years at south-facing sites (Courtney Mustaphi and Pisaric, 2013). These results suggest that bottom-up controls of fire are important regulators of fire regimes in this region; however, these controls may vary in relative importance through time and be mediated by top-down controls.

We present a postglacial fire and vegetation history study from a north-facing, subalpine watershed covered by a wet and cool ESSF forest. This study aims to investigate how fire regimes at a high-elevation ESSF-forested site have been influenced by Holocene climatic variability, changes to the vegetation assemblages, and the quantity of biomass within the catchment. To provide information on the local and regional vegetation cover variability, we 
present a pollen and stomata record established from a sediment core collected from the center of Lake NEL03 (unofficial name). We then integrate vegetation data with a high-resolution charcoal record representing historical forest fire activity to investigate Holocene climate-firevegetation interactions. Inferences on biomass are based on qualitative interpretations of dominant pollen types and total macroscopic charcoal accumulation rates. Sedimentological and other paleoecological information are also discussed to understand other lake-system changes and their relationships to terrestrial vegetation changes.

\subsubsection{Study site}

A large portion of the Nelson Range of the Selkirk Mountains is managed forested land that is crucial to conservation efforts and the continued sustainability of environmental services provided by natural spaces in southeastern British Columbia, Canada. This region contains a large managed area of ESSF forest that has been minimally disturbed by anthropogenic activities and development, such as deforestation, fragmentation and grazing. It is therefore a useful region to examine the natural variability of past ecosystem dynamics; although, since CE 1945, these forests have been influenced by effective modern fire suppression (Nesbitt, 2010; Greene, 2011). A large portion of the population and infrastructure in the region is at the wildland-urban interface and it is one of the most ecologically diverse regions of British Columbia with notable managed lands, including the Harrop-Procter Community Forest, Midge Creek Wildlife Management Area, West Arm Provincial Park, and Kokanee Glacier Provincial Park.

NEL03 (unofficial name; 49²9’46”N, 116 54'17’'W; Fig. 3.1 and 3.2) has a catchment area of 36 ha and is located near the head of a north-northeast trending, glacially- and fluviallyincised valley. It is a small (0.35 ha) subalpine, cirque lake (2074 m a.s.1.), with a subcircular 
morphometry and maximum measured depth of $\sim 2.4 \mathrm{~m}$. Drainage into the lake is ephemeral and outflow, during periods of high water levels, drains north and northeast through Heather Creek to Kootenay Lake. NEL03 is situated within siltstone, argillite, quartzite, and dolomite rock of the Dutch Creek Formation (Mesoproterozoic) overlain with glacial debris from the bedrock and micaceous schists from the nearby Eagle Bay assemblage (Cambrian-Devonian; Journeay et al., 2000). Coarse-textured orthic humo-ferric podzols of the Bonner Association, 50-150 cm deep, cover most of the watershed (Jungen, 1980) and colluvium and exposed bedrock facies occur to the southwest of the lake. Late-lying snowpacks can persist into July, significantly decreasing the length of the fire season at this ridge-shaded site with a generally north-facing aspect.

The Columbia Mountains are located at the eastern reach of the Interior Wet Belt of southeastern British Columbia, where the rugged landscape causes westerly air to converge (Kendrew and Kerr, 1955; Oke, 1987), leading to high total annual precipitation (1400 mm), much of it $(\sim 60 \%)$ in the form of snow. Winters are cold $\left(-8.6^{\circ} \mathrm{C}\right)$ and summers are cool $(10.9$ ${ }^{\circ} \mathrm{C}$; 1981-2009 baseline; Wang et al., 2012) and punctuated by westerly, episodic, convective thunderstorms (Jungen, 1980). Fires can occur as early as April and as late as October (Canadian Wildland Fire Information System, 1959-1999).

The lake is within the Engelmann spruce-subalpine fir wet cold forest zone, dominated by subalpine fir (Abies lasiocarpa), subalpine larch (Larix lyallii), Engelmann spruce (Picea engelmannii); and some whitebark pine (Pinus albicaulis). Arboreal coverage is moderately dense and there is a significant understory of herbs, forbs, sedges, grasses and shrubs. Above the lake, patchy ESSF forest extends $\sim 200 \mathrm{~m}$ to the ridge. The stand age is estimated to be 190 years old (BC Vegetation Resources Inventory) and is classed as experiencing rare stand-initiating events (NDT1). Recent disturbance patterns suggest a mean stand-replacing disturbance interval 
of 150-350 years for ESSF forests (Pollack et al., 1997; Wong et al., 2004) and sedimentary charcoal-based fire reconstructions at this site suggest a Weibull median fire return interval (mFRI) of 226 years (range 20-440 years) over the past 5000 years (Courtney Mustaphi and Pisaric, 2013). Recent observations showed no evidence of mountain pine beetle (MPB; Dendroctonus ponderosae Hopkins, 1902) outbreaks and estimates of windthrow are unknown (Wong et al., 2004); however, multiple large standing-dead larches proximal to the lake suggested low-incidence of windthrow over, at least, the recent past. Tree cores collected from the southeast section of the lake suggested a mixed-age stand of ESSF forest. Some larger subalpine fir had pith dates around the CE mid-1800s and a single sample dated to 1750 , while larger subalpine larches dated to the mid-1600s with one dated to 1602 . These dates suggest that the two most recent reconstructed fires (Courtney Mustaphi and Pisaric, 2013) did not kill all the trees surrounding the lake.

\subsection{Methods}

\subsubsection{Field methods}

During the summers of 2009 and 2010, surface and long cores were collected from the central deep basin of NEL03. Deployed from a boat, a large diameter Glew gravity corer (Glew et al., 2001) was used to collect the uppermost sediments with an intact sediment-water interface. The core was extruded into Whirl-Pak ${ }^{\circledR}$ bags using a vertical extruder (Glew, 1988) at contiguous $0.25-\mathrm{cm}$ intervals, from $0-15 \mathrm{~cm}$ depth, and at $0.5-\mathrm{cm}$ intervals to the base. Deeper sediments were collected in 1-m drives using a 5-cm diameter Livingstone piston corer (Wright et al., 1984) deployed from an anchored floating platform. Coring ceased at $351.5 \mathrm{~cm}$ below the watersediment interface. Piston cores were extruded in the field, wrapped in plastic and aluminum foil, 
and shipped to the Carleton University Paleoecological Laboratory (CUPL) where they were refrigerated at $\sim 4{ }^{\circ} \mathrm{C}$ until being sectioned and bagged at contiguous $0.5-\mathrm{cm}$ intervals. The lake bathymetry was estimated through 18 line depth soundings across the basin.

\subsubsection{Chronostratigraphy}

The surface core and Livingstone cores were overlapped using the presence of tephra shards as well as magnetic susceptibility, loss-on-ignition, and charcoal concentration data, to create a composite stratigraphy from the sediment-water interface to where coring ceased. Sediment ages were established using radiometric methods and an established regional tephrochronology (Foit

et al., 2004; Gavin et al., 2006). The AMS radiocarbon dating results were previously published (Courtney Mustaphi and Pisaric, 2013). Felsic ashfall deposits from Cascadian eruptions were identified as the Mt St Helens Wn tephra (Mullineaux, 1996) dated to CE 1481-82 (468-469 cal yr BP; Yamaguchi 1983, 1985) and the Mazama O tephra layer (Bacon, 1983) dated to $7627 \pm 150$ cal yr BP (Zdanowicz et al., 1999). A redeposited layer of Mazama O tephra occurred in the stratigraphy and all ash deposits were assumed to be near-instantaneous deposition events for age-depth modeling (Lowe, 2008). Radiocarbon dates were calibrated using IntCal09 (Reimer et al., 2009). The age-depth model was produced using the $R$ script Bacon (Blaauw and Christen, 2011) using $\sim 8$ million $t$-walk MCMC algorithm iterations through the probability densities of the calibrated dates to establish a probable age-depth model within a $95 \%$ confidence envelope. 


\subsubsection{Sedimentological and paleoecological methods}

A number of sedimentological methods were used to characterize the sediments. Magnetic susceptibility was measured at contiguous $0.25-0.5 \mathrm{~cm}$ intervals using Bartington Systems MS2B and MS2E sensors to gain insights about the history of erosion in the watershed and deposition in the lake (Dearing, 1999; Gedye et al., 2000). Loss-on-ignition analysis (Dean, 1974; Heiri et al., 2001) used $1 \mathrm{~cm}^{3}$ subsamples taken at contiguous $0.25-0.5 \mathrm{~cm}$ intervals down core that were dried at $105{ }^{\circ} \mathrm{C}$ for 24 hours and then burned at $550{ }^{\circ} \mathrm{C}$ for 4 hours to estimate sediment organic content. The sample was then reheated to $950{ }^{\circ} \mathrm{C}$ for 2 hours to estimate carbonate content and the residual was assumed to represent the siliciclastic content. Particle size distributions were measured at $\sim 10 \mathrm{~cm}$ resolution from $1 \mathrm{~cm}^{3}$ subsamples that were pretreated with $30 \%$ hydrogen peroxide $\left(\mathrm{H}_{2} \mathrm{O}_{2}\right)$ in a water bath $\left(\sim 75{ }^{\circ} \mathrm{C}\right)$ to digest organic material while clastic material remained. Following this, $5 \mathrm{~mL}$ of $50 \mathrm{~g} \mathrm{~L}^{-1}$ sodium hexametaphosphate $\left(\mathrm{Na}_{6} \mathrm{P}_{6} \mathrm{O}_{18}\right)$ was added to disperse the sample before triplicate measurement runs of $60 \mathrm{~s}$, at an obscuration of $10 \pm 2 \%$, using a Beckman Coulter LS 13320 laser diffraction particle size analyzer (Syvitski, 1991).

Pollen preparation was done using $1 \mathrm{~cm}^{3}$ subsamples taken at 4-10 $\mathrm{cm}$ resolution using standard digestion techniques (Fægri and Iversen, 1989) with Lycopodium tablet inoculation (Stockmarr, 1971). The samples were neither fine nor coarse sieved to preserve microscopic charcoal and stomata in the residues. Pollen was identified under 400-1000x magnification to a minimum terrestrial pollen count of 500 grains. Pollen identification was facilitated by the use of a reference collection at the CUPL and dichotomous keys (McAndrews et al., 1973; Bassett et al., 1978; Moore and Webb, 1978). Stomata were identified using keys by Hansen (1995) and Sweeney (2004) and represented local presence within the catchment of each taxon observed (MacDonald, 2001). Microscopic charcoal was also tallied during pollen counts. Pollen zones 
were established through constrained incremental sums of squares cluster analysis (CONISS) of the relative abundance of pollen taxa.

For macroscopic charcoal analysis, contiguous $1 \mathrm{~cm}^{3}$ subsamples of homogeneous sediment were removed and soaked in a metaphosphate solution (Bamber, 1982) for at least 24 hours and then wet sieved through a $150 \mu \mathrm{m}$ mesh. The remaining material was transferred to a Petri dish and examined under a Nikon SMZ800 stereoscope at 6-40x magnification. Charcoal morphologies were classified into six morphotypes following Enache and Cumming (2006) and the total number of macroscopic charcoal pieces was tallied (Whitlock and Larsen, 2001). Other plant macro remains, such as conifer needles and seeds were counted as presence data during charcoal counts.

\subsubsection{Fire episode reconstruction}

Sediment macroscopic charcoal concentrations (pieces $\mathrm{cm}^{-3}$ ) were converted to charcoal accumulation rates (CHAR; pieces $\mathrm{cm}^{-2} \mathrm{yr}^{-1}$ ) and analyzed using CharAnalysis software (Higuera et al., 2009) and the data were processed similarly to Moos and Cumming (2012) and Courtney Mustaphi and Pisaric (2013). The data were resampled to the global median sampling interval of 14 years to create an interpolated CHAR series for peak analysis. The varying background charcoal accumulation rate (bCHAR) was estimated using a LOWESS smoother robust to outliers over a 500-year window that was adequate for capturing centennial-scale variability and will not be strongly biased by high-frequency peaks in CHAR (Gavin et al., 2006). Locally defined CHAR peaks within a 500-year window, were obtained by subtracting the bCHAR component from the interpolated CHAR series (Higuera et al., 2010a) and identified through a $99 \%$ noise cut-off probability established by a 0 - or 1-mean Gaussian mixture model 
(Gavin et al., 2006; Higuera et al., 2010a). The minimum charcoal concentration, within a 75year period prior to a peak, needed a probability $<5 \%$ of coming from the same Poisson distribution as the associated peak to be retained as a significant peak (Higuera, 2009; Higuera et al., 2010a). Identified CHAR peaks were interpreted as fire episodes of $\geq 1$ large fire(s) that occurred within the lake catchment area during a 14-year window of the peak. Identified insignificant peaks could potentially be related to fire activity outside of the lake catchment (Higuera et al., 2010b). Fire return interval (FRI) distributions were calculated from the identified fire episode years and were then fitted with maximum likelihood estimate Weibull models. The FRI distribution passed a one-sample Kolmogorov-Smirnov goodness-of-fit test $(P$ $>0.05$ ) and Weibull median fire return interval with $95 \%$ confidence intervals were calculated (mFRI; Grissino-Mayer, 1999). Fire frequencies were smoothed using a LOWESS smoother with a window span of 1000 years using the tally of number of fires during each 1000-year period using K1D software (Long et al., 1998; Gavin et al., 2006; Higuera, 2009; Hallett and Anderson, 2010). Significant changes to biomass abundance within the catchment, interpreted from bCHAR, were identified by a regime shift index (RSI; $\mathrm{P}=0.0001$, cut-off length $=100 \mathrm{yr}$, Huber's weight function = 5; Rodionov, 2004; Morris et al., 2013).

\subsection{Results}

\subsubsection{Geochronology}

The results from AMS radiocarbon dating of organic material preserved in the long core were presented by Courtney Mustaphi and Pisaric (2013) and are summarized in Table 3.1. In this study, an updated age-depth model was used that made full use of the probability densities of the calibrated radiocarbon ages (Fig. 3.3). This is a more realistic model that avoids the subjective 
nature of controlling the flexibility of a spline curve through an average of the radiocarbon dating errors, which is center-weighted and therefore limits the information within the probability densities of calibrated radiocarbon dates.

\subsubsection{Lithology}

Organic matter content of the sediment was highest (45-60\%) during the early Holocene until the deposition of the Mazama $\mathrm{O}$ tephra $(7627 \pm 150 \mathrm{cal}$ yr BP) and remained at $35-45 \%$ throughout the Holocene until steadily increasing to $55 \%$ after CE $\sim 1915$ (Fig. 3.4). Carbonate content remained low throughout the core $(<10 \%)$ and few calcareous shell remains were found. The high (40-60\%) siliciclastic input through small, steep, ephemeral streams resulted from the influx of a poorly sorted and coarse silty gyttja, containing subangular clasts with occasional sandier silt layers (Fig. 3.4). Conspicuous peaks in magnetic susceptibility were related to the thick tephra and sandy layers and the uppermost tephra layer was much less pronounced than earlier tephras. Clay content remained low, usually $<6 \%$, throughout the core, with the exception of the redeposited ash layer where it increased to $\sim 10 \%$, likely due to degradation of the thick Mazama ash in the soil (Jungen, 1980) prior to transport into the lake.

\subsubsection{Vegetation record}

The pollen record of NEL03 was divided into four zones using CONISS, 9600-7500, 7500-4600, 4600-1300, and 1300 cal yr BP-present (Fig. 3.5). Zone 1 (9600-7500 cal yr BP) was characterised by Pinus-dominated (50-60\%) forests with abundant Alnus (15-30\%), Picea $(<20 \%)$ and Abies $(<12 \%)$. A macroremain of a five-needle Pinus species indicated the local presence of a Strobus subgenus, likely P. albicaulis. The earliest, but not persistent detection of 
Pseudotsuga/Larix occurred at $\sim 8200$ cal yr BP. Deciduous shrub taxa, such as Salix, Artemisia, and Betula, were generally most abundant during this period $(<8 \%)$. Herbaceous pollen abundances were also high $(<2 \%)$ and Chenopodiaceae and pteridophytes were intermittently found $(<1.5 \%)$. Aquatic pollen was most abundant during Zone 1 and Pediastrum was present with counts of $<75$ colonies.

Zone 2 (7500-4600 cal yr BP) remained Pinus-dominated; however, the abundance of Pinus pollen decreased from 55 to $35 \%$, concomitant with increased Picea pollen (10-40\%). A minor abundance of Tsuga $(<1 \%)$ was found between $6000-5000$ cal yr BP and Pseudotsuga/Larix $(<1 \%)$ was found continuously from this zone to present. Abies remained moderately abundant (up to $15 \%$ ) and deciduous trees and shrubs (Populus, Betula, Alnus, Artemisia and Salix) were present on the landscape. Asteraceae, and Caryophyllaceae remained $<2 \%$, Chenopodiaceae was absent, and Ericaceae, Poaceae and pteridophytes were intermittently present $(<2 \%)$. Pediastrum colonies were consistently found with counts $<10$.

Pinus and Picea pollen were generally stable (30-35\%) in Zone 3 (4600-1300 cal yr BP). Abies was variable (2-15\%) and Pseudotsuga/Larix and Cupressaceae were present at low abundances $(<2 \%)$. Tsuga increased to $2 \%$ and appeared continuously from $4000 \mathrm{cal} \mathrm{yr}$ BP. The shrub taxa were stable during Zone 3, generally 10-15\%. Asteraceae, Poaceae and pteridophytes were present $(<1.6 \%)$ and Caryophyllaceae, Ericaceae and Chenopodiaceae were rare. Pediastrum was found with counts $<5$ colonies and was occasionally absent.

Pinus decreased ( 20\%) and varied considerably in Zone 4 (1300 cal yr BP-present). Picea abundance peaked (40-70\%) and Abies generally remained abundant (5-15\%). Pseudotsuga/Larix increased to $2 \%$ and Larix lyallii made up a large portion of the current forest immediately adjacent to the lake. Cupressaceae pollen, likely Thuja plicata, was consistently 
$<1 \%$. Tsuga increased to $2.5 \%$ and Alnus and Artemisia remained low $(<10 \%$ and $<5 \%$, respectively). Artemisia decreased to $<1.5 \%$, Betula, Salix, and Populus remained $<1 \%$, and understory taxa decreased to $<1 \%$ or was rare, as were Pediastrum remains.

\subsubsection{Macroscopic charcoal record and fire-episode reconstruction}

Microscopic charcoal accumulation rates, an indicator of regional biomass burning (Whitlock and Larsen, 2001; Conedera et al., 2009), averaged 1860 pieces $\mathrm{cm}^{-2} \mathrm{yr}^{-1}$ and ranged from 2657700 pieces $\mathrm{cm}^{-2} \mathrm{yr}^{-1}$ (Fig. 3.5). Microscopic charcoal also varied between each pollen zone, averaging 2033 pieces $\mathrm{cm}^{-2} \mathrm{yr}^{-1}$ in Zone 1, 1690 pieces $\mathrm{cm}^{-2} \mathrm{yr}^{-1}$ in Zone 2, 1958 pieces $\mathrm{cm}^{-2} \mathrm{yr}^{-1}$ in Zone 3 and 1786 pieces $\mathrm{cm}^{-2} \mathrm{yr}^{-1}$ in Zone 4. The total macroscopic charcoal record had a global signal-to-noise index (SNI) value of 5.55 and local SNI values were all >3 (3.54-11.91), suggesting the charcoal record from NEL03 is robust for the reconstruction of the local fire history (Kelly et al., 2011). The median charcoal accumulation rate (CHAR) was 0.81 (range 012.2) pieces $\mathrm{cm}^{-2} \mathrm{yr}^{-1}$. Since $9650 \mathrm{cal} \mathrm{yr} \mathrm{BP}$, there had been 44 fire episodes in the watershed of NEL03 (Fig. 3.6). The Weibull median fire return interval (mFRI) was 216 years $(95 \%$ confidence interval 186-256 years) within a range of fire return intervals of $42-630$ years. This fire history reconstruction represented an area fire return interval because the macroscopic charcoal influx represented the fire activity within the lake catchment (Clark, 1988; Higuera et al., 2007; 2010b).

All morphotype CHARs were strongly correlated with total CHAR $(\mathrm{r}=0.69-0.95, p<$ 0.001; Table 2). Morphotypes P, S, C, and F, shared the strongest similarity with total CHAR, having had much higher CHAR values and more CHAR peak dates that agreed with total CHAR peak fire events (Table 3.2; Fig. 3.6). Morphotype CHARs were also significantly correlated; the 
relationship was weakest between types $\mathrm{M}$ and $\mathrm{D}(\mathrm{r}=0.46, p<0.001)$ and strongest between types $\mathrm{C}$ and $\mathrm{P}(\mathrm{r}=0.84, p<0.001)$. Some insignificant peaks in morphotype CHARs occurred coeval with significant peaks in total CHAR. This occurred more often with charcoal morphotypes $\mathrm{M}, \mathrm{D}$, and $\mathrm{F}$. Those morphotypes tended to have lower correlations with total CHAR and generally lower CHARs. Of the four insignificant peaks in total CHAR, 2-3 (5075\%) insignificant peaks of each morphotype CHARs agreed. Insignificant peaks identified in individual morphotype CHAR profiles were much more abundant than in total CHAR, notably with $\mathrm{M}$ and D morphotypes.

\subsubsection{Variability of the fire regime}

The fire frequency was highest during zone 1 (9600-7500 cal yr BP) with 4-8 fires 1000 years $^{-1}$ and a Weibull mFRI of 150 years (12 fire events; Fig. 3.7). The microscopic charcoal input was also the highest of the record (Fig. 3.5). Fires occurred less frequently during zone 2, Weibull $\mathrm{mFRI}=236$ years (10 fire events) and the period between $6500-5500$ cal yr BP conspicuously

showed very low bCHARs, decreased fire frequency (3-4 fires 1000 years $^{-1}$; Fig. 3.7), and low microcharcoal inputs (Fig. 3.5). In zone 3, fire frequency increased slightly with a Weibull mFRI of 200 years (17 fire events). There were five fire episodes during Zone 4 (1300 cal yr BPpresent) with a raw median return interval of 287 years. A Weibull mFRI was not calculated due to the low number of fires within the period. The occurrence of microcharcoal cenospheres in the uppermost sediments of Zone 4 is likely the result of recent transport and deposition of fossil fuel burning products to this remote subalpine location since CE $~ 1920$ (Thevenon and Anselmetti, 2007; Fig. 3.7). 


\subsection{Discussion}

\subsubsection{Vegetation and disturbance regime interpretation}

Zone 1: 9500-7500 cal yr BP

The low pollen influx $\left(<8000\right.$ grains $\left.\mathrm{cm}^{-2} \mathrm{yr}^{-1}\right)$ and low bCHAR suggested the Pinus and Alnus forest of the early Holocene was not as dense as the mid- and late-Holocene forests (Fig. 3.5 and 7). Background CHAR, an indicator of biomass on the terrestrial landscape (Marlon et al., 2006; Carter et al., 2013), was lowest during this early period (Fig. 3.7) and Poaceae pollen was high and suggested that the forest canopy was open and possibly patchy. Patchy open parkland forests are common to modern high elevation sites in the region (Coupé et al., 1991). The RSI analysis of the bCHAR indicated a sustained period of low values during this zone. The lack of a tundratype vegetation assemblage suggested that the immediate postglacial accumulation of sediments was not collected. The presence of conifer stomata and macroremains early in the record suggested the vegetation was subalpine (Fig. 3.5). Indeed, the climatically-controlled timberline was present at higher elevations across much of British Columbia during the early Holocene (Clague and Mathewes, 1989).

Ground fires would be necessary to spread fire between stands and the low accumulation rate of type S charcoal (Fig. 3.6), likely sourced from woody biomass, also suggested that tree density was low. The charcoal record of NEL03 during the early Holocene was consistent with a composite record of biomass burning from boreal regions of northwestern North America and global fire activity (Marlon et al., 2013; Fig. 3.7). This suggests broad-scale climatic controls influenced the fire regime of this region during the early Holocene. Summer temperatures at this time were $1-5^{\circ} \mathrm{C}$ warmer than present in southeastern British Columbia (Rosenberg et al., 2004; 
Chase et al., 2008) and promoted a high diversity of vegetation types in Pinus forests that experienced a higher fire frequency at NEL03 (Fig. 3.5 and 3.6). Fire activity was highest during this period with a Weibull mFRI of 150 years, due to increased summer insolation (Berger and Loutre, 1991) and warmer summer temperatures (Chase et al., 2008). The warmer than present conditions lengthened the fire season promoting fire ignition and spread and a longer fire season. Broad scale climatic controls leading to warmer summer conditions were probably the dominant influence of the higher fire frequency during this period of low biomass Pinus forests.

\section{Zone 2: 7500-4600 cal yr BP}

ESSF forests began to establish closer to the lake between 7500 and 4600 cal yr BP (Fig. 3.5 and 3.7). The thick Mazama $\mathrm{O}$ ashfall of $7627 \pm 150$ cal yr BP may have been a significant disturbance at a time when climate-mediated vegetation changes were occurring in the catchment. A significant vegetation transition at the time of the Mazama O tephra was also found in the pollen record of Dog Lake, British Columbia (160 km to the northeast; Hallett and Hills, 2006). Pseudotsuga/Larix appeared continuously after $7000 \mathrm{cal}$ yr BP and Larix lyallii continued to be a significant proportion of the modern forest surrounding the lake. Larix lyallii is commonly associated with ESSF forests, especially on slightly drier sites (Coupé et al., 1991). The first arrival of Tsuga heterophylla pollen in the record around 5200 cal yr BP was likely due to long range transport as its abundance increased within lower elevation forests (Fig. 3.5; Rosenberg et al., 2004; Gavin et al., 2006). Short diameter Tsuga pollen grains are known to be transported long distances (Gavin et al., 2005; Day et al., 2013). Deciduous taxa, including Betula, Alnus, Artemisia, and Salix, which are uncommon in ESSF forests (Coupé et al., 1991), decreased throughout the period and indicated the further establishment of ESSF forests (Fig. 
3.5). During the early to mid Holocene (NEL03 zone 2), summer temperatures cooled as orbital geometry changes led to decreased summer insolation (Fig. 3.7; Berger and Loutre, 1991; Rosenberg et al., 2004; Chase et al., 2008).

The bCHAR and the arboreal pollen influx increased during this period; yet, varied considerably (Fig. 3.7). The bCHAR increased between 7600-6500 cal yr BP and fire frequency was largely unchanged with 3-4 fires 1000 years $^{-1}$. A noticeable drop in bCHAR and the lowest arboreal pollen influx occurred between $6500-5500 \mathrm{cal}$ yr BP and suggested the forest was much less productive than any other period before increasing again at $5500 \mathrm{cal}$ yr BP (Fig. 3.6 and 3.7). Northwestern (boreal) North America regional biomass burning trends also exhibited an abrupt decrease at 6000 cal yr BP (Marlon et al., 2013), consistent with cold chironomid-inferred July temperatures in southeast British Columbia (Rosenberg et al., 2004; Chase et al., 2008). During this time there was a short period of increased siliciclastic content and particle sizes in the catchment that may have related to increased transport in the catchment (Fig. 3.4) due to the reduced forest cover and may have contributed to a reduced pollen influx (Fig. 3.7). The reduced pollen and charcoal accumulation rates were depressed over a 1000-year period and suggested decreased biomass abundance caused by cooler summer temperatures $\sim 6000$ cal yr BP (Fig. 3.7).

Following this period of cooler summer temperatures that caused low forest production, the relative abundance of Picea and Abies pollen continued to increase, indicating further encroachment of ESSF forest into the upper mid-elevation Pinus forests. After $5500 \mathrm{cal}$ yr BP, arboreal pollen influx and bCHAR increased and some of the largest peak CHARs of the record occurred (Fig. 3.6 and 3.7). The RSI of the bCHAR series indicated a significant 1000-year period of increased biomass abundance within the watershed (Fig. 3.7). Conditions seemed to have promoted increased abundance of ESSF trees that supported much larger fires. Fire 
frequency also doubled to 6 fires 1000 years $^{-1}$ (Fig. 3.7), which suggested that the accumulation of biomass became an important bottom-up control of fire frequency. A long-term build-up of fuels, interacting with top-down fire controls, was required for fire occurrence in subalpine Larix-Pinus-Betula forests of the western Alps in Europe over the past 8000 years (Blarquez and Carcaillet, 2010). During this period of cooling summer temperatures, long-term climatic controls became less important relative to the abundance of biomass fuels in the catchment.

Zone 3: 4600-1300 cal yr BP

Similar to the modern assemblage, the mid-to-late Holocene (NEL03 zone 3) forest of the catchment appeared to be dominated by ESSF species. The forests also contained Larix/Pseudotsuga (likely Larix lyallii), Pinus, at least partially consisting of Pinus albicaulis, and a variety of shrubs (Fig. 3.5). This is consistent with earlier studies in the Columbia Mountains that found evidence of the establishment of modern forests by 4500-4000 cal yr BP (Fig. 3.5; Hebda, 1995; Gavin et al., 2006). Tsuga heterophylla pollen was not consistently found until 4000 cal yr BP and its earliest presence was slightly earlier at NEL03 than at Eagle Lake which is located further north and at similar elevation (Rosenberg et al., 2003). The increase in Tsuga pollen has been attributed to decreased continentality and increased winter moisture in the Interior Wet Belt region (Gavin et al., 2011). Cupressaceae, including Thuja plicata, pollen increased during this period due to the continued establishment of interior cedar-hemlock (ICH) forests found at elevations below ESSF forests (Coupé et al., 1991). The forest composition was generally stable and the increased abundance of Salix and pteridophyte pollen (Fig. 3.5) suggested increased moisture at the site. 
Fire frequency varied concomitant with changes to biomass (Fig. 3.7), which suggested that increased biomass production and fuel loads influenced fire activity. Arboreal pollen influx was relatively stable throughout the period, but increased at the beginning and ending of Zone 2 as did bCHAR values (Fig. 3.7). The RSI analysis also showed that these variations in bCHAR were significant. Fire frequency peaked during periods of limited glacier advances in southern British Columbia (Fig. 3.7), which suggested climate-mediated impacts on vegetation were an important control of the fire regime. Fire frequency seemed to peak during periods of reduced glacial activity as indicated by glacial dynamics on the coastal mountain systems, while there seemed to be a less clear pattern between fire frequency and reduced glacial advances in central British Columbia and the Rockies (Fig. 3.7). Climate-mediated influence of millennial-scale fire regimes was also shown in the Picea engelmannii-Abies lasiocarpa forests of the Markaganut plateau in Utah (Morris et al., 2013). During periods of increased biomass abundance, fire frequencies increased, doubling in frequency for a period around $2000 \mathrm{cal}$ yr BP (Fig. 3.7).

\section{Zone 4: 1300 cal yr BP-present}

Dominance of Picea in these forests was reached during the most recent pollen zone. Pinus reached lowest influx and relative abundance, yet the forest remained similar to the previous zone (Fig. 3.5 and 3.7). The presence of Pinus stomata and current populations of few whitebark pine ( $P$. albicaulis) suggested continued presence within the watershed throughout the Holocene. The increased Cupressaceae and Tsuga abundance was associated with the expansion of interior cedar-hemlock (ICH) forests found at low-to-mid elevations (Hebda, 1995; Gavin et al., 2006). The increased fire frequency at the start of this zone corresponded to periods of increased bCHAR that were related to the amount of biomass on the landscape (Fig. 3.7; Marlon et al., 
2006). This increase occurred later than the climatically influenced regional and global increase in biomass burning identified between 3000-2000 cal yr BP (Marlon et al., 2013). This lag could be due to the elevation of this site, having a delayed climate-mediated vegetation change. This discrepancy with broad-scale patterns of biomass burning indicated the increased importance of local bottom-up controls of the fire regime. Fire activity between five different catchments within a $550 \mathrm{~km}^{2}$ area of this region were largely independent, and since $2500 \mathrm{cal} \mathrm{yr} \mathrm{BP}$, fire activity became increasingly asynchronous between sites with a north-facing aspect versus sites with south-facing aspects (Courtney Mustaphi and Pisaric, 2013). Fire frequency decreased throughout Zone 4, possibly due to climate-mediated influences on the vegetation during the past millennium. Recent sediments since CE 1920 also contained cenospheres related to the burning of fossil fuels in the region; although, the input remained very small with only $4-10 \%$ of total microcharcoal being classified as spherules.

\subsubsection{Comparison with other Holocene Engelmann spruce forest records}

Earlier work compared the fire records from five sites from nearby watersheds, which included NEL03, and found that aspect was an important control of fire frequency and fire episode synchroneity over the past 5000 years (Courtney Mustaphi and Pisaric, 2013). Both fire frequency and fire synchroneity were similar between NEL03 and Cooley Lake, located $50 \mathrm{~km}$ to the west and also situated in a north-facing ESSF forest. Forest composition records were similar over the past 7000 years; the Cooley Lake record also showed a general decrease in Pinus and increasing Picea, with a significant, yet varied proportion of Abies (Gavin et al., 2006). The Cooley Lake charcoal record showed a short period of decreased charcoal concentration around 5600 cal yr BP, which was $\sim 500$ years later than the conspicuous decrease at NEL03. This could 
possibly be due to the lower elevation of the Cooley Lake site relative to NEL03 ( 500 m) or other spatial variability in the biomass abundance in ESSF forests.

The vegetation history of this catchment showed an initial forest that was Pinus dominated with Alnus near the lake and relatively low terrestrial biomass within the catchment (Fig. 3.5 and 3.7). Pinus pollen decreased throughout the Holocene as Picea, Abies, and Pseudotsuga/Larix, increased as ESSF forest began to dominate at this elevation and became much more dense by 5500 cal yr BP. A similar Holocene vegetation sequence has been described at Morris Pond, a subalpine (3129 m asl) site in southwest Utah, having decreased Pinus pollen and concomitant increased Picea and Abies pollen. At this site, millennial-scale fire regimes were influenced by forest structure, biomass, and fuel connectivity (Morris et al., 2013). The millennial-scale fire history at Morris Pond was similar, with increased fire frequency during the early Holocene, variable mid Holocene fire frequency, and decreased fire frequency during the past millennium. However, the mid Holocene millennial scale fire frequency was out of phase between the two sites by 1000 years, having occurred earlier at the more northern NEL03 site. A conspicuous mid-Holocene decrease in bCHAR occurred at Morris Pond between 6200-4200 cal yr BP, and overlapped with the bCHAR minima at NEL03 (6500-5500 cal yr BP; Fig. 3.7). The differences in the fire records suggests that climatic variability experienced at each site varied or that other local site factors may have become important controls of the fire regime. The similarly timed decrease in bCHAR was interpreted as a short-duration period where the interactions between broad-scale climatic control and local controls resulted in similar changes to biomass abundance in these ESSF forests. 


\subsubsection{Charcoal morphology record}

The charcoal morphotype concentrations and accumulation rates were highly correlated throughout the Holocene, which differed from other studies that employed the same classification (Enache and Cumming, 2009). The high degree of correlation was likely due to the combination of the stationarity of the fuel types through the persistent dominance of a mixedconifer forest and the very small catchment area of NEL03 that limited differential transport and sorting of macroscopic charcoal fragments. Enache and Cumming (2007) showed that precipitation within the watershed correlated with the robust morphotypes that were less susceptible to breakage, which suggested a link between transport and taphonomic processes and morphotype assemblages. Differential transport and sorting of charred plant parts has been observed in the field following wildfires (Scott et al., 2000) and could influence the morphotype assemblages deposited in lake sediments.

\subsubsection{Varying controls of the fire regime}

The early Holocene had warmer summer temperatures, higher insolation, and maintained a Pinus-dominated forest with significant Alnus and produced more frequent fire events $(\mathrm{n}=11$, $25 \%$ of the total record); although, with much lower CHARs than the latter half of the record. By 5500 cal yr BP, the biomass of the conifer forest became dense enough to support high-severity fires (Fig. 3.7) and produced consistently higher peaks in CHAR, with more charcoal of all morphotype classes (Fig. 3.6). The interaction between a cooling climate and the change from Pinus-dominated to ESSF-dominated forest at the site, which remained dominant through the mid Holocene to present, led to a relatively homogeneous fire regime across the pollen zones with a mFRI of $\sim 216$ years since 7600 cal yr BP. This suggested that vegetation composition was 
not a significant control of fire since the establishment of ESSF forests. There remained much variability in fire frequency that occurred across the pollen zones. At centennial-to-millennial scales, the accumulation of forest biomass controlled the fire regime. It is difficult to assess if these variations in biomass and forest production were mediated by slight variations in climate. Comparisons with regional isotope records of temperature and precipitation/evaporation do not show any clear patterns (not shown; Nelson et al., 2011; Ersek et al., 2012; Steinman et al., 2012), but peaks in fire frequency had occurred during periods of reduced glacial extents (Fig. 3.7; Luckman et al., 1993; Reyes and Clague, 2004; Menounos et al., 2009).

Although some influence of climate on fire regime variability was suggested by the relationship between fire frequency and glacial advances, further investigation of climate-fire interactions could be facilitated by development of high-resolution Holocene hydroclimatic records for the region (Wilson et al., 1994; Gedalof et al., 2004; Booth, 2008; Steinman et al., 2012). If hydroclimatic records could not be directly established using the NEL03 sediment archive, a high-resolution pollen record could be created to interpret centennial scale climate variability and would provide insight into post-disturbance forest successional changes. Establishing climate records from the same archive would reduce errors associated with examining other records with different chronologies and permit a detailed analysis of decadal-tocentennial scale climate influences on the fire regime.

Local site conditions seem to be important controls of the fire regime since the early Holocene climate cooled and ESSF forests began to dominate during the mid Holocene. Since the establishment of ESSF forests in the watershed, climate variability and vegetation composition changes do not fully explain the Holocene fire regime variability at NEL03 (Fig. 3.6); therefore, local site factors such as fuel conditions, lightning frequency, topography, and 
especially fuel abundance must have been important (Gavin et al., 2006; 2007; Hu et al., 2006;

Higuera et al., 2009; Courtney Mustaphi and Pisaric, 2013).

\subsection{Conclusion}

In this study, we have presented a Holocene vegetation record and a high-resolution fire history record from sedimentary macroscopic charcoal preserved in a lake sediment core from southeast British Columbia, Canada. We have shown that the early Holocene warm and dry, low biomass abundance, Pinus-dominated forests burned frequently. As summer climate cooled during the mid Holocene, an ESSF forest established and was characterized by millennial-scale variability in forest biomass and related fire activity. It remains unclear to what degree slight variations in climate over the past 6000 years influenced forest productivity, but this does support the idea that bottom-up local site factors have been important controls of the fire regime during this period. High-resolution analyses of vegetation variability may reveal more information regarding climate-vegetation-fire interactions. Additional sites in the region with Holocene-length records are needed to understand the varying importance of top-down and bottom-up controls of fire activity throughout the entire Holocene. Further high-resolution analyses aimed at building a mechanistic understanding of decadal to centennial scale climate-fire-vegetation interactions would be beneficial to land management and conservation planning in the region.

\subsection{Acknowledgements}

This study was funded by the Natural Sciences and Engineering Research Council of Canada (NSERC) Supplemental Strategic Grant program and a NSERC Discovery grant to M.F.J.P and a Jeletzky Memorial Award to C.J.C.M. We thank Ze'ev Gedalof, Joelle T. Perreault, and Lori Daniels, for assisting in the field; Danielle E. Paull, Ronan M. Drysdale, Namdar Moazzami, Sonam Drakto, and Kerry-Lynn Robillard, for assistance in the laboratory; and we thank Carley Crann for insightful discussions about age-depth modeling. We also thank Danielle E. Paull for commenting on manuscript drafts. 


\subsection{References}

Bacon, C.R., 1983. Eruptive history of Mount Mazama and Crater Lakes caldera, Cascade Range, USA. Journal of Volcanology and Geothermal Research 18, 57-115.

Bamber, R.N., 1982. Sodium hexametaphosphate as an aid in benthic sample sorting. Marine Environmental Research 7, 251-255.

Bassett, I.J., Crompton, C.W., Parmelee, J.A., 1978. An atlas of airborne pollen grains and common fungus spores of Canada. Canada Department of Agriculture Research Branch monograph no. 18. Supply and Services Canada: Hull, Canada.

Berger, A., Loutre, M.F., 1991. Insolation values for the climate of the last 10 million years. Quaternary Sciences Review 10, 297-317.

Blaauw, M., Christen, J.A., 2011. Flexible paleoclimate age-depth models using an autoregressive gamma process. Bayesian Analysis 6, 457-474.

Blarquez O., Carcaillet C., 2010. Fire, fuel composition and subalpine ecosystem resilience threshold in subalpine ecosystem. PLoS ONE 5, e12480.

Blott, S.J., Pye, K., 2001. GRADISTAT: a grain size distribution and statistics package for the analysis of unconsolidated sediments. Earth Surface Processes and Landforms 26, 1237-1248.

Booth, R.K., 2008. Testate amoebae as proxies for mean annual water-table depth in Sphagnumdominated peatlands of North America. Journal of Quaternary Science 23, 43-57.

Carter, V.A., Brunelle, A., Minckley, T.A., Dennison, P.E., Power. M.J., 2013. Regionalization of fire regimes in the Central Rocky Mountains, USA. Quaternary Research 80, 406-416.

Chase, M., Bleskie, C., Walker, I.R., Gavin, D.G., Hu, F.S., 2008. Midge-inferred Holocene summer temperatures in Southeastern British Columbia, Canada. Palaeogeography, Palaeoclimatology, Palaeoecology 257, 244-259.

Clague, J.J., Mathewes, R.W., 1989. Early Holocene thermal maximum in western North America: new evidence from Castle Peak, British Columbia. Geology 17, 277-280.

Clark, J.S., 1988. Particle motion and the theory of charcoal analysis: source area, transport, deposition, and sampling. Quaternary Research 30, 67-80. 
Conedera, M., Tinner, W., Neff, C., Meurer, M., Dickens, A.F., Krebs, P., 2009. Reconstructing past fire regimes: methods, applications, and relevance to fire management and conservation. Quaternary Science Reviews 28, 555-576.

Coupé, R.A., Stewart, A.C., Wikeem, B.M., 1991. Engelmann spruce - subalpine fir zone. In: Meidinger, D.V., Pojar, J. (Eds.), Ecosystems of British Columbia. Special Report Series 6. BC Ministry of Forests, Victoria, pp. 223-236.

Courtney Mustaphi, C.J., Pisaric, M.F.J., 2013. Synchronous forest fire regimes between watersheds with similar aspect during the late Holocene, southeastern British Columbia, Canada. Journal of Biogeography 40, 1983-1996.

Da Silva, E., 2009. Wildfire history and its relationship with top-down and bottom-up controls in the Joseph and Gold Creek watersheds, Kootenay Mountains, British Columbia. Unpublished MSc. Thesis, Department of Geography, University of Guelph, Guelph, Canada.

Day, L.T., Oswald, W.W., Doughty, E.D., Foster, D.R., 2013. Analysis of hemlock pollen size in Holocene lake sediments from New England. Quaternary Research 79, 362-365.

Daniau, A.-L., Tinner, W., Bartlein, P.J., Harrison, S.P., Prentice, I.C., Brewer, S., Friedlingstein, P., Harrison-Prentice, T.I., Inoue, J., Marlon, J.R., et al., 2012. Predictability of biomass burning in response to climate changes. Global Biogeochemical Cycles 26, GB4007.

Dean, W.E., 1974. Determination of carbonate and organic matter in calcareous sediments and sedimentary rocks by loss on ignition: Comparison with other methods. Journal of Sedimentary Petrology 44, 242-248.

Dearing, J.A., 1999. Magnetic susceptibility. In: Walden, J., Oldfield, F., Smith, J. (Eds.), Environmental Magnetism: a practical guide. Technical Guide No. 6. Quaternary Research Association, London, pp. 35-62.

Dorner, B., 2001. Natural landscape pattern and range of natural variability in the Arrow TSA. Arrow Innovative Forest Practices Agreement (IFPA). Final project report. Internal document.

Enache, M.D., Cumming, B.F. 2006. Tracking recorded fires using charcoal morphology from the sedimentary sequence of Prosser Lake, British Columbia (Canada). Quaternary Research 65, 282-292. 
Enache, M.D., Cumming, B.F. 2007. Charcoal morphotypes in lake sediments from British Columbia (Canada): an assessment of their utility for the reconstruction of past fire and precipitation. Journal of Paleolimnology 38, 347-363.

Enache, M.D., Cumming, B.F. 2009. Extreme fires under warmer and drier conditions inferred from sedimentary charcoal morphotypes from Opatcho Lake, central British Columbia, Canada. The Holocene 19, 835-846.

Ersek, V., Clark, P.U., Mix, A.C., Cheng, H., Edwards, R.L., 2012. Holocene winter climate variability in mid-latitude western North America. Nature Communications 3, 1219.

Fægri, K., Iversen, J., 1989. Textbook of pollen analysis. John Wiley and Sons, New York.

Foit, F.F., Gavin, D.G., Hu, F.S., 2004. The tephra stratigraphy of two lakes in south-central British Columbia, Canada and its implications for mid-late Holocene volcanic activity at Glacier Peak and Mount St. Helens, Washington, USA. Canadian Journal of Earth Sciences 41, 14011410 .

Gavin, D.G., Brubaker, L.B., McLachlan, J.S., Oswald, W.W., 2005. Correspondence of pollen assemblages with forest zones across steep environmental gradients, Olympic Peninsula, Washington, USA. The Holocene 15, 648-662.

Gavin, D.G., Hu, F.S., Lertzmen, K., Corbett, P., 2006. Weak climatic control of stand-scale fire history during the late Holocene. Ecology 87, 1722-1732.

Gavin, D.G., Hallett, D.J., Hu, F.S., Lertzman, K.P., Prichard, S.J., Brown, K.J., Lynch, J.A., Bartlein, P.J., Peterson, D.L., 2007. Forest fire and climate change in western North America: Insights from sediment charcoal records. Frontiers in Ecology and the Environment 5, 499-506.

Gavin, D.G., Henderson, A.C.G., Westover, K.S., Fritz, S.C., Walker, I.R., Leng, M.J., Hu, F.S., 2011. Abrupt Holocene climate change and potential response to solar forcing in western Canada. Quaternary Science Reviews 30, 1243-1255.

Gedalof, Z., 2011. Climate and Spatial Patterns of Wildfire. In: McKenzie, D., Miller, C., Falk, D. (Eds.), The Landscape Ecology of Fire. Springer, pp. 89-116.

Gedalof, Z., Peterson, D.L., Mantua, N.J., 2004. Columbia River flow and drought since 1750. Journal of the American Water Resources Association 40, 1579-1592. 
Gedalof, Z., Peterson, D.L., Mantua, N.J., 2005. Atmospheric, climatic and ecological controls on extreme wildfire years in the northwestern United States. Ecological Applications 15, 154174.

Gedye, S.J., Jones, R.T., Tinner, W., Ammann, B., Oldfield, F., 2000. The use of mineral magnetism in the reconstruction of fire history: a case study from Lago di Origlio, Swiss Alps. Palaeogeography, Palaeoclimatology, Palaeoecology 164, 101-110.

Glew, J.R. 1988. A portable extruding device for close interval sectioning of unconsolidated core samples. Journal of Paleolimnology 1, 235-239.

Glew, J.R., Smol, J.P., Last, W.M., 2001. Sediment core collection and extrusion. In: Last, W.M., Smol, J.P. (Eds.), Tracking Environmental Change Using Lake Sediments. Volume 1: Basin Analysis, Coring, and Chronological Techniques. Kluwer Academic Publishers, Dordrecht, pp. 73-105.

Greene, G.A., 2011. Historical fire regime of the Darkwoods: quantifying the past to plan for the future. MSc Thesis, Department of Geography, University of British Columbia, Vancouver.

Hallett, D.J., Hills, L.V., 2006. Holocene vegetation dynamics, fire history, lake level and climate change in the Kootenay Valley, southeastern British Columbia, Canada. Journal of Paleolimnology 35, 351-357.

Hallett, D.J., Anderson, R.S., 2010. Paleofire reconstruction for high-elevation forests in the Sierra Nevada, California, with implications for wildfire synchrony and climate variability in the late Holocene. Quaternary Research 73, 180-190.

Hansen, B.C.S., 1995. Conifer stomata analysis as a paleoecological tool: an example from the Hudson Bay Lowlands. Canadian Journal of Botany 73, 244-252.

Hebda, R.J., 1995. British Columbia vegetation and climate history with focus on 6 ka BP. Géographie Physique et Quaternaire 49, 55-79.

Heiri, O., Lotter, A.F., Lemcke, G., 2001. Loss on ignition as a method for estimating organic and carbonate content in sediments: Reproducibility and comparability of results. Journal of Paleolimnology 25, 101-110.

Hessl, A.E., 2011. Pathways for climate change effects on fire: Models, data, and uncertainties. Progress in Physical Geography 35, 393-407. 
Heyerdahl, E.K., Brubaker, L.B., Agee, J.K., 2001. Spatial controls of historical fire regimes: A multiscale example from the interior west, USA. Ecology 82, 660-678.

Heyerdahl, E.K., Brubaker, L.B., Agee, J.K., 2002. Annual and decadal climate forcing of historical fire regimes in the interior Pacific Northwest, USA. Holocene 12, 597-604.

Heyerdahl, E.K., Lertzman, K., Karpuk, S., 2007. Local-scale controls of a low-severity fire regime (1750-1950), southern British Columbia, Canada. Écoscience 14, 40-47.

Higuera, P.E., 2009. CharAnalysis 0.9: Diagnostic and analytical tools for sediment-charcoal analysis [User's Guide]. Available from http://CharAnalysis.googlepages.com

Higuera, P.E., Peters, M.E., Brubaker, L.B., Gavin, D.G., 2007. Understanding the origin and analysis of sediment-charcoal records with a simulation model. Quaternary Science Reviews 26, 1790-1809.

Higuera, P.E., Brubaker, L.B., Anderson, P.M., Hu, F.S., Brown, T.A., 2009. Vegetation mediated the impacts of postglacial climate change on fire regimes in the south-central Brooks Range, Alaska. Ecological Monographs 79, 201-219.

Higuera, P.E., Gavin, D.G., Bartlein, P.J., Hallett, D.J., 2010a. Peak detection in sedimentcharcoal records: impacts of alternative data analysis methods on fire-history interpretations. International Journal of Wildland Fire 19, 996-1014.

Higuera, P.E., Whitlock, C., Gage, J.A. 2010b. Linking tree-ring and sediment-charcoal records to reconstruct fire occurrence and area burned in subalpine forests of Yellowstone National Park, USA. Holocene 21, 327-341.

Hu, F.S., Brubaker, L.B., Gavin, D.G., Higuera, P.E., Lynch, J.A., Rupp, T.S., Tinner, W., 2006. How climate and vegetation influence the fire regime of the Alaskan Boreal biome: The Holocene perspective. Mitigation and Adaptation Strategies for Global Change 11, 829-846.

Johnson, E.A., Fryer, G.I., Heathcott, M.J. 1990. The influence of man and climate on frequency of fire in the interior wet belt forest, British Columbia. Journal of Ecology 78, 403-412.

Johnson, E.A., Wowchuk, D.R. 1993. Wildfires in the southern Canadian Rocky Mountains and their relationship to mid-tropospheric anomalies. Canadian Journal of Forest Research 23, 1213-1222 
Journeay, JM, Williams, SP, Wheeler, JO. 2000. Tectonic assemblage map, Kootenay Lake, British Columbia-Alberta-USA. Geological Survey of Canada, Open File 2948b. 1:1,000,000.

Jungen, J.R. 1980. Soil resources of the Nelson map area (82F). RAB Bulletin 20, Report No. 28 British Columbia Soil Survey. Province of British Columbia, Ministry of Environment, Resource Analysis Branch. Queen's Printer for BC, Victoria, pp. 217.

Kendrew, W.G., Kerr, D., 1955. The Climate of British Columbia and the Yukon Territory. Queen's Printer, Ottawa, pp. 222.

Kelly, R.F., Higuera, P.E., Barrett, C.M., Hu, F.S., 2011. A signal-to-noise-index to quantify the potential for peak detections in sediment-charcoal records. Quaternary Research 75, 11-17.

Kitzberger, T., Brown, P.M., Heyerdahl, E.K., Swetnam, T.W., Veblen, T.T., 2007. Contingent Pacific-Atlantic Ocean influence on multicentury wildfire synchrony over western North America. Proceedings of the National Academy of Sciences of the United States of America 104, 543-548.

Long, C.J., Whitlock, C., Bartlein, P.J., Millspaugh, S.H., 1998. A 9000-year fire history from the Oregon Coast Range, based on a high-resolution charcoal study. Canadian Journal of Forest Research 28, 774-787.

Lowe, D.J. 2008. Tephrochronology and its application: a review. Quaternary Geochronology 6: 107-153.

Luckman, B.H., Holdsworth, G., Osborn, G.D., 1993. Neoglacial glacier fluctuations in the Canadian Rockies. Quaternary Research 39, 144-153.

MacDonald, G.M., 2001. Conifer stomata. In: Smol, J.P., Birks, H.J.B., Last, W.M., Bradley, R.S., Alverson, K. (Eds.), Tracking environmental change using lake sediments. Volume 3: Terrestrial, Algal, and Siliceous Indicators. Kluwer Academic Publishers, Dordrecht, pp. 33-48.

Marlon, J., Bartlein, P.J., Whitlock, C., 2006. Fire-fuel-climate linkages in the northwestern U.S. during the Holocene. Holocene 16, 1059-1071.

Marlon, J.R., Bartlein, P.J., Gavin, D.G., Long, C.J., Anderson, R.S., Brilese, C.E., Brown, K.J., Colombaroli, D., Hallett, D.J., Power, M.J., Scharf, E.A., Walsh, M.K., 2012. Long-term perspective on wildfires in the western USA. Proceedings of the National Academy of Sciences of the USA 109, E535-E543. 
Marlon, J.R., Bartlein, P.J., Daniau, A.-L., Harrison, S.P., Maezumi, S.Y., Power, M.J., Tinner, W., Vannière, B., 2013. Global biomass burning: a synthesis and review of Holocene paleofire records and their controls. Quaternary Science Reviews 65, 5-25.

McAndrews JH, Berti AA, Norris G. 1973. Key to the Quaternary pollen and spores of the Great Lakes region. University of Toronto Press: Toronto.

Menounos, B., Osborn, G.D., Clague, J.J., Luckman, B.H., 2009. Latest Pleistocene and Holocene glacier fluctuations in western Canada. Quaternary Science Reviews 28, 2049-2074.

Moore PD, Webb JA. 1978. An illustrated guide to pollen analysis. Hodder and Stroughton: London.

Moos, M.T., Cumming, B.F., 2012. Climate-fire interactions during the Holocene: a test of the utility of charcoal morphotypes in a sediment core from the boreal region of north-western Ontario (Canada). International Journal of Wildland Fire 21, 640-652.

Morris, J.L., Brunelle, A., DeRose, R.J., Seppä, H., Power, M.J., Carter, V., and Bares, R., 2013. Using fire regimes to delineate zones in a high-resolution lake sediment record from the western United States. Quaternary Research 79, 24-36.

Mullineaux, D.R., 1996. Pre-1980 tephra-fall deposits erupted from Mount St. Helens, Washington, U.S. Geological Survey Professional Paper 1563, pp. 1-99.

Nelson, D.B., Abbott, M.B., Steinman, B., Polissar, P.J., Stansell, N.D., Ortiz, J.D., Rosenmeier, M.F., Finney, B.P., Riedel, J., 2011. Drought variability in the Pacific Northwest from a 6,000-yr lake sediment record. Proceedings of the National Academy of Sciences doi:

10.1073/pnas.1009194108.

Nesbitt, J.H., 2010. Quantifying forest fire variability using tree rings Nelson, British Columbia 1700-Present. MSc. Thesis, University of British Columbia, Vancouver.

Oke, T.R., 1987. Boundary layer climates. Methuen, London, pp. 435.

Pollack, J., Quesnel, H., Hauk, C., MacLean, H., 1997. A quantitative evaluation of natural age class distributions and stand replacement intervals in the Nelson Forest Region. Forest Sciences, Nelson Forest Region, B.C. Ministry of Forests, Technical Report TR-015. 
Reimer, P.J., Baillie, M.G.L., Bard, E., Bayliss, A., Beck, J.W., Blackwell, P.G., Bronk Ramsey, C., Buck, C.E., Burr, G.S., Edwards, R.L., et al., 2009. IntCal09 and Marine09 radiocarbon age calibration curves, $0-50,000$ years cal BP. Radiocarbon 51, 1111-1150.

Reyes, A.V., Clague, J.J., 2004. Stratigraphic evidence for multiple Holocene advances of Lillooet Glacier, southern Coast Mountains, British Columbia. Canadian Journal of Earth Sciences 41, 903-918.

Rodionov, S.N., 2004. A sequential algorithm for testing climate regime shifts. Geophysical Research Letters, 31, L09204.

Rosenberg, S.M., Walker, I.R., Mathewes, R.W., 2003. Postglacial spread of hemlock (Tsuga) and vegetation history in Mount Revelstoke National Park, British Columbia, Canada. Canadian Journal of Botany 81, 139-151.

Rosenberg, S.M., Walker, I.R., Mathewes, R.W., Hallett, D.J., 2004. Midge-inferred Holocene climate history of two subalpine lakes in southern British Columbia, Canada. Holocene 14, 258271.

Scott, A.C., Cripps, J.A., Collinson, M.E., Nichols, G.J., 2000. The taphonomy of charcoal following a recent heathland fire and some implications for the interpretation of fossil charcoal deposits. Palaeogeography, Palaeoclimatology, Palaeoecology 164, 1-31.

Steinman, B.A., Abbott, M.B., Mann, M.E., Stansell, N.D., Finney, B.P., 2012. 1500-year quantitative reconstruction of precipitation in the Pacific Northwest. Proceedings of the National Academy of Sciences 109, 11619-11623.

Steventon, J.D., 1997. Historic disturbance rates for interior biogeoclimatic subzones of the Prince Rupert Forest Region. Extension Note No. 26. Forest Sciences, Prince Rupert Forest Region, BC Forest Service, Smithers, BC.

Stockmarr, R.J., 1971. Tablets with spores used in absolute pollen analysis. Pollen Spores, 13, 615-621.

Sweeney, C.A., 2004. A key for the identification of stomata of the native conifers of Scandinavia. Review of Palaeobotany and Palynology 128, 281-290.

Syvitski, J.P.M. (ed.), 1991. Principles, methods, and application of particle size analysis. Press Syndicate of the Cambridge University Press, New York, pp. 368. 
Thevenon, F., Anselmetti, F.S., 2007.Charcoal and fly-ash particles from Lake Lucerne sediments (Central Switzerland) characterized by image analysis: anthropologic, stratigraphic and environmental implications. Quaternary Science Reviews 26, 2631-2643.

Trouet, V., Taylor, A.H., Wahl, E.R., Skinner, C.N., Stephens, S.L., 2010. Fire-climate interactions in the American West since 1400 CE. Geophysical Research Letters 37, L04702.

Wang, T., Hamann, A., Spittlehouse, D., Murdock, T.N. 2012. Climate WNA - High-Resolution Spatial Climate Data for Western North America. Journal of Applied Meteorology and Climatology 61, 16-29.

Westerling, A.L., Hidalgo, H.G., Cayan, D.R., Swetnam, T.W., 2006. Warming and earlier spring increase western US forest wildfire activity. Science 313, 940-943.

Whitlock, C., Larsen, C.P.S., 2001. Charcoal as a Fire Proxy. In: Smol, J.P., Birks, H.J.B., Last, W.M., Bradley, R.S., Alverson, K. (Eds.), Tracking environmental change using lake sediments. Volume 3: Terrestrial, Algal, and Siliceous Indicators. Kluwer Academic Publishers, Dordrecht, pp. 75-97.

Whitlock, C., Higuera, P.E., McWethy, D.B., Briles, C.E., 2010. Paleoecological Perspectives on Fire Ecology: Revisiting the Fire-Regime Concept. The Open Ecology Journal 3, 6-23.

Wilson, S.E., Cumming, B.F., Smol, J.P., 1994. Diatom-salinity relationships in 111 lakes from the Interior Plateau of British Columbia, Canada: The development of diatom-based models for paleosalinity and paleoclimatic reconstructions. Journal of Paleolimnology 12, 197-221.

Wong, C.M., Sandmann, H., Dorner, B., 2004. Historical variability of natural disturbances in British Columbia: a literature review. FORREX-Forest Research Extension Partnership, Kamloops, British Columbia, Canada.

Wright, H.E.J., Mann, D.H., Glaser, P.H., 1984. Piston corers for peat and lake sediments. Ecology 65, 657-659.

Yamaguchi, D.K., 1983. New tree ring dates for recent eruptions of Mount St. Helens. Quaternary Research 20, 246-250.

Yamaguchi, D.K., 1985. Tree-ring evidence for a two-year interval between recent prehistoric explosive eruptions of Mount St. Helens. Geology 13, 554-557. 
Zdanowicz, C.M., Zielinski, G.A., Germani, M.S., 1999. Mount Mazama eruption: Calendrical age verified and atmospheric impact assessed. Geology 27, 621-624. 
Table 3.1: Uncalibrated radiocarbon ages, $2 \sigma$ calibrated ages (IntCal09 calibration curve; Reimer et al., 2009), and tephrochronology, used to develop the age-depth model.

\begin{tabular}{rrrrrrrl}
\hline $\begin{array}{c}\text { Depth } \\
\text { top } \\
(\mathbf{c m})\end{array}$ & $\begin{array}{c}\text { Depth } \\
\text { bottom } \\
\text { (cm) }\end{array}$ & $\begin{array}{c}\text { Raw } \\
\text { year BP) }\end{array}$ & $\begin{array}{c}\text { Raw }{ }^{14} \mathbf{C} \\
\text { error } \\
\text { (years) }\end{array}$ & $\begin{array}{c}{ }^{13} \mathbf{C}:{ }^{12} \mathbf{C} \\
\text { ratio }\end{array}$ & $\begin{array}{c}\text { Calibrated age } \\
\text { (cal year BP) }\end{array}$ & Material & Reference \\
\hline 0 & & & & & -59 & & Top of core \\
27.5 & 28 & & & & $468-469$ & MSH Wn & Yamaguchi, 1985 \\
90.5 & 95 & 2230 & 30 & -26 & $2153-2335$ & Wood & Beta-301980 \\
217.5 & 218.5 & 5690 & 40 & -23.7 & $6399-6630$ & Wood & Beta-301981 \\
244.5 & 253 & & & & & Ash redeposit & \\
266.5 & 292.5 & & & & $7477-7777$ & Mazama O & Zdanowicz et al, 1999 \\
317 & 317.5 & 7920 & 40 & -24.9 & $8606-8977$ & Plant material & Beta-301982 \\
349.5 & 350 & 8600 & 50 & -24.4 & $9495-9678$ & Wood & Beta-301983 \\
& 351.5 & & & & & & \\
\hline
\end{tabular}


Table 3.2: Summary of total and morphotype charcoal accumulation rates (CHAR) results.

\begin{tabular}{lccccccc}
\hline & Total & M & P & S & C & D & F \\
\hline Mean CHAR (pieces $\mathrm{cm}^{-2} \mathrm{yr}^{-1}$ ) & 0.81 & 0.03 & 0.28 & 0.16 & 0.15 & 0.014 & 0.16 \\
$\begin{array}{l}\text { Median peak return interval } \\
\text { (years) }\end{array}$ & 216 & 337 & 211 & 225 & 226 & 407 & 239 \\
$\begin{array}{l}\text { Correlation with total }(p<0.001) \\
\text { Mean relative abundance of total }\end{array}$ & 1 & 0.69 & 0.95 & 0.84 & 0.92 & 0.69 & 0.77 \\
CHAR (\%) & & 5.3 & 36.4 & 19.7 & 19 & 2.3 & 17.3 \\
Standard deviation of relative & & & & & & & \\
abundance of total CHAR (\%) & & 5.8 & 16.2 & 11.9 & 10.3 & 3.6 & 11.3 \\
Significant peaks & 44 & 25 & 45 & 42 & 42 & 11 & 37 \\
Insignificant peaks & 4 & 37 & 5 & 6 & 12 & 57 & 18 \\
Agreeing peaks ( $N$ and \%) & & 17 & 41 & 37 & 36 & 8 & 26 \\
& & $68 \%$ & $91 \%$ & $88 \%$ & $86 \%$ & $83 \%$ & $70 \%$ \\
$\begin{array}{l}\text { Agreeing insignificant } \\
\text { morphotype CHAR peaks }\end{array}$ & & & & & & & \\
With significant total CHAR & & 17 & 2 & 0 & 3 & 27 & 10 \\
peaks & & & & & & & \\
\hline
\end{tabular}


a)

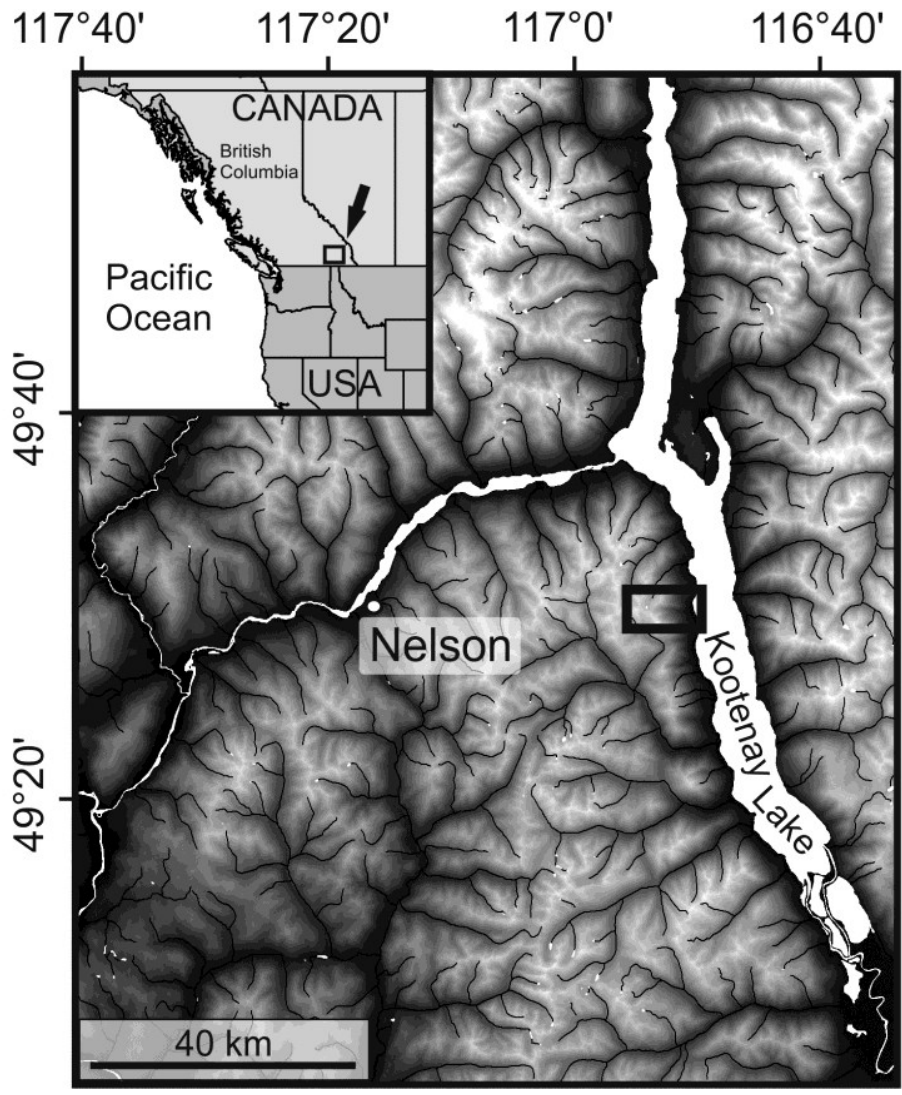

b)

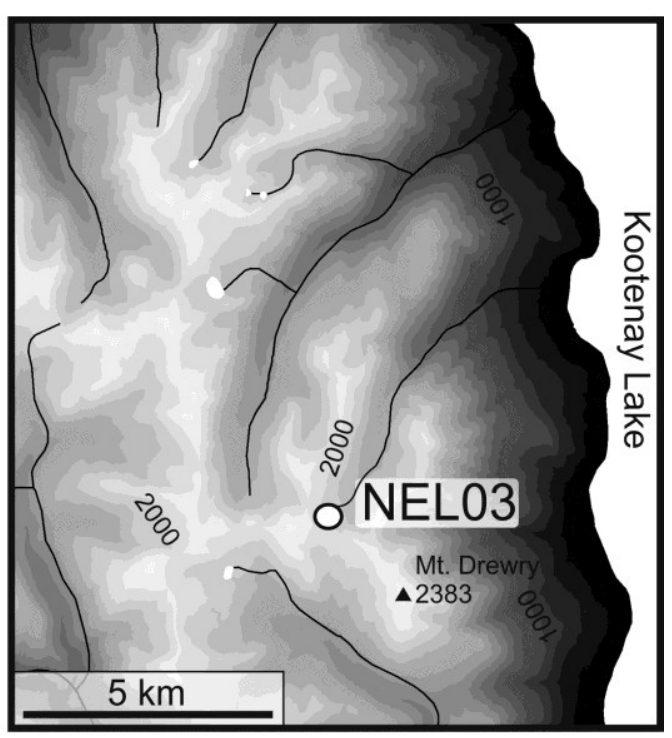

c) NEL03
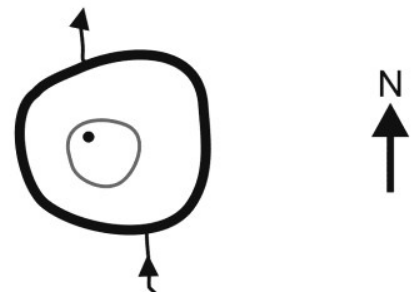

$50 \mathrm{~m}$

Figure 3.1: a) Location of study region, black box shows b) the lake site (100 $\mathrm{m}$ topographic contours), and c) shows the lake bathymetry ( $2 \mathrm{~m}$ isobath) and coring locations. 


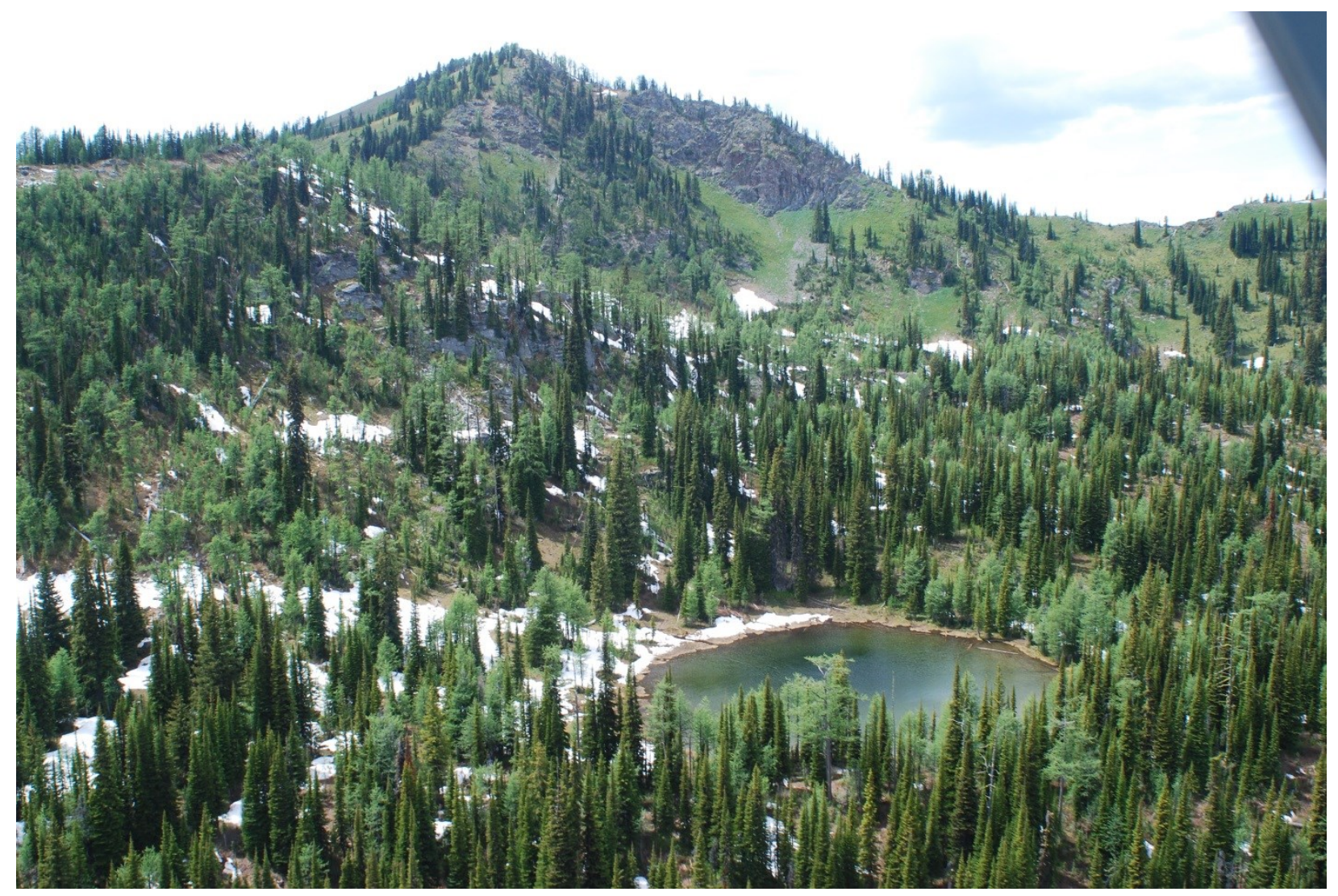

Figure 3.2: Photograph of NEL03 facing south-southwest (Photo: Ze'ev Gedalof). 


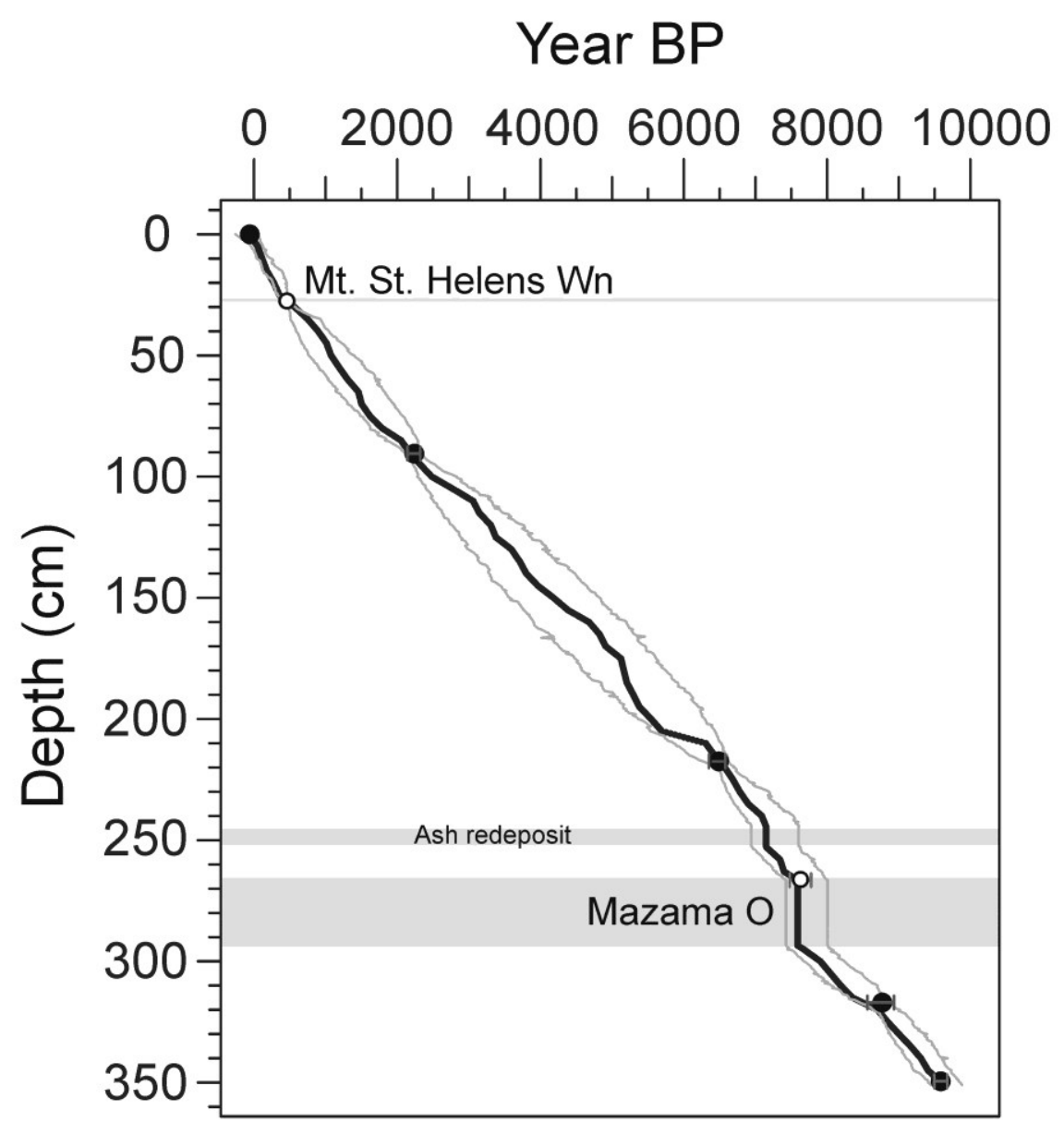

Figure 3.3: Age-depth model (black line) of the highest probability density of 8 million random walk iterations within the $95 \%$ confidence enveloped (gray lines) using calibrated radiocarbon dates (black circles; IntCa109, Reimer et al., 2009) and known tephra deposit dates (open circles) developed in the program Bacon. The $2 \sigma$ error range of radiocarbon dates and the error estimate for the Mazama $\mathrm{O}$ eruption event are shown by dark grey error bars. Tephra thicknesses within the stratigraphy are illustrated by gray bands. 


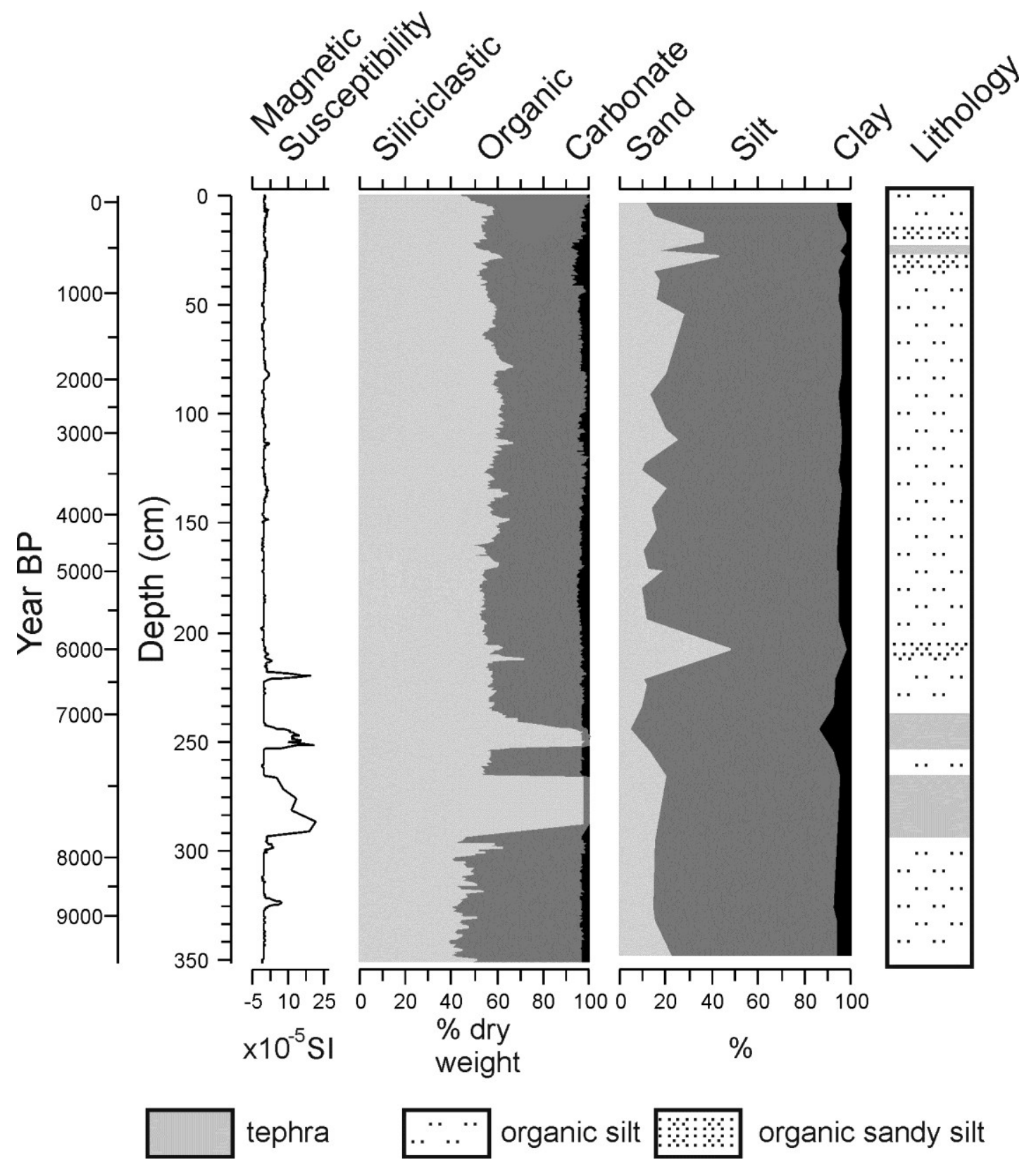

Figure 3.4: Physical sedimentology and general lithology of the composite stratigraphy collected from NEL03. Loss-on-ignition analysis was used to estimate the relative proportion of organic, carbonate and siliciclastic content and particle size distributions were used to calculate the sand-, silt-, and clay-sized fractions of the siliciclastic sediments using GRADISTAT (Blott and Pye, 2001). 


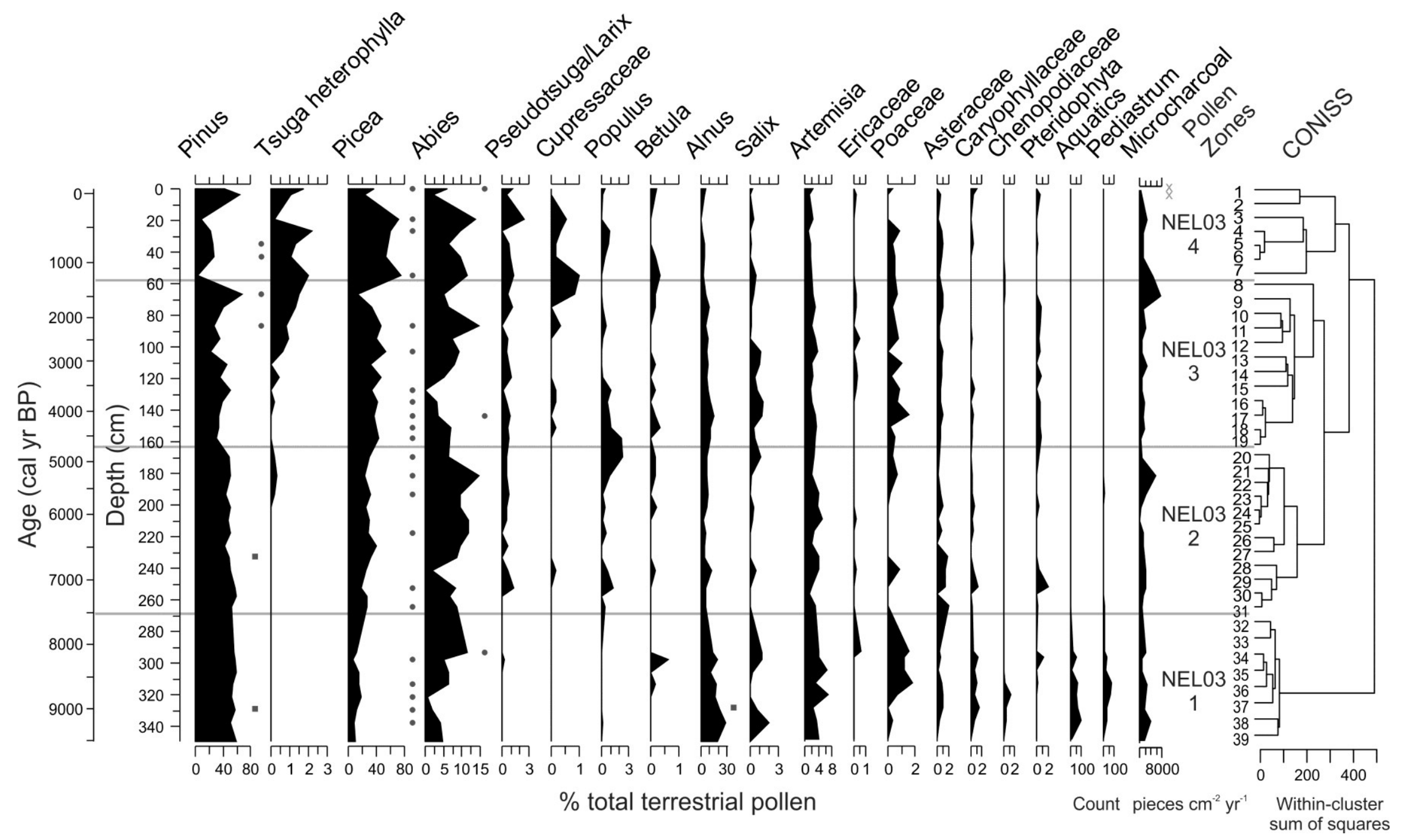

Figure 3.5: Pollen percentage data of selected taxa from NEL03, Pediastrum and aquatic pollen presented as counts and some rarer taxa are not shown. The presence of coniferous taxa stomata on pollen slides are shown by gray dots and macrofossil presence observed during macroscopic charcoal analysis are shown by gray squares. Microcharcoal accumulation rates are shown and note the presence of cenospheres near the top (gray ' $\mathrm{x}$ ' symbol). Pollen zones were established using CONISS. 

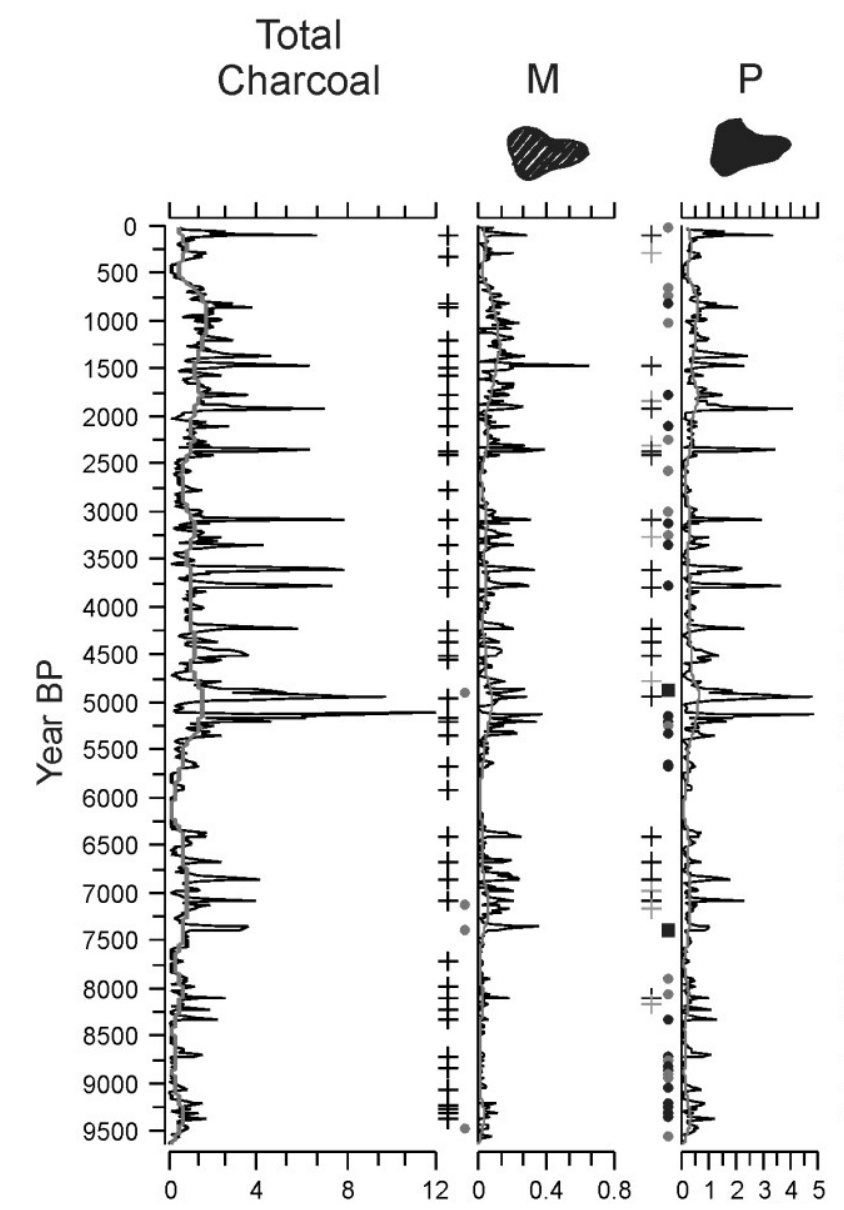

Charcoal Morphotypes

Total

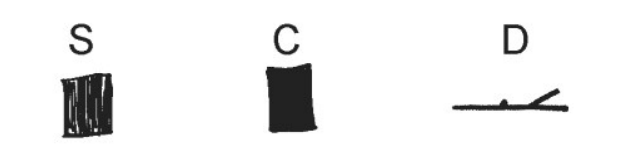

F
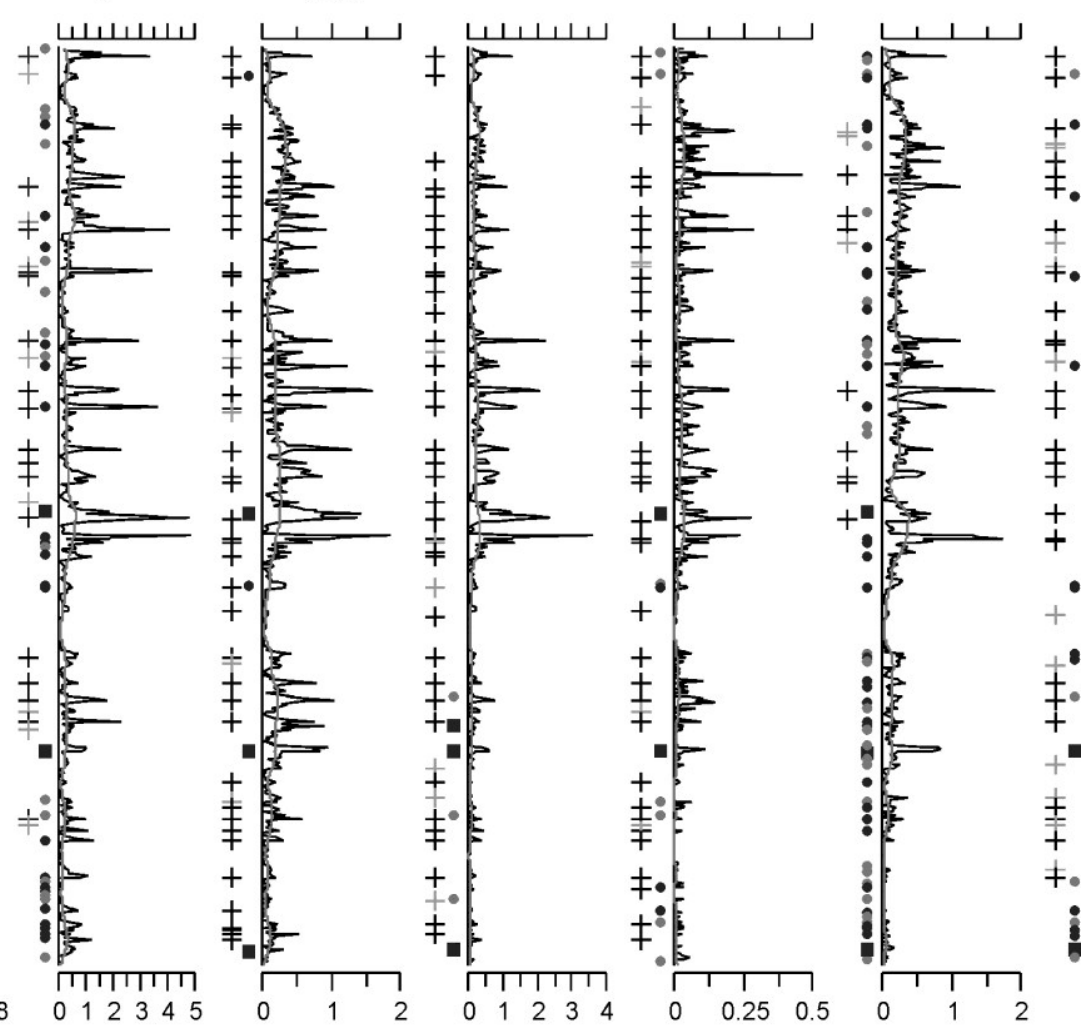

Figure 3.6: Fire episode reconstruction at NEL03 over the past 9650 cal yr BP using total macroscopic charcoal accumulation rates (black line) showing 44 significant peak events ('+' symbol) above the variable background rate (grey line). Grey circles represent insignificant peaks in CHAR defined by a cut-off probability of a minimum charcoal concentration value within 75 years before a peak having $\geq 5 \%$ chance of coming from the same Poisson distribution as the maximum charcoal count associated with the peak (Higuera, 2009). CHAR values for each macroscopic charcoal morphotype counted, using the morphotype classification of Enache and Cumming (2006), are also shown (black lines) with the associated variable background rates (grey lines). Significant peaks in morphotype CHAR that agree ( $\leq \pm 24$ years) with total charcoal peak events are shown by black '+' symbols, grey '+' symbols signify significant peaks that do not agree, black circles represent insignificant peaks in morphotype CHAR that agree with significant peaks in total CHAR, grey circles represent insignificant peaks in morphotype CHAR, and insignificant morphotype peaks that agree with total CHAR insignificant peaks are show by black squares. 


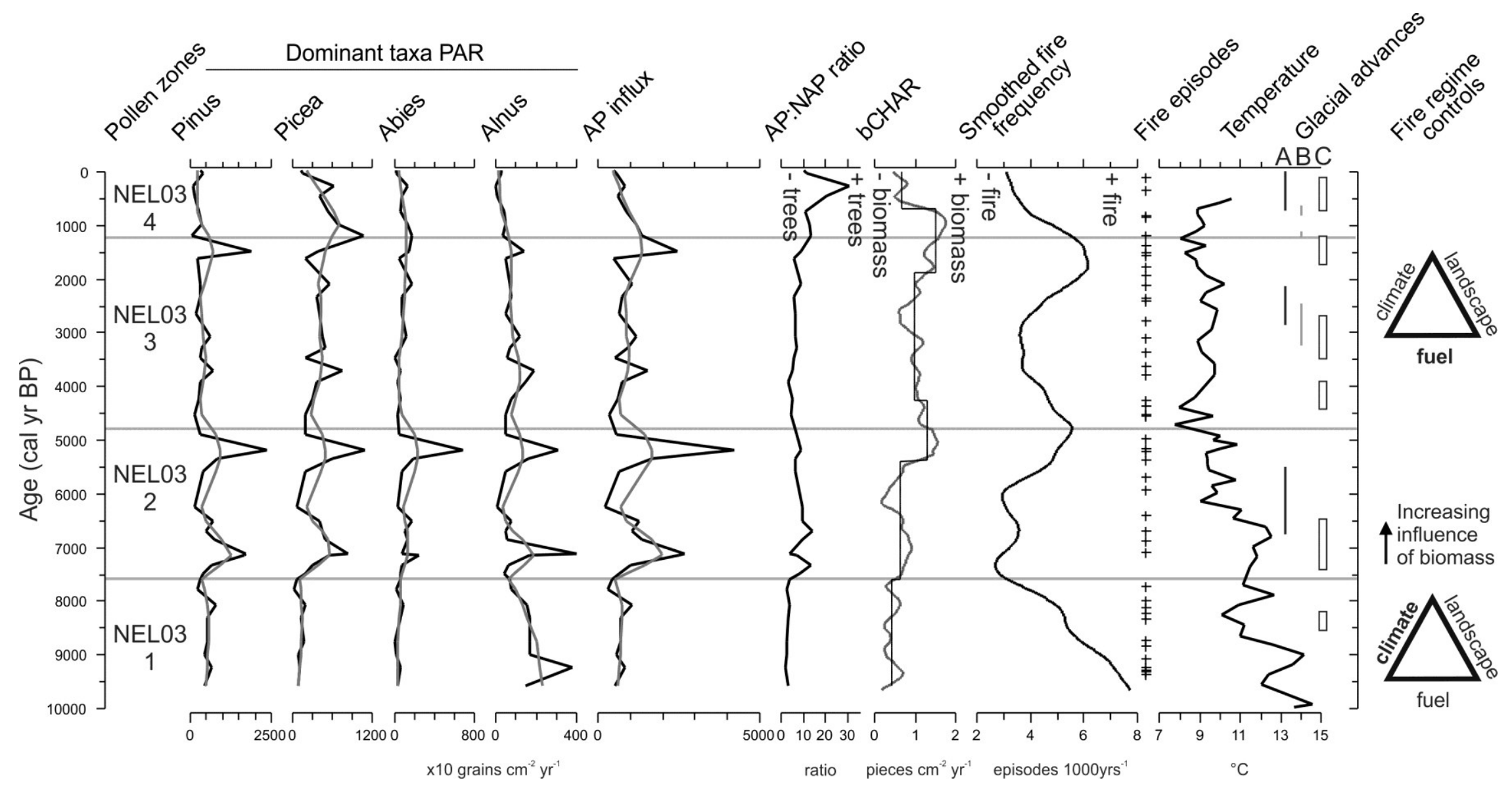

Figure 3.7: Holocene vegetation and disturbance history summary at the NEL03 catchment. Pollen zones represent significant changes to the terrestrial plant community. Arboreal pollen (AP) influx, smoothed with a LOWESS with a span of 0.2 (gray line), and the ratio of AP to non-arboreal pollen (NAP) are presented to show the changes to the density of trees in the area. Background charcoal accumulation rate (bCHAR) shows changes to abundance of biomass within the catchment and the solid black line shows the fire regime zones derived from a regime shift algorithm (RSI; $\mathrm{P}=0.0001$, cut-off length $=100$ yr, Huber's WF $=5$; Rodionov, 2004). Smoothed fire frequency shows the long-term changes to fire activity, '+' symbols represent reconstructed fire episodes. A chironomidinferred mean July temperature reconstruction shows the general Holocene pattern in the southern interior of British Columbia (Chase et al., 2008). A) Black bars represent the maximum extents of glacier advances along the Coastal Ranges (Reyes and Clague, 2004), B) the gray bars show advances at the central Rocky Mountains (Luckman et al., 1993), and C) the white bars represent the general pattern of glacier advances across central and southern British Columbia, summarized by Menounos et al. (2009). The relative influence of regional climate, catchment landscape (topography, elevation, aspect), and fuel condition (biomass, fuel connectivity) controls of the decadal-to-centennial scale fire regime are emphasized by skewing of the fire regime triangles based on the relative importance of each set of factors (Whitlock et al., 2010). 


\section{A 7500-year record of climate-fire-vegetation interactions at a mountain valley site, southeast British Columbia, Canada}

\subsection{Abstract}

Fire is the most important abiotic disturbance in the interior cedar-hemlock (ICH) and Engelmann spruce-subalpine fir (ESSF) forest zone of southeastern British Columbia, Canada. The varying influences of the spatial controls on fire have produced forest stands that are heterogeneous in age, structure, and species composition. High-severity fires in these forests are drivers of the landscape-scale dynamics of the ecosystem. Here we present a retrospective study of the occurrence of high-severity fires and vegetation assemblage changes to understand which controls have been important in the past and how the relative importance of the controls have changed throughout the Holocene. Past fire activity and vegetation has been inferred from highresolution macroscopic charcoal and pollen analysis of lake sediments collected from a low elevation valley site in the Columbia Mountains. Early Holocene forests were Pinus dominated, and Engelmann-spruce subalpine fir forests developed by 6400 cal a BP. Tsuga heterophylla arrived by $4400 \mathrm{cal}$ a BP and the modern interior cedar-hemlock forests expanded throughout the lower elevations to present. Fire episodes occurred with a Weibull median fire return interval of 186 years over the past 7500 years. Climate was a major influence on early Holocene fire frequency and local controls of fire activity have been important since $\sim 6000$ cal a BP. Forest biomass and major climate-mediated forest compositional changes were not major influences on fire frequency at this site, suggesting that other local controls have been important controls on fire in the catchment.

Key words: charcoal; disturbance; Holocene; lake sediments; mixed-conifer forests; wildfire 


\subsection{Introduction}

Climate warming is projected to increase fire frequency, severity, and area burned across boreal regions of western North America and increase carbonaceous emissions (Spracklen et al. 2009) due to lengthening of the fire season, and changes to the variability of fire weather (Whitlock et al. 2003; Westerling et al. 2006; Tymstra et al. 2007; Flannigan et al. 2009). Forests and the disturbance regimes acting upon them contribute to the carbon flux between the terrestrial environment and the atmosphere, influencing atmospheric composition and climate (Kasischke et al. 2013). Wildfires threaten human life and infrastructure and have varying socioeconomic impacts, which depend on the land-management strategies and various stakeholder perspectives interacting at the wildland-urban interface. The threat of wildfires is also superimposed upon the crucial ecological role it plays. Fires are an important disturbance in montane mixed-conifer forests that influence stand composition and age distributions, biogeochemical cycles, soil stability, and can have complex dynamics in association with other types of abiotic and biotic disturbances. Quantitative records of fire are necessary to understand how forests will respond to future climate warming and human land-use changes.

High-severity fires are the most important disturbances in Engelmann spruce-subalpine fir (ESSF) forests and are a driver of the landscape-scale dynamics of the ecosystem (Lindgren and Lewis 1997). These forests dominate much of mid-elevations in the Columbia Mountains of southeast British Columbia, Canada. The rugged topography forces westerly air to converge and produces high total annual precipitation that promotes the development of dense and diverse forests that are ecologically and socioeconomically important. Many studies have investigated forest fire histories of the Engelmann spruce-subalpine fir forests of the region (Pollack et al. 1997; Steventon 1997; Wong et al. 2004; Gavin et al. 2006; Nesbitt 2010; Courtney Mustaphi 
and Pisaric 2013; In press). Earlier investigations of multiple sites have examined the varying influence of top-down (climatic) controls and bottom-up (local scale) controls of fire activity in the region during the Holocene (Gavin et al. 2006; Courtney Mustaphi and Pisaric 2013; In press). At a high elevation site in the region, the influence of fire controls varied in relative importance throughout the Holocene, where climate, insolation, and climate-mediated vegetation composition, were important during the early Holocene (Courtney Mustaphi and Pisaric, In press) and these controls were overridden by the importance of local site factors during the mid and late Holocene (Gavin et al. 2006; Courtney Mustaphi and Pisaric 2013; In press). Aspect has been shown to be an important local spatial control of late Holocene fire regimes in Engelmann spruce-subalpine fir forests (Courtney Mustaphi and Pisaric 2013) and centennial to millennial scale increases in biomass abundance within the watershed was an important local control at subalpine elevations (Courtney Mustaphi and Pisaric In press). Fires during the late Holocene have been synchronous at decadal to centennial scales at sites sharing a similar aspect and additional paleoecological investigations of full Holocene records are needed to examine the causes of independence and asynchrony of fire activity in the region (Courtney Mustaphi and Pisaric 2013). Longer term records of vegetation and fire can be used to discern the relative importance of local site factors (aspect, topography, fire breaks), fuels (abundance, vegetation type), and climatic variability on fire regimes.

Here, we present a 7500-year record of vegetation and forest activity derived from the lake sediments from a mountain valley lake. We examine the local area fire history of the catchment through high resolution macroscopic charcoal analysis and interpret the relative importance of the spatial controls of fire occurrence. We then explore how the controls of the fire regime have varied through time by examining other fire, vegetation, and paleoclimatic records. 


\subsection{Methods}

\subsubsection{Study site}

The Columbia Mountains of interior British Columbia, Canada, have a rugged landscape and are part of the Interior Wet Belt where annual precipitation is generally higher than surrounding regions. Sasquatch Lake is a small ( $2 \mathrm{ha})$, nearly oval lake that is moderately deep $\left(\mathrm{Z}_{\max }=4.6 \mathrm{~m}\right)$ and has a catchment area of 120 ha (Fig. 4.1). There are few ephemeral stream inputs from the adjacent slopes that transport snowmelt and storm water to the lake and a minor outlet draining northwest through Lemon Creek to the Slocan River. The lake is situated at $1054 \mathrm{~m}$ asl in a narrow T-shaped junction of the 6 Mile Creek and Lemon Creek valleys. The valley walls are steep and reach 700-1200 m above the lake. Local bedrock is Middle Jurassic porphyritic granite, granodiorite, and granitic gneiss, of the Nelson Batholith (Little 1960; Wheeler and McFeely 1991). Soils are shallow, usually 50-150 cm deep, rapidly draining, lithic humo-ferric podzols of the Buhl Creek Association (Jungen 1980) with significant colluvium and rock outcrops. Currently, the western slope is continuously forested and the eastern slopes are densely forested up to $\sim 1500 \mathrm{~m}$ asl where the timberline is geomorphically controlled by colluvium patches and alpine colluvium and exposed bedrock dominate above 1750-1900 m around the Mt Cornfield horn.

The study site experiences strong seasonality and receives $1214 \mathrm{~mm}$ of precipitation annually, $44 \%$ of which falls as snow. Summers are warm (mean $14{ }^{\circ} \mathrm{C}$ ) with episodic convective thunderstorms (255 $\mathrm{mm}$ of the total rainfall). Winters are moderately cold and snowy (mean December to February temperature $=-6.8^{\circ} \mathrm{C} ; 382 \mathrm{~mm}$ of precipitation; 1981-2009; Wang 
et al. 2012). The fire season begins as early as April and lasts as late as October (Canadian Forest Service, 2010).

Similar to most regions of the Interior Wet Belt of the Columbia Mountains, low to mid elevation (500-1200 m) vegetation cover is interior cedar-hemlock (ICH) forests (Ketcheson et al. 1991), dominated by uneven-aged stands of fire intolerant western redcedar (Thuja plicata Donn ex D. Don) and western hemlock [Tsuga heterophylla (Raf.) Sarg.]. A fire scar and stand age study of three ICH stands (807-1161 m asl) suggested that these stands experience low-tomoderate severity fires with 112-137 years since last fire (Nesbitt 2010). Canopy tree density ranged from 167-221 living trees $\mathrm{ha}^{-1}$, the subcanopy consisted of 533-666 trees $\mathrm{ha}^{-1}$, and the regeneration layer had 3508-8037 individuals $\mathrm{ha}^{-1}$. Fire years at low to mid elevations within the 6 Mile Creek valley were established for CE 1834, 1863, 1872, and 1897 (Nesbitt 2010). There was evidence of selective winter timber harvesting of larger diameter trees off of the road approaching the site. Sasquatch Lake is situated within moist-warm ICH forests that experience infrequent stand initiating events with a mean disturbance interval of 200 years. Mid elevations are composed of wet-cool Engelmann spruce-subalpine fir forests [ESSF; Picea engelmannii Parry ex Engelm.; Abies lasiocarpa (Hook.) Nutt.] with minor abundances of Douglas-fir [Pseudotsuga menziesii (Mirb.) Franco], western larch (Larix occidentalis Nutt.), and lodgepole pine (Pinus contorta var. latifolia Engelm. ex S. Watson), which experience rare stand-initiating events with a mean disturbance return interval of 250-350 years (Pollack et al. 1997; Wong et al. 2004). Moderate to large severity outbreaks of mountain pine beetle (Dendroctonus ponderosae Hopkins) caused tree mortality upslope from Sasquatch Lake between CE 2005 and 2007 (BC Ministry of Forestry and Range 2012). 


\subsubsection{Field methods}

During summer 2009, lake sediment cores were collected from the eastern portion of the central deep basin of Sasquatch Lake. The sediment-water interface and uppermost sediments were collected using a large diameter Glew gravity corer deployed from a boat, then extruded into Whirl-Pak ${ }^{\circledR}$ bags using a vertical extruder at contiguous $0.25-\mathrm{cm}$ intervals, from $0-15 \mathrm{~cm}$ depth, and at 0.5-cm intervals to the base (Glew et al. 2001; Courtney Mustaphi and Pisaric 2013). Deeper sediments were collected using a 5-cm diameter Livingstone piston corer in 1-m drives (Wright et al. 1984) and coring ceased at $531.5 \mathrm{~cm}$ below the water-sediment interface. Piston cores were extruded in the field, wrapped in plastic and aluminum foil, shipped to the Carleton University Paleoecological Laboratory (CUPL), and subsectioned and bagged at contiguous 0.5cm intervals.

\subsubsection{Laboratory methods}

A composite stratigraphy was established through overlapped magnetic susceptibility, loss on ignition, and charcoal concentration data profiles of the surface and deeper sediment cores. An age-depth model was developed using a cubic spline through four dates obtained from accelerator mass spectrometry radiocarbon dating of organic material that was presented by Courtney Mustaphi and Pisaric (2013). Radiocarbon dates were calibrated using IntCal09 (Reimer et al. 2009). The magnetic properties of sediments reflect the minerals present and magnetic susceptibility was used to interpret changes to the erosion and deposition regime of the watershed (Dearing 1999). The magnetic susceptibility of the surface sediments was measured

from $1 \mathrm{~cm}^{3}$ subsamples using a Bartington Systems MS2B sensor. Prior to being subsectioned, magnetic susceptibility of the piston cores was measured from an open core face using a 
Bartington Systems MS2E1 sensor. Sediment organic content was estimated through loss-onignition analysis (Dean 1974; Heiri et al. 2001), which used $1 \mathrm{~cm}^{3}$ subsamples taken at 0.25-2.5 $\mathrm{cm}$ intervals and dried at $105{ }^{\circ} \mathrm{C}$ for 24 hours. The dried samples were burned at $550{ }^{\circ} \mathrm{C}$ for 4 hours, then reburned at $950{ }^{\circ} \mathrm{C}$ for 2 hours for estimated carbonate content, and the residual material represented the siliciclastic content. Using a Beckman Coulter LS 13320 laser diffraction particle size analyzer, particle size distributions (PSDs) were derived from $1 \mathrm{~cm}^{3}$ subsamples taken at $\sim 10 \mathrm{~cm}$ intervals. Organic material was digested through pretreatment with $30 \%$ hydrogen peroxide $\left(\mathrm{H}_{2} \mathrm{O}_{2}\right)$ in a hot water bath $\left(\sim 75^{\circ} \mathrm{C}\right)$ for 8 hours, and then the residues were dispersed with $5 \mathrm{~mL}$ of sodium hexametaphosphate prior to triplicated measurements. Replicated measurements were averaged and the distributions were processed in GRADISTAT v8 that calculated percent sand, silt and clay fractions (Blott and Pye 2001).

For sediment macroscopic charcoal analysis, contiguous $1 \mathrm{~cm}^{3}$ subsamples were removed at 0.25-0.5 cm intervals, soaked in a metaphosphate solution (Bamber 1982) for at least 24 hours, and then wet sieved through a $150 \mu \mathrm{m}$ mesh. The larger fraction was transferred to a Petri dish and the number of macroscopic charcoal pieces was tallied under a Nikon SMZ800 stereoscope at 6-40 X magnification (Whitlock and Larsen 2001). Sediment macroscopic charcoal concentrations (pieces $\mathrm{cm}^{-3}$ ) were converted to charcoal accumulation rates (CHAR; pieces $\mathrm{cm}^{-2}$ $\mathrm{yr}^{-1}$ ) and analyzed using CharAnalysis software (Higuera 2009; Higuera et al. 2009). Raw charcoal concentrations were resampled to 12-year intervals to create an interpolated CHAR series for peak analysis. Background charcoal accumulation rates (bCHARs) were estimated locally over a 500-year window using a LOWESS smoother robust to outliers. CHAR peaks were defined by subtracting the estimated background CHAR component from the interpolated CHAR series (Higuera et al. 2010) and identified through a noise cut-off probability at the $99^{\text {th }}$ 
percentile established by a Gaussian mixture model (Higuera et al. 2010). Minimum charcoal concentrations within a 75 -year period prior to a peak with a probability $<5 \%$ of coming from the same Poisson distribution as the associated peak were retained as significant peaks (Higuera 2009; Higuera et al. 2010). CHAR peaks represented fire episodes of $\geq 1$ large fire(s) that occurred in the lake catchment area within a 12-year period. Fire frequencies were smoothed using a LOWESS smoother with a window span of 1000 years through the tally of number of fires during each 1000-year period (Long et al. 1998; Gavin et al. 2006; Higuera 2009; Hallett and Anderson 2010).

Pollen was processed from $1 \mathrm{~cm}^{3}$ subsamples, removed at a median interval of $15 \mathrm{~cm}$, through standard digestion techniques (Fægri and Iversen 1989) with Lycopodium tablet inoculation (Stockmarr 1971), and were neither fine nor coarse sieved to preserve microscopic charcoal and stomata in the residues. Pollen was enumerated under 400-1000x microscopy to a minimum terrestrial pollen count of 500 grains and identification was aided using keys (McAndrews et al. 1973; Bassett et al. 1978; Moore and Webb 1978) and a reference collection at the CUPL. Stomata were identified during pollen counts using keys by Hansen (1995) and Sweeney (2004) and represented local presence of each taxon observed. Microscopic charcoal was also tallied during pollen counts and plant macroremains were identified during macroscopic charcoal counts and were presented as local presence of taxa.

\subsubsection{Data analyses}

Vegetation zones were established through constrained incremental sum of squares cluster analysis (CONISS) of the terrestrial pollen assemblages. To identify significant changes to the fire regimes between each pollen zone, two-sample Kolmogorov-Smirnov (KS) tests were used 
to examine whether the null hypotheses were true; that the fire return intervals (FRIs) distributions from each adjacent identified pollen zone came from the same underlying distributions.

\subsection{Results}

\subsubsection{General sedimentology}

The magnetic susceptibility was generally low, -1 to $3 \times 10^{-5} \mathrm{SI}$, with higher variability from 7568-4000 cal a BP and since 750 cal a BP to present (Fig. 4.2). Multiple peaks were associated with increased siliciclastic content determined through loss-on-ignition analysis. Siliciclastic content accounted for $60-90 \%$ of the sediment dry weight and had decreased throughout the Holocene as organic content increased (10-45\%), most notably during the past 60 years. Sediment carbonate content was consistently low, $<9 \%$, throughout the entire record. Particle size distribution data showed that the sediments were predominantly poorly sorted, very fine sandy coarse and medium silts with a low clay content $(<10 \%)$. The lack of conspicuous tephra deposits from Holocene Cascadian eruptions frequently found in this region (Jungen 1980; Foit et al. 2004; Gavin et al. 2006; Courtney Mustaphi and Pisaric 2013) could be due to the sheltered location of the basin.

\subsubsection{Vegetation record}

Pollen zone 1: 7561-6400 cal a BP - Pinus-Picea-Abies-Pseudotsuga/Larix

The pollen record from Sasquatch Lake suggested early-to-mid-Holocene forests in the valley were dominated by Pinus (40-55\%) and Alnus (15-25\%), and Picea (1-15\%) increased throughout pollen zone 1, while Pseudotsuga/Larix (5-15\%) and Abies ( $\leq 3 \%)$ tended to decrease 
(Fig. 4.3). Deciduous tree taxa (Betula and Populus) and shrub taxa (Salix and Artemisia) were highest during this period. Artemisia decreased throughout the period from 8 to $2 \%$. Grass (Poaceae) and other small plants were less abundant and pollen from aquatic taxa was rarely observed. The relatively mesic valley bottom conditions also supported Lycopodiaceae and pteridophyta (fern) species. Pediastrum counts were generally high, up to 50-200 colonies per 500 pollen grains.

Pollen zone 2: 6400-4400 cal a BP - Pinus-Picea-Abies-Pseudotsuga/Larix

The vegetation assemblage remained consistent until 4400 cal a BP (Fig. 4.3). Picea remained an important constituent of the assemblage (15-20\%), higher than during the previous pollen zone. Pinus decreased slightly (50-40\%) as did Pseudotsuga/Larix, Alnus, and Artemisia. Pediastrum also remained high.

Pollen zone 3: 4400-1500 cal a BP - Pinus-Picea-Tsuga-Cupressaceae

Forests with abundant Pinus, Picea, and Pseudotsuga/Larix continued during this period and Alnus ranged from 7-15\%. Tsuga pollen, likely representing Tsuga heterophylla, was first present (1\%) by $4700 \mathrm{cal}$ a BP, and was abundant (8-30\%) by $4400 \mathrm{cal}$ a BP (Fig. 4.3). A Tsuga stoma was found at 2000 cal a BP, but local presence had probably occurred earlier. The appearance of Tsuga in the watershed appeared to be abrupt and within a few hundred years rapidly changed the forest of the lower elevations. Cupressaceae also increased during this period and likely represents Thuja plicata. Picea, Abies, Pseudotsuga/Larix pollen and deciduous and shrub taxa pollen decreased during the period, as did Pediastrum counts. The modern ICH forests established by $4400 \mathrm{cal}$ a BP in the valley, similar to previous vegetation studies in 
southeast British Columbia (Hebda 1995; Rosenberg et al. 2003; Gavin et al. 2006; 2011; Hallett and Hills 2006; Courtney Mustaphi and Pisaric In press).

Pollen Zone 4: 1500 cal a BP-present - Pinus-Picea-Tsuga-Cupressaceae

Since $1500 \mathrm{cal}$ a BP, Pinus pollen remained very high (50-60\%), Tsuga remained at 15\%, and Picea decreased to $10 \%$ (Fig. 4.3). Alnus abundance was similar to Zone 3 ranging from 4-16\%. The forest that surrounded the lake had remained interior cedar-hemlock (ICH) with Engelmann spruce-subalpine fir (ESSF) forests dominating the slopes above the lake.

\subsubsection{Fire episode reconstruction and calibration}

The recent fire history was established using observational records from the Canadian National Fire Database (CNFDB; CE 1917-2011) and dendrochronological methods at sites in the 6 Mile Creek valley (Fig. 4.4a). Fires during the past century were lightning-caused and predominantly at mid to high elevations in the ESSF forests. One human-caused fire to the northeast of the lake in CE 1944 did not result in a large influx of charcoal to the lake; however, charcoal slowly increased during the following decade, and indicated that most of the charcoal produced during that fire was transported away from the basin due to the topography. Stand ages and fire scar dates were established at four sites in the 6 Mile Creek valley (Nesbitt 2010) and suggested lowto-moderate severity fires were common at the valley bottom during the CE 1800s. Fire return intervals were not established due to low sample depths; however, times since last fire ranged between 112-144 years (Nesbitt 2010).

The fire episode reconstruction had a global signal-to-noise index (SNI) of 3.76 (range 1.17-18.25) and was below a threshold of 3.0 (Kelly et al. 2011) at six separate periods 
accounting for $23.3 \%$ of the record (1752 years). Most troughs in the SNI were just below 3.0 and troughs below 2.5 occurred during three periods and accounted for only $8.6 \%$ of the record (648 years), which suggested that some short portions of the fire episode reconstruction need to be interpreted with caution. These short periods may have been caused by variable sedimentation rates influenced by the steep catchment. The decomposition of the CHAR data into a peak component and a varying background rate (bCHAR) identified 41 significant peaks that represented fire episodes and one insignificant peak at 61 cal a BP (CE 1889; Fig 4.4b and Fig. 4.5). The most recent fire episode identified was $97 \mathrm{cal} \mathrm{a} \mathrm{BP} \mathrm{(CE} \mathrm{1853)} \mathrm{and} \mathrm{the} \mathrm{oldest} \mathrm{fire}$ episode in the record was 7525 cal a BP. One reconstructed fire episode date differed from the original fire reconstruction of Courtney Mustaphi and Pisaric (2013) because of the longer charcoal data time series used here. The reconstructed fire episode of 4789 cal a BP was no longer found to be a significant peak in the record presented here. Raw fire return intervals (FRI) ranged from 36-744 years with a mean FRI of 186 years $(n=40$, median $=156$ years $)$. The FRI distribution was fitted with a Weibull model, using maximum likelihood techniques. The distribution passed a one-sample Kolmogorov-Smirnov (KS) goodness-of-fit test at $P>0.05$, demonstrating that the raw FRI distribution and modelled distribution come from the same underlying distribution (Higuera 2009). The Weibull median fire return interval was 186 years $(\mathrm{n}=40)$ with $95 \%$ confidence envelope of 139-235 years, estimated from 1000 bootstrapped samples.

\subsubsection{Fire regimes}

The fire frequency varied throughout the record from a maximum of 10 fires per 1000 years prior to $7000 \mathrm{cal}$ a BP to 4 fires per 1000 years by $5500 \mathrm{cal}$ a BP and remained between $4-8$ fires per 
1000 years during the remainder of the record (Fig. 4.3). Weibull median fire return intervals (mFRI) were estimated for each vegetation zone defined by CONISS analysis of the pollen assemblages (Fig. 4.6). Pollen zone 1 had a mFRI of 120 years (9 fires) and the mFRI of zone 2 was 221 years (10 fires). During pollen zone 3, 15 fires occurred with a mFRI of 160 years. There were seven fire episodes during pollen zone 4, which had a mFRI of 230 years (Fig. 4.6). The results from the KS tests of the FRI distributions from each pollen zone suggested no difference between pollen zone 1 and $2(P=0.86)$, significant similarity between pollen zones 2 and $3(P=0.92)$, and no difference between zones 3 and $4(P=0.50)$.

\subsection{Discussion}

\subsubsection{Fire history}

Sasquatch Lake provided a 7500-year record of sedimentation, vegetation change and fire activity (Figs. 4.2, 4.3, and 4.4). The organic sandy silt sediments accumulated from the deposition of autochthonous and allochthonous organic matter and the clastic input from the erosion and intermittent rapid mass movement of bedrock, colluvium, and soils, from the steep slopes in the catchment area (Fig 4.1, 4.2, and 4.5). Dendroecological studies in the valley indicated low-to-moderate severity fires were common during the 1800s (Nesbitt 2010) and recent fires have occurred mainly at mid elevations (Fig. 4.4a). During the recent period, two proximal fires occurred near the lake in 1920 and 1944, but were not prominent in the sedimentcharcoal record (Fig. 4.4b). Most ephemeral streams within the 1920 burn area channeled into the 6 Mile Lakes and to the north into Lemon Creek; and, similarly, the topography of the burned area of the 1944 fire channeled runoff toward Lemon Creek and its smaller tributaries. The complex terrain and small catchment size of Sasquatch Lake may account for the absence of a 
CHAR peak in the sediments for these two documented fire events. During the decade that followed the 1944 fire there was a small increase in CHAR which may be due to lagged erosion and deposition effects (Fig. 4.4b). Post fire accumulation of charcoal to the center of other lakes had been shown to have continued for up to 7 years (Whitlock and Millspaugh 1996). The nearest site sampled for dendrochronological analysis was $1 \mathrm{~km}$ south of the Sasquatch Lake (Fig 4.4a). One fire scar was observed at this site, but could not be dated. Canopy trees initiated from CE 1639-1889 and were dominated (90\%) by fire-intolerant species. This suggested that a lowto-moderate severity fire had spread across this portion of the valley in CE 1889 and resulted in an insignificant CHAR peak in the Sasquatch Lake record that had cleared the regeneration layer of the stand (Fig. 4.4b). Alternatively, the CE 1889 insignificant CHAR peak may have represented extra-locally transported charcoal from fires down valley during the $1890 \mathrm{~s}$, as evidenced by fire scars from low-to-moderate burns at the three more distant dendrochronology sites in the 6 Mile Creek valley (Nesbitt 2010). The CE 1853 reconstructed fire may be related to fire scars from the 1830s and 1860s, as those dates were within the dating error of the sediment age-depth model.

The forests within the catchment burned 41 times throughout the record with a Weibull mFRI of 186 years (Fig. 4.5). The pine and Engelmann spruce-subalpine fir forests of the early to mid Holocene burned frequently (5-9 fires per 1000 a) from 7500-6000 cal a BP (Fig. 4.3 and 4.7) and fire frequency decreased as regional temperatures decreased (Fig. 4.7). The warmer summer temperatures during the early Holocene caused a higher fire frequency through a lengthened fire season and increased probability of warm and dry conditions that were conducive to fire (Fig. 4.7; Berger and Loutre 1991; Chase et al. 2008). Higher fire frequencies were also found at Lake NEL03, a high elevation site in the region (36 km southeast; Courtney Mustaphi 
and Pisaric In press). During the mid and late Holocene, 4-6 fires per 1000 years occurred with a slight increase to 8 fires per 1000 years at 2000 cal a BP (Fig. 4.7). When compared to composite biomass burning indices of western North America and boreal latitudes, the Sasquatch Lake fire record differed with the exception of decreased fire frequency and bCHAR at 3000 cal a BP, followed by increased values at $2000 \mathrm{cal}$ a BP (Fig. 4.7; Marlon et al. 2013). This suggested that the Sasquatch Lake fire record was responding to regional-scale influences on the fire regime during the very early portion of the record, when summer temperatures were warmer, and from 3000-2000 cal a BP. The decreased fire frequency at $\sim 3000$ cal a BP coincides with the initiation of glacial advances in the Rocky Mountains (Luckman et al. 1993), suggesting the decrease in fire frequency may be related to regionally colder winters, increased winter precipitation and cooler summers or longer snowmelt seasons. The changes to climate would have led to increased snow packs that would maintain more mesic conditions into the spring, leading to an overall reduction in the probability of fire. The Sasquatch Lake fire record suggests that local site factors such as fuel conditions, fuel connectivity, lightning frequency, topography, and other factors are important controls of the fire regime (Gavin et al. 2006; 2007; Hu et al. 2006; Higuera et al. 2009; Courtney Mustaphi and Pisaric 2013), but that local controls can be overridden by climatic influences. Unlike the Holocene fire record at the north facing NEL03 site, the fire frequency of Sasquatch Lake does not increase during periods of increased biomass in the catchment estimated by bCHAR and pollen influx (Fig. 4.7; Courtney Mustaphi and Pisaric In press).

Fire frequency varied throughout the Holocene, but distinct changes to the fire regime was not concomitant with major changes within the vegetation assemblages. One of the most significant ecosystem changes during the record was the arrival of Tsuga heterophylla to the interior of British Columbia around 4400 cal a BP, a period of decreased continentality and 
increased winter moisture in the Interior Wet Belt region (Gavin et al. 2011) that resulted in the establishment of the modern forests in the Columbia Mountains (Hebda 1995, Rosenberg et al. 2003; Gavin et al. 2006). Interior cedar-hemlock forests began to dominate the lower elevations in the region; however, there was no change to the FRI distributions prior to and after the assemblage change (pollen zones 2 and 3). This may be due to this site capturing the fire activity of lower and mid elevation forests due to the catchment morphometry. A similar range of fire frequencies were found at Lake NEL01 (Fig. 4.7), a mid-elevation site surrounded by Engelmann spruce-subalpine fir forests, during the late Holocene (20 km southwest; Courtney Mustaphi and Pisaric 2013). This suggested that assemblage changes from Engelmann-spruce subalpine fir forests to interior cedar-hemlock forests at lower-to-mid elevation sites may not be an important influence on forest fire frequency in the Columbia Mountains as these forest types may experience high-severity fires at similar frequencies.

\subsubsection{Controls of the fire regime}

The Pinus, Picea, Pseudotsuga/Larix forests of the early Holocene experienced higher fire frequencies that were influenced by warmer summer temperatures (Chase et al. 2008). As Holocene summer temperatures cooled, local controls became more important and may explain why the fire activity at Sasquatch Lake was different from the regional biomass burning trend of western North America (Marlon et al. 2013) and nearby Lake NEL03 (Courtney Mustaphi and Pisaric In press). Important local controls include aspect (Courtney Mustaphi and Pisaric 2013), topography, disturbance interactions (Veblen et al. 1994), and soil moisture among others. Fire activity during the past 5000 years occurred at similar frequencies and was synchronous with other sites in the region that had south-facing aspects (Courtney Mustaphi and Pisaric 2013). The 
expansion of interior cedar-hemlock forests, a major climatically-mediated change in vegetation composition around $4400 \mathrm{cal}$ a BP did not significantly alter the fire frequency. The influence of local controls are expressed through the difference between the Sasquatch Lake fire record and the regional biomass burning trends (Fig. 4.7), which suggested that small-scale spatial controls remained important for most of the record since $\sim 6000$ cal a BP. Between $2500-2000$ cal a BP, the fire frequency at Sasquatch Lake increased, as did fire activity at NEL03 and regional biomass. This suggested that broad-scale controls became more important than local controls as the dominant influence of the fire regime for a short period.

\subsection{Conclusions}

The lake sediment record of Sasquatch Lake provided a 7500-year long record of sedimentation, vegetation, and fire activity of this small watershed. Forests during the early portion of the record were dominated by Pinus and changed to Engelmann-spruce subalpine fir forests by the mid Holocene. Interior cedar-hemlock forests established throughout the lower elevations by $4400 \mathrm{cal}$ a BP and have remained to present. Fire regimes were strongly influenced by climate during the early to mid Holocene and as Holocene temperatures continued to cool local controls dominated the fire activity. Some agreement of the Sasquatch Lake fire history record with regional records suggested that broad-scale controls, likely climatically-driven, can override local factors as the dominate controls of the fire regime under certain conditions. Further details about the fire regime controls can be established by further analyzing additional Holocene-length fire, vegetation, and paleoclimatic records. 


\subsection{Acknowledgements}

We thank Eugénie Paul-Limoges and Ze'ev Gedalof for assisting in the field, and Kerry-Lynn Robillard, Sonam Drakto, Ronan M. Drysdale, Namdar Moazzami, Joss Williams, and Danielle E. Paull for assistance in the laboratory. Thanks to Phil Higuera for the use of CharAnalysis software. We also thank Joshua R. Thienpont, Emma Davis, and Sarah Quann, for commenting on earlier drafts of this manuscript. Details about infrastructure near the study site were provided by Justin Dexter and Ken Haynes (BC MoFLNRO) and Darrell Gunn (BC MoTI). This study was funded by the Natural Sciences and Engineering Research Council of Canada (NSERC) Supplemental Strategic Grant and a NSERC Discovery grant to M.F.J.P and a George A. Jeletzky Memorial Award to C.J.C.M. 


\subsection{References}

Bamber RN (1982) Sodium hexametaphosphate as an aid in benthic sample sorting. Marine Environmental Research 7, 251-255.

Bassett IJ, Crompton CW, Parmelee JA (1978) An atlas of airborne pollen grains and common fungus spores of Canada. Canada Department of Agriculture Research Branch monograph no. 18. Supply and Services Canada. (Hull, Canada).

Berger A, Loutre MF (1991) Insolation values for the climate of the last 10 million years. Quaternary Sciences Review 10, 297-317.

BC Ministry of Forests, Lands and Natural Resources Operations (2012) Provincial aerial overview of forest health. (Victoria, Canada) Available online http://www.for.gov.bc.ca/hre/bcmpb

Blott SJ, Pye K (2001) GRADISTAT: a grain size distribution and statistics package for the analysis of unconsolidated sediments. Earth Surface Processes and Landforms 26, 1237-1248.

Canadian Forest Service (2010) National Fire Database - Agency Fire Data. (Natural Resources Canada, Canadian Forest Service, Northern Forestry Centre: Edmonton, Alberta). http://cwfis.cfs.nrcan.gc.ca/en_CA/nfdb

Chase M, Bleskie C, Walker IR, Gavin DG, Hu FS (2008). Midge-inferred Holocene summer temperatures in Southeastern British Columbia, Canada. Palaeogeography, Palaeoclimatology, Palaeoecology 257, 244-259.

Courtney Mustaphi CJ, Pisaric MFJ (2013) Synchronous forest fire regimes between watersheds with similar aspect during the late Holocene, southeastern British Columbia, Canada. Journal of Biogeography 40, 1983-1996.

Courtney Mustaphi CJ, Pisaric MFJ (In press) Holocene climate-fire-vegetation interactions at a subalpine watershed in southeastern British Columbia, Canada. Quaternary Research.

Dean WE (1974) Determination of carbonate and organic matter in calcareous sediments and sedimentary rocks by loss on ignition: Comparison with other methods. Journal of Sedimentary Petrology 44, 242-248.

Dearing JA (1999) Magnetic susceptibility. In 'Environmental magnetism: a practical guide' Technical Guide No. 6. (Eds J Walden, F Oldfield, J Smith) pp. 35-62. (Quaternary Research Association: London) 
Fægri K, Iversen J (1989) Textbook of pollen analysis. (John Wiley and Sons: New York, USA).

Flannigan MD, Krawchuk MA, de Groot WJ, Wotton BM, Gowman LM (2009) Implications of changing climate for global wildland fire. International Journal of Wildland Fire 18, 186-201.

Foit FF, Gavin DG, Hu FS (2004) The tephra stratigraphy of two lakes in south-central British Columbia, Canada and its implications for mid-late Holocene volcanic activity at Glacier Peak and Mount St. Helens, Washington, USA. Canadian Journal of Earth Sciences 41, 1401-1410.

Gavin DG, Hu FS, Lertzman K, Corbett P (2006) Weak climatic control of stand-scale fire history during the late Holocene. Ecology 87, 1722-1732.

Gavin DG, Hallett DJ, Hu FS, Lertzman KP, Prichard SJ, Brown KJ, Lynch JA, Bartlein PJ, Peterson DL (2007) Forest fire and climate change in western North America: Insights from sediment charcoal records. Frontiers in Ecology and the Environment 5, 499-506.

Gavin DG, Henderson ACG, Westover KS, Fritz SC, Walker IR, Leng MJ, Hu FS (2011) Abrupt Holocene climate change and potential response to solar forcing in western Canada. Quaternary Science Reviews 30, 1243-1255.

Glew JR, Smol JP, Last WM (2001) Sediment core collection and extrusion. In 'Tracking Environmental Change Using Lake Sediments. Volume 1: Basin Analysis, Coring, and Chronological Techniques' (Eds WM Last, JP Smol) pp. 73-105. (Kluwer Academic Publishers: Dordrecht).

Hallett DJ, Hills LV (2006) Holocene vegetation dynamics, fire history, lake level and climate change in the Kootenay Valley, southeastern British Columbia, Canada. Journal of Paleolimnology 35, 351-357.

Hallett, DJ, Anderson RS (2010) Paleofire reconstruction for high-elevation forests in the Sierra Nevada, California, with implications for wildfire synchrony and climate variability in the late Holocene. Quaternary Research 73, 180-190.

Hansen BCS (1995) Conifer stomata analysis as a paleoecological tool: an example from the Hudson Bay Lowlands. Canadian Journal of Botany 73, 244-252.

Hebda RJ (1995) British Columbia vegetation and climate history with focus on 6 ka BP. Géographie Physique et Quaternaire 49, 55-79. 
Heiri O, Lotter AF, Lemcke G (2001) Loss on ignition as a method for estimating organic and carbonate content in sediments: Reproducibility and comparability of results. Journal of Paleolimnology 25, 101-110.

Higuera PE (2009) CharAnalysis 0.9: diagnostic and analytical tools for sediment-charcoal analysis. Available at: http://CharAnalysis.googlepages.com/.

Higuera PE, Brubaker LB, Anderson PM, Hu FS, Brown TA (2009) Vegetation mediated the impacts of postglacial climatic change on fire regimes in the south-central Brooks Range, Alaska. Ecological Monographs 79, 201-219.

Higuera PE, Gavin DG, Bartlein PJ, Hallett DJ (2010) Peak detection in sediment-charcoal records: impacts of alternative data analysis methods on fire-history interpretations. International Journal of Wildland Fire 19, 996-1014.

Hu FS, LB Brubaker, DG Gavin, PE Higuera, JA Lynch, TS Rupp, W Tinner (2006) How climate and vegetation influence the fire regime of the Alaskan Boreal biome: The Holocene perspective. Mitigation and Adaptation Strategies for Global Change 11, 829-846.

Jungen, J.R. (1980) Soil resources of the Nelson map area (82F). British Columbia Soil Survey. Province of British Columbia, Ministry of Environment, Resource Analysis Branch. Victoria, BC, RAB Bulletin 20, Report No. 28, 217pp + 4 maps.

Kasischke ES, Amiro BD, Barger NN, French NHF, Goetz SJ, Grosse G, Harmon ME, Hicke JA, Liu S, Masek JG (2013) Impacts of disturbance on the terrestrial carbon budget of North America. Journal of Geophysical Research - Biogeosciences 118, 303-3016.

Kelly RF, Higuera PE, Barrett CM, Hu FS (2011) A signal-to-noise-index to quantify the potential for peak detections in sediment-charcoal records. Quaternary Research 75, 11-17.

Ketcheson MV, Braumandl TF, Meidinger D, Utzig G, Demarchi DA, Wikeem BM (1991) Interior cedar-hemlock zone. In 'Ecosystems of British Columbia' (Eds D Meidinger, J Pojar). pp. 167-181. (Research Branch BC Ministry of Forests: Victoria)

Lindgren S, Lewis KJ (1997) Ecological processes in the McGregor Model Forest: Interactions with insects and pathogens. (McGregor Model Forest Association: Prince George, $\mathrm{BC})$

Little HW (1969) Nelson (west half) Kootenay and Similkameen Districts, British Columbia. Geology map 1090A. 1:253,440. (Geological Survey of Canada, Surveys and Mapping Branch) 
Long CJ, Whitlock C, Bartlein PJ, Millspaugh SH (1998) A 9000-year fire history from the Oregon Coast Range, based on a high-resolution charcoal study. Canadian Journal of Forest Research 28, 774-787.

Luckman BH, Holdsworth G, Osborn GD (1993) Neoglacial glacier fluctuations in the Canadian Rockies. Quaternary Research 39, 144-153.

Marlon JR, Bartlein PJ, Daniau A-L, Harrison SP, Maezumi SY, Power MJ, Tinner W, Vannière B (2013) Global biomass burning: a synthesis and review of Holocene paleofire records and their controls. Quaternary Science Reviews 65, 5-25.

McAndrews JH, Berti AA, Norris G (1973) Key to the Quaternary pollen and spores of the Great Lakes region. (University of Toronto Press: Toronto)

Moore PD, Webb JA. 1978. An illustrated guide to pollen analysis. (Hodder and Stroughton, London)

Moritz MA, Morais ME, Summerell LA, Carlson JM, Doyle J (2005) Wildfires, complexity, and highly optimized tolerance. Proceedings of the National Academy of Science of the USA 102, 17912-17917.

Nesbitt JH (2010) Quantifying Forest Fire Variability Using Tree Rings Nelson, British Columbia 1700-Present. MSc. Thesis. (University of British Columbia, Vancouver)

Pollack J, Quesnel H, Hauk C, MacLean H (1997) A quantitative evaluation of natural age class distributions and stand replacement intervals in the Nelson Forest Region. Technical Report TR015 Forest Sciences, Nelson Forest Region. (British Columbia Ministry of Forests: Nelson)

Reimer PJ, Baillie MGL, Bard E, Bayliss A, Beck JW, Blackwell PG, Bronk Ramsey C, Buck CE, Burr GS, Edwards RL, Friedrich M, Grootes PM, Guilderson TP, Hajdas I, Heaton TJ, Hogg AG, Hughen KA, Kaiser KF, Kromer B, McCormac FG, Manning SW, Reimer RW, Richards DA, Southon JR, Talamo S, Turney CSM, van der Plicht J, Weyhenmeyer CE (2009) IntCal09 and Marine09 radiocarbon age calibration curves, 0-50,000 years cal BP. Radiocarbon 51, 1111-1150.

Rosenberg SM, IR Walker, RW Mathewes (2003) Postglacial spread of hemlock (Tsuga) and vegetation history in Mount Revelstoke National Park, British Columbia, Canada. Canadian Journal of Botany 81, 139-151. 
Spracklen DV, Mickley LJ, Logan JA, Hudman RC, Yevich R, Flannigan MD, Westerling AL (2009) Impacts of climate change from 2000 to 2050 on wildfire activity and carbonaceous aerosol concentrations in the western United States. Journal of Geophysical Research 114, D20301.

Steventon JD (1997) Historic disturbance rates for interior biogeoclimatic subzones of the Prince Rupert Forest Region. Extension Note No. 26. Forest Sciences, Prince Rupert Forest Region. (BC Forest Service: Smithers, BC)

Stockmarr RJ (1971) Tablets with spores used in absolute pollen analysis. Pollen Spores 13, 615621.

Sweeney CA (2004) A key for the identification of stomata of the native conifers of Scandinavia. Review of Palaeobotany and Palynology 128, 281-290.

Tymstra C, Flannigan MD, Armitage OB, Logan K (2007) Impact of climate change on area burned in Alberta's boreal forest. International Journal of Wildland Fire 16, 153-160.

Veblen TT, Hadley KS, Nel EM, Kitzberger T, Reid M, Villalba R (1994) Disturbance regime and disturbance interactions in a Rocky Mountain subalpine forest. Journal of Ecology 82, 125-135.

Wang T, Hamann A, Spittlehouse D, Murdock TN (2012) Climate WNA - High-Resolution Spatial Climate Data for Western North America. Journal of Applied Meteorology and Climatology 61, 16-29.

Westerling AL, Hidalgo HG, Cayan DR, Swetnam TW (2006) Warming and earlier spring increase western U.S. forest wildfire activity. Science 313, 940-943.

Wheeler JO, McFeely P (1991) Tectonic assemblage map of the Canadian Cordillera and adjacent parts of the United States of America. Map 1712A. 1:2,000,000. (Geological Survey of Canada, Surveys and Mapping Branch)

Whitlock C, Shafer SL, Marlon J (2003) The role of climate and vegetation change in shaping past and future fire regimes in the northwestern US and the implications for ecosystem management. Forest Ecology and Management 178, 5-21.

Whitlock C, Millspaugh SH (1996) Testing the assumptions of fire history studies: an examination of modern charcoal accumulation in Yellowstone national Park, USA. The Holocene 6, 7-15 
Whitlock C, Larsen C (2001) Charcoal as a fire proxy. In 'Tracking Environmental Change Using Lake Sediments - Vol 3: Terrestrial, algal, and siliceous indicators' (Eds JP Smol, HJ Birks, WM Last). pp. 75-95. (Kluwer Academic Publishers, Dordrecht)

Wong CM, Sandmann H, Dorner B (2004) Historical variability of natural disturbances in British Columbia: a literature review. (FORREX-Forest Research Extension Partnership: Kamloops)

Wright HEJ, Mann DH, Glaser PH (1984) Piston corers for peat and lake sediments. Ecology 65, 657-659. 


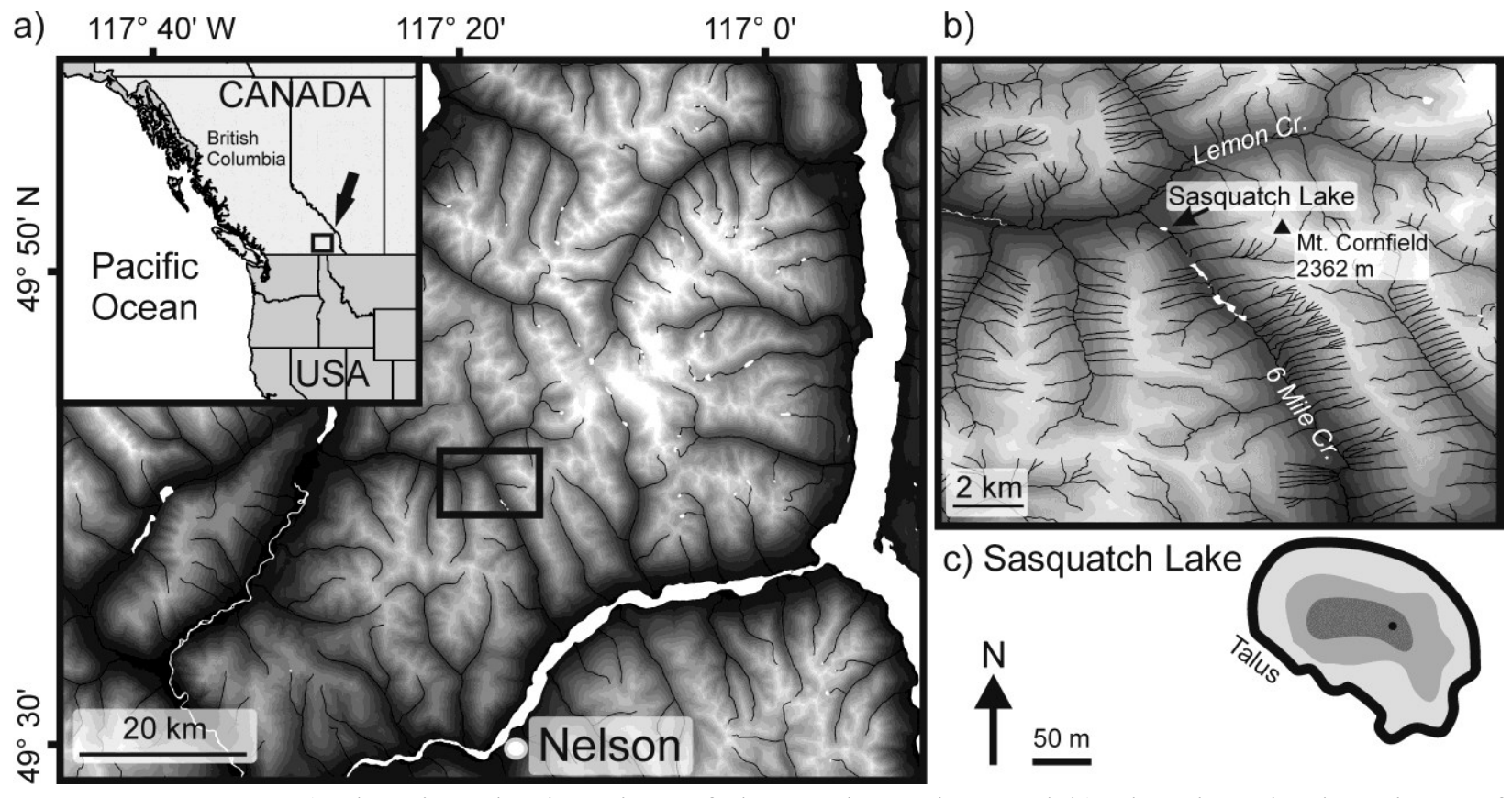

Figure 4.1: Map a) showing the location of the study region and b) showing the locations of Sasquatch Lake and surrounding watersheds. c) Sasquatch Lake bathymetry (2 $\mathrm{m}$ shaded contours) and coring location (black circle). 


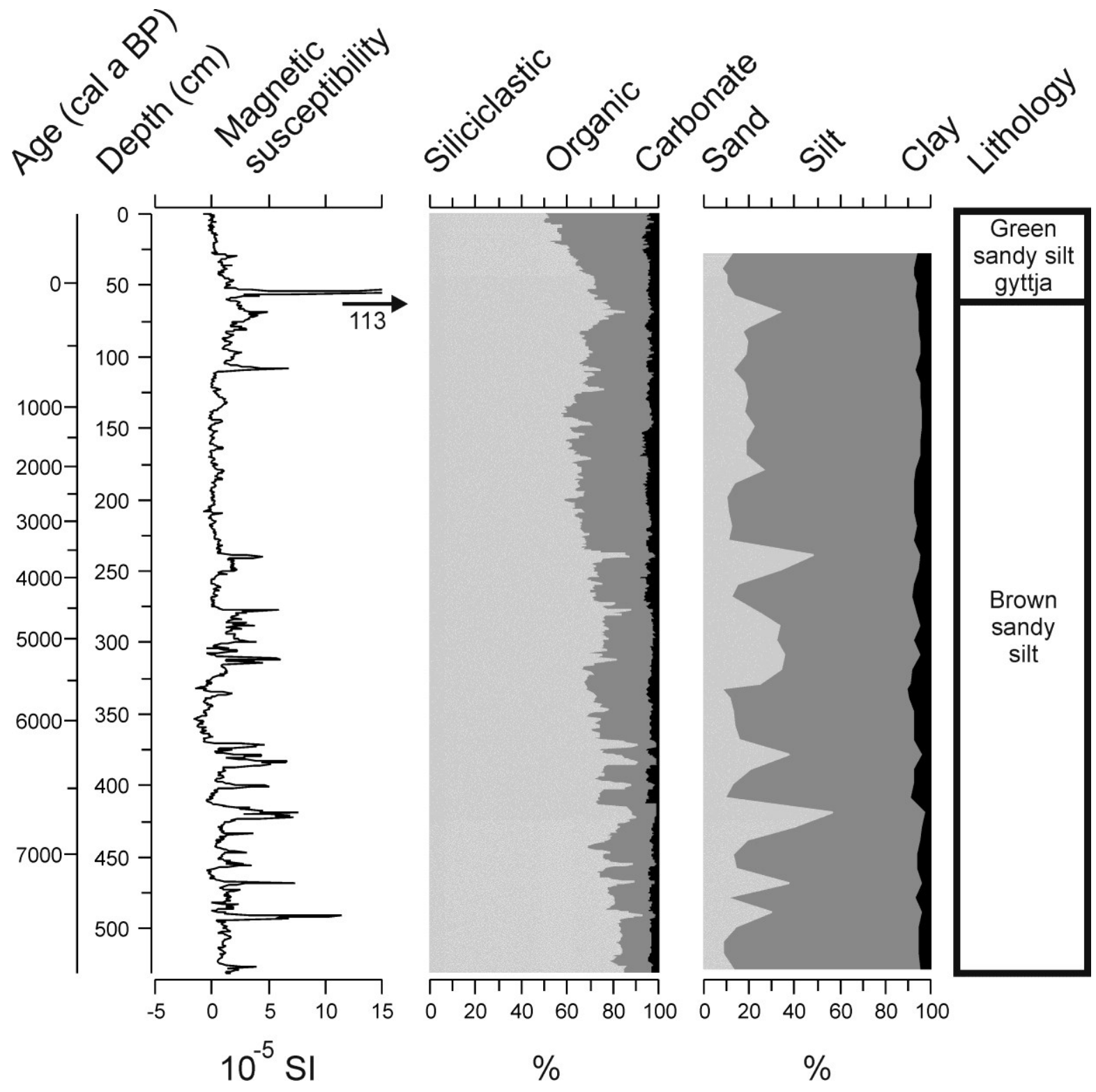

Figure 4.2: General sedimentology of the composite core from Sasquatch Lake, including magnetic susceptibility, loss on ignition, and particle size data. 


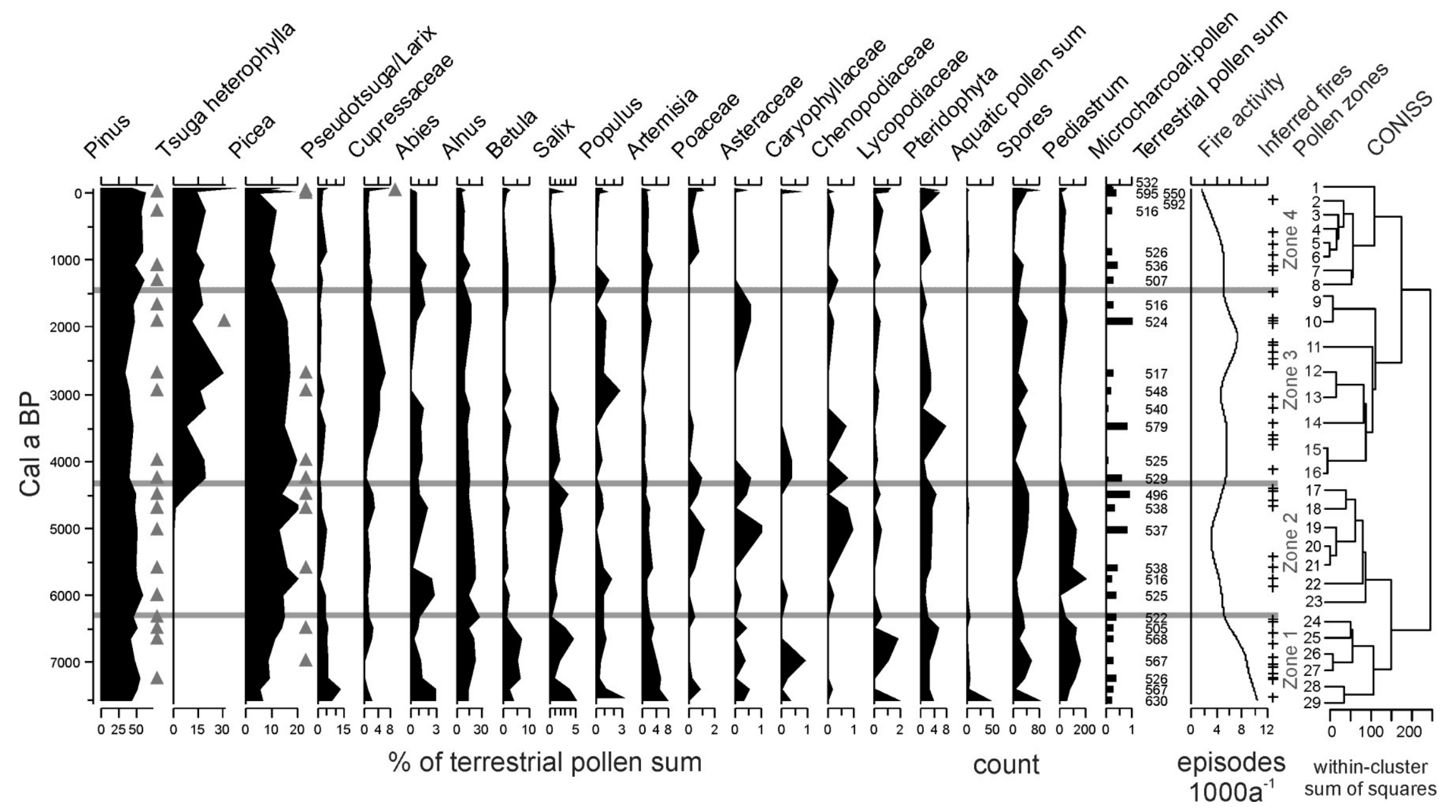

Figure 4.3: Holocene pollen spectra of the Sasquatch Lake sediment stratigraphy. Pinus to pteridophyta presented as percent relative abundance of the terrestrial pollen sum. Pediastrum and aquatic pollen are presented as counts. Stomata presence data are shown by grey triangles for the corresponding taxa. Inferred fire episodes are shown as + symbols and the smoothed fire frequency presents the long term variability of the fire regime (episodes $1000 \mathrm{a}^{-1}$; see Fig. 4.5 for more details). Pollen assemblage zones were established through CONISS analysis of the terrestrial pollen counts. 

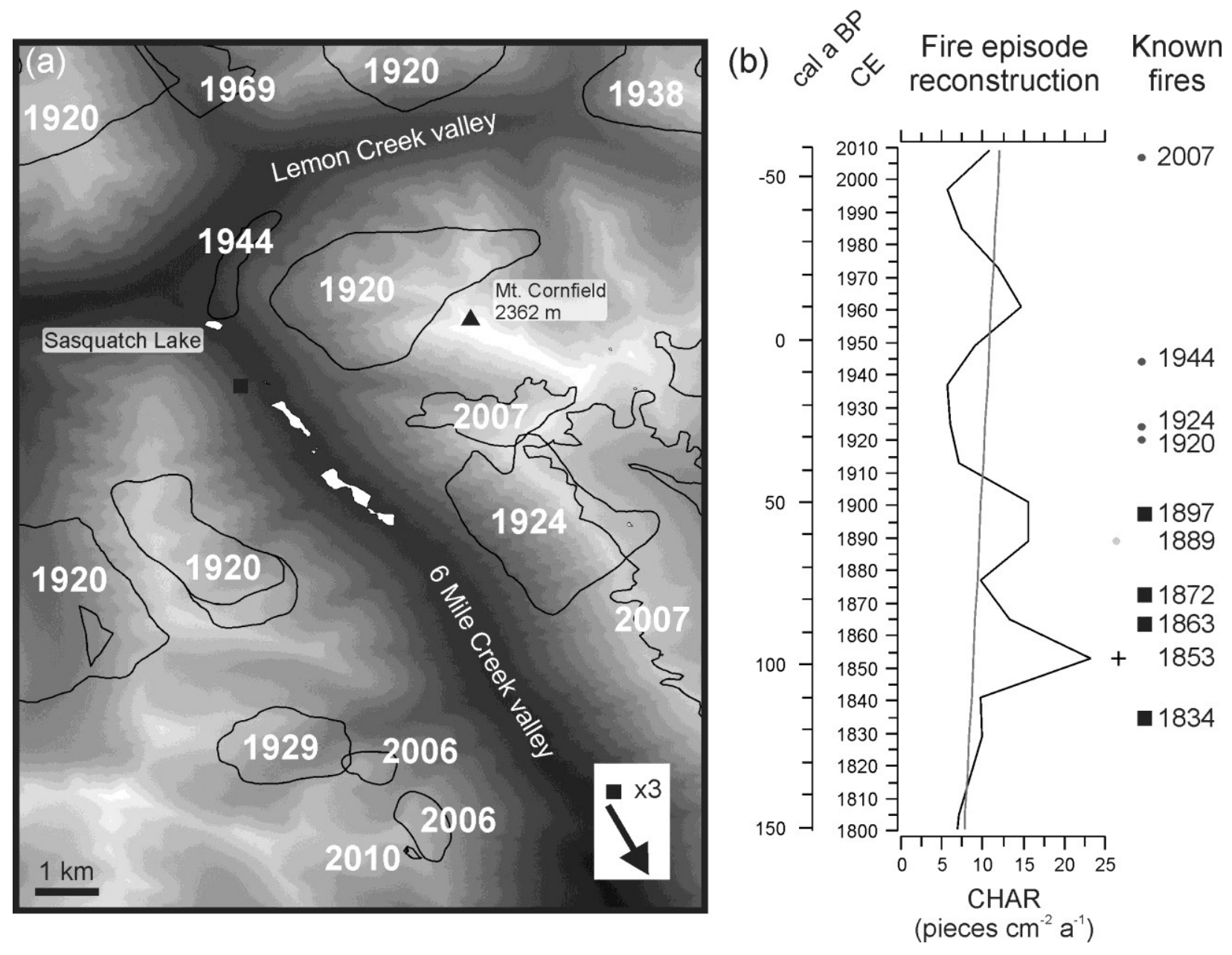

Figure 4.4: Summary of known fire information near Sasquatch Lake. (a) Locations and forest fire perimeters from the Canadian national fire database (1917-2010; Canadian Forest Service 2013) of all lightning caused fires, with the exception of one human caused fire (CE 1944; dates shown in Common Era (CE). Fire scar and dendroecological sites from Nesbitt (2010; black squares), three sites were further south in the valley. (b) CHAR and bCHAR from CE 1800-2009 and significant and insignificant peaks identified by the decomposition in CharAnalysis with known fire dates from Canadian wildfire database and dendroecological study (Nesbitt 2010). The 6 Mile Creek forest service road (FSR) was established in 1917, Lemon Creek FSR was established in 1924, and Sasquatch Lake campsite (REC\#2124) was established in 1998 (BC Ministry of Transportation and Infrastructure; BC Ministry of Forests, Lands and natural Resource Operations). 


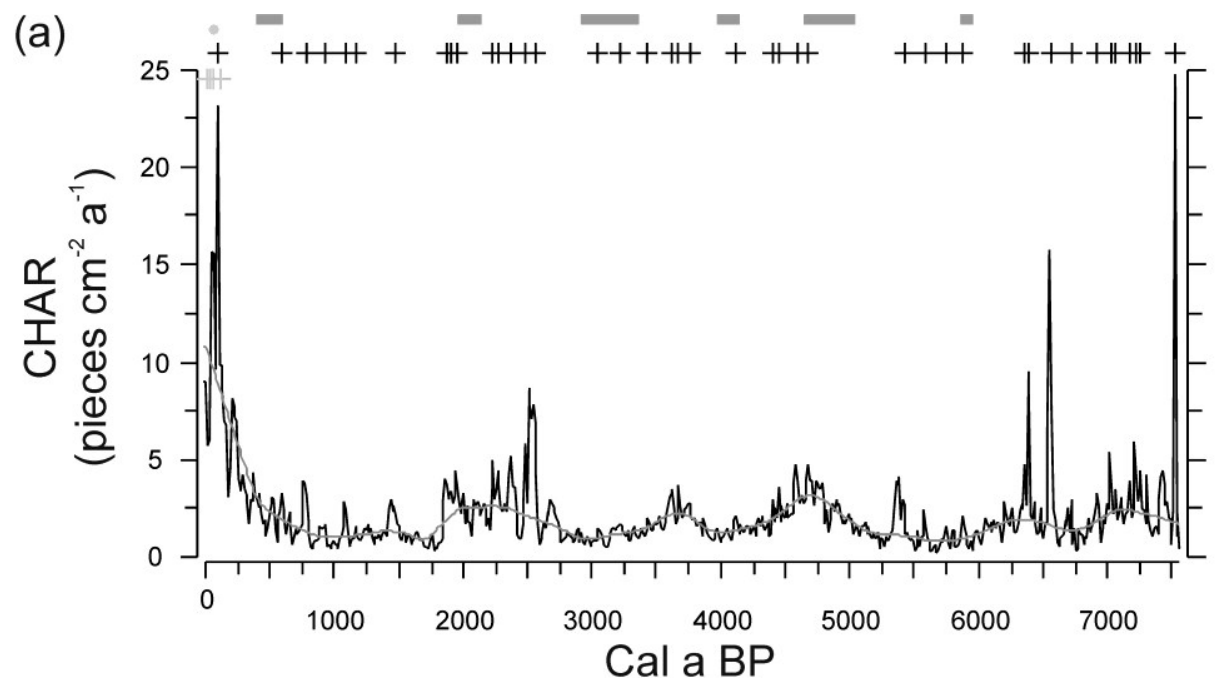

(b)

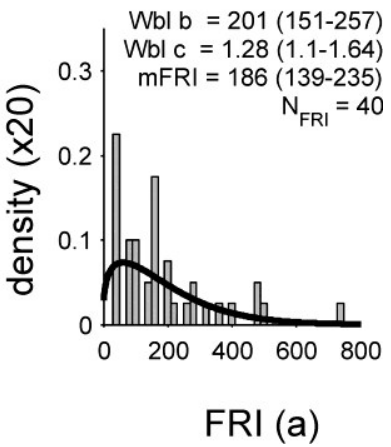

Figure 4.5: (a) Decomposition of the CHAR record (black line) and the background CHAR (bCHAR; grey line) with reconstructed fire episodes (black '+' symbols), insignificant peaks (grey dot), and known fire dates established from fire scars in the valley (Nesbitt 2010; grey '+' symbols). Dark grey bars indicate portions of the time series that fall below a signal-to-noise index threshold value of 3.0 (Kelly et al. 2011). (b) Histogram of the fire return intervals (FRIs) and Weibull modeled distribution. Median FRI was calculated from the Weibull modeled distribution and 95\% confidence intervals (in parentheses) and Weibull $b$ and $c$ parameters are shown with $95 \%$ confidence intervals. 

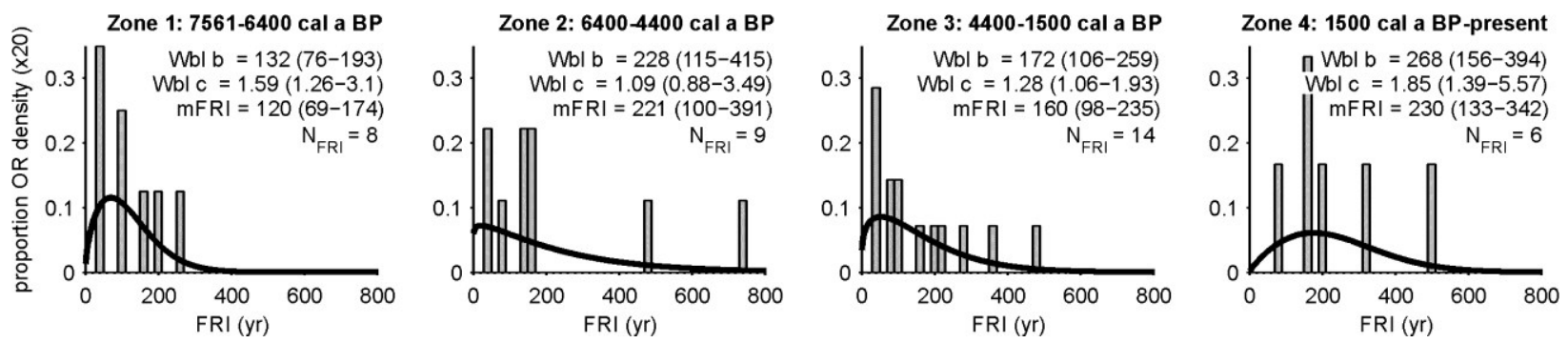

Figure 4.6: Histograms of the fire return intervals (FRIs) and Weibull modeled distributions for each pollen zone identified by CONISS. Median FRI was calculated from the Weibull modeled distribution and 95\% confidence intervals (in parentheses) and Weibull $b$ and $c$ parameters are shown with $95 \%$ confidence intervals. 


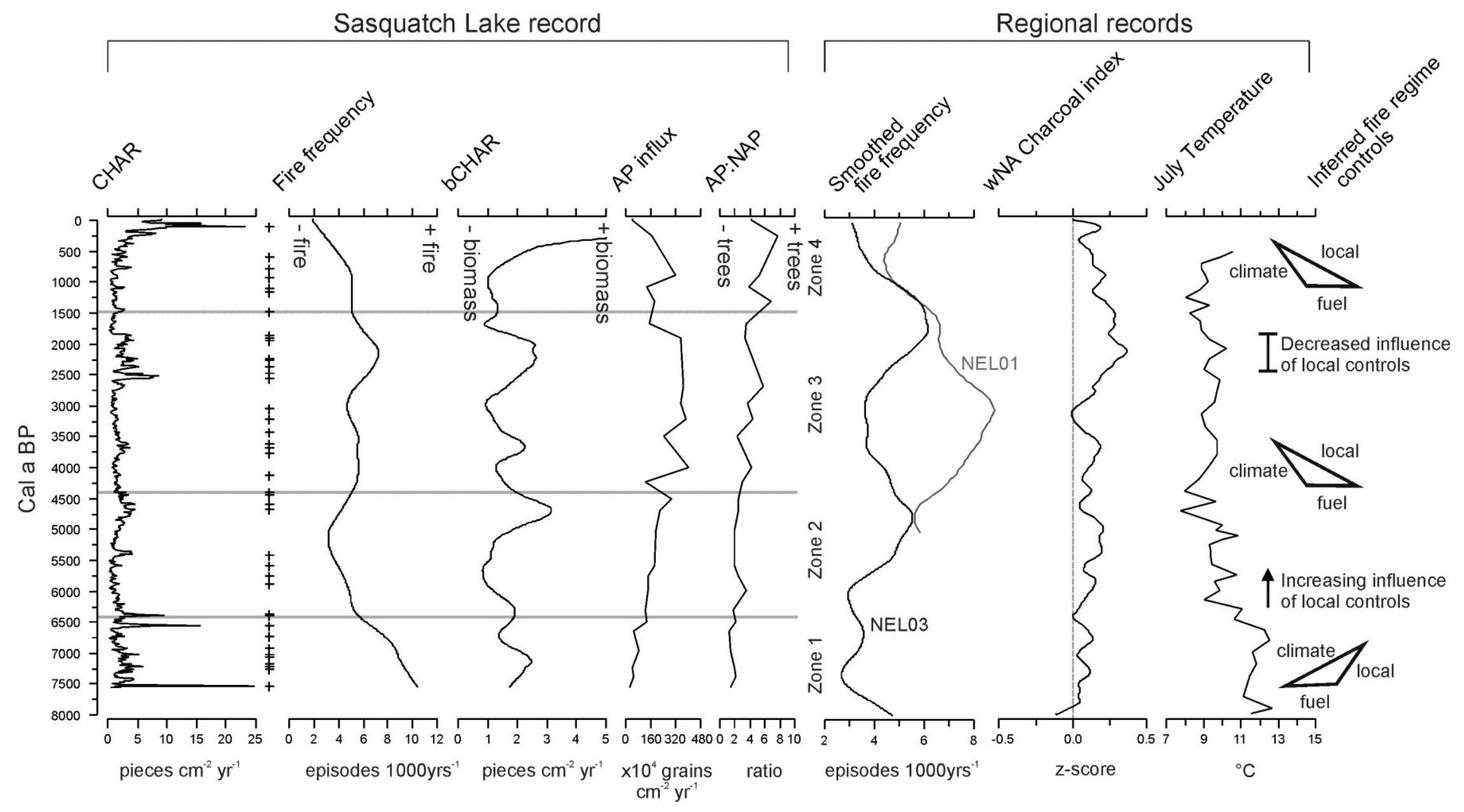

Figure 4.7: Summary of the fire record at Sasquatch Lake, including the charcoal accumulation rates (CHAR), fire episode reconstruction (+ symbols), fire frequency, and background charcoal. The arboreal pollen (AP) influx and AP to non-arboreal pollen (NAP) are shown as an additional indicator of biomass in the catchment. Horizontal grey lines delineate pollen zones identified through CONISS. Regional records of fire activity, biomass and climate are shown for comparison. The smoothed fire frequency of Lake NEL01 (Courtney Mustaphi and Pisaric 2013) and NEL03 (Courtney Mustaphi and Pisaric In press) is presented as a local fire record comparison. The z-scores of standardized charcoal index show the biomass burning trend in western North America established from 66 sites in the region (Marlon et al. 2013). A chironomid-inferred mean July temperature reconstruction shows the general Holocene temperature pattern of the southern interior of British Columbia (Chase et al. 2008). To illustrate the changes to the fire regime controls throughout the Holocene, the relative influence of regional climate, local controls (catchment landscape, topography, elevation, aspect), and fuel condition (biomass, fuel connectivity) controls of the centennial-to-millennial scale fire regime are represented and emphasized by skewing of the fire regime triangles (Moritz et al. 2005; Whitlock et al. 2010) based on the relative importance of each set of factors (Courtney Mustaphi and Pisaric In press). 


\section{A classification for macroscopic charcoal morphologies found in Holocene lacustrine sediments}

\subsection{Abstract}

Macroscopic charcoal analysis of lake sediment records is widely used to reconstruct forest fire histories. Development of fire histories often relies on a tally of total charcoal per sediment volume analysed; however, recent studies have shown that additional paleoecological information can be collected by classifying the macroscopic charcoal morphology. The shape and diagnostic features of deposited charcoal yields information about fuel sources, fire variables, and aids in identifying secondary charcoal deposits and calibrating sediment records with known historical fires. This reduces noise in the proxy-fire signals and enhances paleoecological inferences. Furthermore, quantified charcoal morphology distribution studies at multiple sites across a landscape could provide detailed information about specific historical fire events that would not be available if charcoal concentration was the only data available.

Here we present a classification of 27 macroscopic charcoal morphologies observed in the Holocene-aged sediments of seven lake sites located in mixed-conifer boreal forests of southeastern British Columbia, Canada. The morphology classification presented here was developed following the observation of $>100,000$ macroscopic $(>150 \mu \mathrm{m})$ charcoal fragments; although, this paper focuses on the presentation of the morphological classes established, their identification, and potential fuel sources if they are known. The results from the quantification of charcoal in the sediment records are not presented here. This classification system builds on other morphological classifications that have been previously identified, but is more inclusive of the morphological variability observed and is flexible to modification for use when applied to other study settings. Morphological data can be collected quickly during charcoal counts and requires no additional material or apparatus. Future work should focus on quantifying charcoal morphologies at multiple sites with known fires to assess the usefulness of obtaining large morphological and anthracological datasets, and to broaden the system to other biomes, such as mixed and hardwood forests, grasslands, peat, heathlands, and tundra.

Key words: anthracology; charcoal; fire history; lake sediments; morphology; morphotypes; paleobotany; paleoecology; Quaternary; wildfire 


\subsection{Introduction}

Sedimentary charcoal analysis is an established paleoenvironmental research method that investigates natural wildfire and human-induced fire events across many temporal scales (Conedera et al., 2009; Scott, 2010; Scott and Damblon, 2010). These studies are critical to understand past climate-fire-vegetation interactions, landscape-scale ecosystem evolution, human-environment interactions, and for modeling future fire risk to inform land management policy and decision making (Gavin et al., 2007; Hessl, 2011). Proxies for fire occurrence, such as charcoal remains or polycyclic aromatic hydrocarbons, are preserved in sedimentary environments (Conedera et al., 2009) and can be used to reconstruct fire histories for a defined spatial scale. Charcoal is produced during wildfires through the incomplete burning of biomass fuels that is then transported and accumulates in depositional environments (Whitlock and Larsen, 2001). Deposited macroscopic charcoal $(>125 \mu \mathrm{m})$ in lake sediments tends to have a source area of $<500 \mathrm{~m}$ (Lynch et al., 2002); however, during some intense fires with very strong convection, this charcoal may travel greater distances before deposition (Pisaric, 2002; Tinner et al., 2006). This makes macroscopic charcoal analysis a powerful tool for reconstructing fire histories within lake watersheds.

Macroscopic charcoal analysis has multiple benefits as a method for reconstructing fire histories: charcoal is identified using simple and well established diagnostic properties (e.g. lustre, colour, cleavage, streak, nonmagnetic), identification is normally not time intensive, and the per sample cost is low. Methodological overviews are available in the literature that discuss the entire fire history reconstruction process, from site selection and data acquisition (Clark, 1988; Whitlock and Millspaugh, 1996; Whitlock and Larsen, 2001; Conedera et al., 2009; Mooney and Tinner, 2011), to data processing, and statistical detection and calibration of 
historical wildfire events (Gavin et al., 2006; Higuera, 2009; Higuera et al., 2009; 2010; 2011; Kelly et al., 2011).

Many studies focus on tallying charcoal pieces per sediment volume (charcoal concentration) or measuring charcoal area by sediment volume, and then converting concentration values into charcoal accumulation rates (CHAR; charcoal pieces $\left.\mathrm{cm}^{-2} \mathrm{yr}^{-1}\right)$. CHAR data are then decomposed into the variable background charcoal accumulation rate and the peak component that represents a paleofire event (e.g. Gavin et al., 2006; Hallett and Hills, 2006; Higuera et al., 2009). Other studies have pursued morphological measurements, such as quantifying charcoal length and width to begin to discern potential fuel sources such as grasses, wood, or leaves (Umbanhowar and McGrath, 1998), and have shown that morphological data adds more detail to paleoecological interpretations (Jensen et al., 2007). Macroscopic charcoal analysis has been furthered by studies of charcoal morphology that has provided additional information about fuel sources involved during past fire events and how vegetation-fire interactions have varied through time (Enache and Cumming, 2006; 2007; 2009; Moos and Cumming, 2012; Walsh et al., 2008; 2010a; 2010b). Morphological data, collected from multiple sites in adjacent watersheds, has the potential to be useful in the reconstruction of fire severity, location, or extent, adding more information than total charcoal data alone (Higuera et al., 2011). Sedimentary charcoal morphology data would also present more information for calibrating known fire dates with those observed in the sediment record. Because of the differential fragility of certain charcoal morphotypes, morphology data may also be indicative of false positive local proxy-fire signals caused by secondary charcoal deposition in a sediment record (Enache and Cumming, 2007; Conedera et al., 2009; Moos and Cumming, 2012). Classification of charcoal morphology based on published keys (Enache and Cumming, 2006) can be done quickly during 
charcoal counting and does not require time consuming linear measurements. Morphology is an underused proxy tool for investigating vegetation disturbance dynamics and history (Conedera et al., 2009).

Previously published morphological classification schemes are available for montane boreal forests (Enache and Cumming, 2006; 2007; 2009), mixed forests, and grassland sites (Jensen et al., 2007; Walsh et al., 2008; 2010a; 2010b). Source materials have been deduced from observation and experimentation by burning plant parts in the laboratory (Jensen et al., 2007). Walsh et al. (2010a; 2010b) also demonstrated that classifying charcoal as woody, herbaceous, or lattice-shaped, benefits interpretations of past vegetation and fire regime variability during the Holocene by yielding quantitative data for interpreting successional changes to the local vegetation.

This paper focuses on the use of macroscopic charcoal analysis on lacustrine sediments for reconstructing local (watershed-scale) Holocene fire histories, specifically those of subalpine and valley mixed-conifer forests, and describes a charcoal morphology classification that can be applied to macroscopic charcoal remains found in any sedimentary environment. Here we present a morphological classification for sedimentary charcoal in the size range of $150 \mu \mathrm{m}$ to approximately $2 \mathrm{~cm}$.

The classification system presented here is designed to: 1) be inclusive of the morphological variability of macroscopic charcoal pieces preserved in lake sediments from sites within mixed-conifer forests and to provide more paleoecological information for interpretation; 2) be used for multivariate data analyses through morphology abundance distributions to yield paleoecological information that cannot be extracted from total charcoal concentration data, especially if multiple extralocal-to-local sites are systematically analyzed and additional fire 
record calibration steps are undertaken; 3) be adaptable and flexible when applied to new study sites through the addition of new classes and/or subclasses with minimal disruption to the quantitative utility of inter-site comparison. 4) Will have some translation into previous classification systems, such as Enache and Cumming (2006; 2007) or Walsh et al. (2010a) because these morphologies are included or expanded upon here.

\subsection{Study region}

The morphologies described here have been observed during macroscopic charcoal analysis of seven lake sites in southeastern British Columbia, Canada (Figure 5.1a and 5.1b). These sites are surrounded by dense Engelmann spruce-subalpine fir (Figure 1c and 1e), interior cedar-hemlock (Figure 5.1d), ponderosa pine (Figure 5.1f), and interior Douglas-fir (Figure 5.1g) forests, representing four major biogeoclimatic zones of British Columbia (Pojar et al., 1987; Meidinger and Pojar, 1991). Subcanopies are vegetated by herbaceous plants and shade-tolerant trees and shrubs (Parish et al., 1996) and ponderosa pine forests have significant grass cover between standing trees. Table 5.1 shows general vegetation information for each study site.

The lake sites are located in the Columbia Mountains and the leeward side of the Purcell Mountains and Rocky Mountain Trench (Figure 5.1). Mean annual temperature is slightly warmer in the west $\left(8.4^{\circ} \mathrm{C}\right.$; City of Castlegar) than the east $\left(5.7^{\circ} \mathrm{C}\right.$; City of Cranbrook; Climate Normals 1971-2000; Environment Canada). The difference is largely due to the higher elevations of the Purcell Mountains in the east. Total annual precipitation in the West Kootenays (755 mm) is nearly double that of the East Kootenay region $(383 \mathrm{~mm})$. Summer is punctuated by westerly, episodic, convective thunderstorms (Jungen, 1980) and the fire season is concentrated during June through September (Schroeder and Buck, 1970); although fires can occur in southeastern 
British Columbia as early as April and as late as October (Canadian Wildland Fire Information System [CWFIS], 1959-1999). The differing climes of each region support characteristically differing biogeoclimatic zones (Pojar et al., 1987). Low- to mid-elevation sites in the west have fire return intervals of 0-200 years and are classified as having mixed-severity forest fire regimes, while higher elevation sites experience stand-replacing high-severity fires (Blackwell et al., 2003; Nesbitt, 2010). Low-elevation sites in the east experience low-to-moderate severity fire regimes with fire return intervals of 0-35 years (Blackwell et al., 2003).

The lakes sampled for this study are small $(<1-8$ ha) with little or no inflows and outflows and are shallow $\left(Z_{\max }=0.85-9.0 \mathrm{~m}\right)$ with simple basin morphometries. A list of sites is presented in Table 5.1 and each is shown in Figure 5.1. Presently, the sites have continuous forests surrounding the lakes. NEL01 has a small emergent macrophyte bed at the southeast edge, and CRN4 has a broad and continuous bed of sedges (Carex) encircling the lake.

\subsection{Methods}

During the summers of 2008-2010, Holocene-aged lake sediments from seven lakes were collected by coring the deep, central basins of each lake. The coring, geochronology, and charcoal analysis methods are described in detail in Courtney Mustaphi and Pisaric (2013). A continuous sediment record with an intact sediment-water interface was obtained through a combination of gravity coring and piston coring (Wright et al., 1984; Glew et al., 2001). Core sections were correlated with one another using tephra layers where available, organic content and magnetic susceptibility values, and geochronological methods. A homogeneous $1 \mathrm{~cm}^{3}$ subsample was removed at each 0.25 or $0.5 \mathrm{~cm}$ interval down each core stratigraphy, soaked in a metaphosphate solution (Bamber, 1982) for at least 24 hours, and then wet sieved through a 150 
$\mu \mathrm{m}$ mesh. The remaining material was transferred to a Petri dish and examined under a Nikon SMZ800 stereoscope at 6-40x magnification. A survey of the observed charcoal morphologies was catalogued while macroscopic charcoal was tallied.

\subsection{Morphology classifications}

Morphology and morphological features were observed from >100,000 Holocene-aged sedimentary charcoal fragments and were classified into seven broad categories, which included a total of 27 subclasses of charcoal morphologies. These classifications were based on charcoal fragment shape, structure, and texture; some classes were previously identified in other charcoal morphology studies (Enache and Cumming, 2006; Jensen et al., 2007). A full key and description of each charcoal morphotype can be found in Appendix 1. The classification system allows for expansion or contraction depending on the goal of future studies and the charred

remains observed. Seven charcoal morphological classes (A to G; Figures 5.2 to 5.5) with detailed diagnostic properties and probable or known fuel sources of the morphotype material are presented in Appendix 1 (note: not all sources are known).

\subsubsection{Type A: polygonal charcoal}

Charcoal with an overall 2-dimensional polygon shape have been commonly observed in many studies (Enache and Cumming 2006; 2007; 2009; Moos and Cumming, 2011) and are likely the product of foliage burning and from wood that was then rounded during transport. Subclasses were derived based on the presence of structures or void spaces within the polygon. 


\subsubsection{Type B: ortho-angular polygons and polyhedra (blocky shaped)}

Blocky-shaped charcoal is very common at forested sites and seems to be primarily a product of wood burning.

\subsubsection{Type C: long and complex}

Charcoal elongated in one direction but contains conspicuous features likely had specific plant source material such as leaf veins, twigs, and thin stem parts. Some of the Type C charcoal could be matched with source material collected in the field during sampling and burned in the laboratory.

\subsubsection{Type D: long and simple}

Short thin filaments are often found associated with wood-sourced charcoal due to the tendency of blocky charcoal to fragment into fibres. Burned needles can also produce longer filamentous charcoal. Thin filaments are almost hair-like in thickness and very fragile (D1), while slightly thicker charcoal (D2) can be manipulated with little breakage.

\subsubsection{Type E: spheroidal}

Charcoal that is 3-dimensional and rounded likely formed from the direct burning or subsequent condensation of burn products from liquid or resinous sources such as fossil fuels, accelerants, sap and pitch. These are macroscopic forms of the charcoal and tar particles that have black and glossy tar spherules, fusiforms, and agglomerated types, with mulberry or raspberry shapes (Franzén and Malmgren, 2012). 


\subsubsection{Type F: irregular}

Charcoal with complicated shapes, including tubes and more massive nodes are classed as irregular and have not been identified in other studies. This source material is likely herbaceous plant roots and woody root material.

\subsubsection{Type G: glassy}

Glassy charcoal is similar in appearance to amorphous obsidian and can be harder than other charcoal. The source materials are siliceous plant structures that may melt during hot fires then solidify into amorphous glass.

\subsubsection{Additional types}

Other burned and charcoalized plant parts can often maintain their morphology after burning, transport, and entombment within the sedimentary environment, and can be used for paleoecological interpretations. We encourage analysts to add new classes and subclasses as the studies demand.

\subsubsection{Defining diagnostic features}

Once charcoal morphology has been assessed by an analyst, the major features of the charcoal are then discerned. The morphology subcategories pertain to major structural and textural features observed on or within the charcoal fragment. The simplest feature is that the charcoal is solid black, with varying degrees of luster, and without any other conspicuous features. Upon magnified examination, the charcoal may have some microtexturing, such as waviness, crenulations, uniform stippling, or variability in luster across the surface. When broken by an 
analyst, the fragments remain solid black and opaque. Charcoal that is solid black and has obvious foliations and a fibrous texture exhibits luster that reflects these lineations from the surface. This charcoal often cleaves into fibrous bundles or individual elongated fragments. Elongated charcoal often appears solid black or has a charred woody texture. Another potential major feature is if the charcoal particle contains conspicuous void spaces. These can appear as a mesh or lattice in two or three dimensions that have square or rectangular void spaces, and may have secondary features, such as thick veins running through the lattice or may be extremely thin and delicate. Round void spaces can make up the majority of the surface area of the charcoal or simply be a discernable feature within the charcoal. Spheroidal and glassy charcoal may have an oily texture on the surface and can contain vesicles. The presence of clearly visible cellular structures on the surface of charcoal can also be used to distinguish morphology subtypes. Branching patterns and spurs can also be used to distinguish some morphologies. Figure 5.6 moves an analyst through identification of charcoal, to classifying the charcoal shape and then major features.

\subsection{Morphology classification process}

During active macroscopic charcoal analysis of prepared sediment samples, the material needs to be observed and manipulated under stereomicroscopy. A decision process for dealing with potential charcoal fragments is presented in Table 5.2 and the flowchart key presented in Figure 5.6 aids in categorising charcoal morphology based on the shape and features observed as an analyst manipulates the material. This key features all of the defined morphology classes and could be expanded to include additional charcoal morphologies that may be found at other study 
sites, such as charred flowers, bud scales, and cones, that could be insightful to paleoecological or anthropogenic interpretations of the charcoal records.

\subsection{Summary}

The morphotypes presented cover the full morphological variability observed within seven postglacial lake sediment archives collected from four major biogeoclimatic zones of British Columbia, Canada. These forests contain various fuel types, conditions and densities, and experience a wide range of fire regimes at decadal to multicentennial frequencies (Gavin et al., 2006; Da Silva, 2009; Nesbitt, 2010), and the charcoal produced has a wide range of discernible morphological variability (Figure 5.7); although some morphologies found in sediment records are difficult to define a single possible source (Figure 5.8).

Charcoal morphology reflects the fuel source of the deposited charcoal. Using a morphology classification that encapsulates the whole variability of charcoal morphotypes observed in a depositional environment it reduces the reliance on individual indicator-type morphologies. Interpretations based on a single or few morphotypes are limited because they do not make use of the full variability of charcoal morphotypes in a sample. By classifying and quantifying all morphotypes the entire morphology assemblage can be analysed alongside other paleoenvironmental measurements and proxies. Source materials have been deduced through detailed observation and from laboratory experimental burning (Jensen et al., 2007) and calibration studies (Enache and Cumming, 2006). Charcoal morphology analyses have been important to the study of pre-Quaternary records (Scott, 1974; 2010) and the morphology classification scheme presented here can be applied to older sedimentary records. Analyses from multiple sites in nearby watersheds may be useful for teasing apart information on fire extent, 
location, and charcoal transportation and deposition mechanics. Such information will rely upon further detailed empirical studies of recent fires combined with observational data and calibration of that information with charcoal morphology data from sedimentary records.

\subsection{Conclusion and future direction}

Macroscopic charcoal analysis of Holocene lake sediment records is an important source of fire history and paleoecological information across local, regional, and global spatial scales, and at annual to millennial time scales (Whitlock and Larsen, 2001; Conedera et al., 2009). Studies have shown that charcoal morphology reflects the source fuels that were burned during a wildfire (Umbanhower and McGrath, 1998; Jensen et al., 2007) and are useful for paleoecological interpretations (Enache and Cumming, 2006; Walsh et al., 2010a; 2010b; Franzén and Malmgren, 2012; Moos and Cumming, 2012). The charcoal morphology key presented here can easily be applied to macroscopic charcoal studies and the classes can be expanded upon to meet the needs of a given study based on the material observed. Reconstructions could focus on a specific morphology that is calibrated to the fossil record through correlation with a defined fire variable (Enache and Cumming, 2007). Additional paleoecological information will be discerned through quantitative analysis of sedimentary charcoal morphology abundance data collected across multiple sites that are then calibrated with observational fire information and/or experimental fuel burning data. This mixed approach to reconstructing fire histories offers strong potential to advance paleoenvironmental inferences, especially when used with other paleoecological indicators of environmental change.

Charcoal morphology analysis will benefit from its application to multiple lake sediment sites and calibration with well established fire histories to examine the relationship between 
biomass burning and the deposition of macroscopic charcoal morphotypes. Notably, some effort should be given to studying multiple sites, impacted by multiple well-documented fires; quantitatively focusing on the charcoal morphologies produced, including details about where and how the charcoal is deposited across the landscape and calibration between observation data and proximal sediment archives. Experimental burning of fuels under variable moisture and density conditions to better understand the distribution of charcoal morphologies produced is also necessary. Combining this information will enrich paleofire calibrations and benefit quantitative interpretation of past events. A deeper understanding of past fire behaviour on the landscape can be achieved by integrating quantitative macroscopic charcoal with information about past known fires to discern any morphotype assemblage relationships with fire extent, severity, weather and fuel types and conditions. This is imperative to understanding future vegetation-fire responses under a variable climate and changing human land use. An improved understanding of past fire-vegetation interactions is important toward predicting future fire regime scenarios at an extra-local scale.

\subsection{Acknowledgments and funding}

This research benefitted from fruitful discussions with Emma Davis, Joelle T. Perreault, and Katherine Sigurdson. We thank Ze'ev Gedalof, Eugenie Paul-Limoges, Joelle T. Perreault, and Lori Daniels, for assisting in the field; Danielle E. Paull, Ronan M. Drysdale, Namdar Moazzami, Kerry-Lynn Robillard, and Rachel Young, for assistance in the laboratory; and Philip Courtney Mustaphi for aid with the figures. This manuscript benefitted from comments and suggestions by Jesse C. Vermaire, Trevor J. Porter, Emma Davis, Vanessa Stretch, and Danielle E. Paull. This study was funded by the Natural Sciences and Engineering Research Council of Canada (NSERC) Supplemental Strategic Grant program and a NSERC Discovery grant to M.F.J.P and a Jeletzky Memorial award to C.J.C.M. 


\subsection{References}

Bamber RN (1982) Sodium hexametaphosphate as an aid in benthic sample sorting. Marine Environmental Research 7: 251-255.

Blackwell BA, Gray RW, Green RN, Feigl F, Berry T, Ohlson D, and Hawkes B (2003) Developing a coarse scale approach to the assessment of forest fuel conditions in southern British Columbia. Report submitted to Forest Innovation Investment. Victoria, BC, Canada.

Clark JS (1988) Particle motion and the theory of charcoal analysis: source area, transport, deposition and sampling. Quaternary Research 30: 67-80.

Conedera M, Tinner W, Neff C, Meurer M, Dickens AF, and Krebs P (2009) Reconstructing past fire regimes: methods, applications, and relevance to fire management and conservation. Quaternary Science Reviews 28: 555-576

Courtney Mustaphi CJ, Pisaric MFJ (2013) Synchronous forest fire regimes between watersheds with similar aspect during the late Holocene, southeastern British Columbia, Canada. Journal of Biogeography 40: 1983-1996.

Da Silva E (2009) Wildfire history and its relationship with top-down and bottom-up controls in the Joseph and Gold Creek watersheds, Kootenay Mountains, British Columbia. Masters thesis, University of Guelph, Canada. 138p.

Enache MD and Cumming BF (2006) Tracking recorded fires using charcoal morphology from the sedimentary sequence of Prosser Lake, British Columbia (Canada). Quaternary Research 65: 282-292.

Enache MD and Cumming BF (2007) Charcoal morphotypes in lake sediments from British Columbia (Canada): an assessment of their utility for the reconstruction of past fire and precipitation. Journal of Paleolimnology 38: 347-363.

Enache MD and Cumming BF (2009) Extreme fires under warmer and drier conditions inferred from sedimentary charcoal morphotypes from Opatcho Lake, central British Columbia, Canada. Holocene 19: 835-846.

Franzén LG and Malmgren BA (2012) Microscopic charcoal and tar (CHAT) particles in peat: a 6500-year record of palaeo-fires in southern Sweden. Mires and Peat 10: Article 01: 1-25. 
Gavin DG, Hallett DJ, Hu FS, Lertzman KP, Prichard SJ, Brown KJ, Lynch JA, Bartlein PJ, and Peterson DL (2007) Forest fire and climate change in western North America: insights from sediment charcoal records. Frontiers in Ecology and the Environment 5: 499-506.

Glew JR, Smol JP, and Last WM (2001) Sediment core collection and extrusion. In: Last WM and Smol JP (Eds.) Tracking Environmental Change Using Lake Sediments. Volume 1: Basin Analysis, Coring, and Chronological Techniques. Dordrecht: Kluwer Academic Publishers, 73105.

Hallett DJ and Hills LV (2006) Holocene vegetation dynamics, fire history, lake level and climate change in the Kootenay Valley, southeastern British Columbia, Canada. Journal of Paleolimnology 35: 351-357.

Hessl AE (2011) Pathways for climate change effects on fire: Models, data, and uncertainties. Progress in Physical Geography 35: 393-407.

Higuera PE (2009) CharAnalysis 0.9: diagnostic and analytical tools for sediment charcoal analysis. Available at: http://CharAnalysis.googlepages.com/.

Higuera PE, Brubaker LB, Anderson PM, Hu FS, Brown TA (2009) Vegetation mediated the impacts of postglacial climatic change on fire regimes in the south-central Brooks Range, Alaska. Ecological Monographs 79: 201-219.

Higuera PE, Gavin DG, Bartlein PJ, and Hallett DJ (2010) Peak detection in sediment-charcoal records: impacts of alternative data analysis methods on fire-history interpretations. International Journal of Wildland Fire 19: 996-1014.

Higuera PE, Whitlock C, Gage JA (2011) Linking tree-ring and sediment-charcoal records to reconstruct fire occurrence and area burned in subalpine forests of Yellowstone National Park, USA. Holocene 21: 327-341.

Jensen K, Lynch EA, Calcote R, and Hotchkiss SC (2007) Interpretation of charcoal morphotypes in sediments from Ferry Lake, Wisconsin, USA: do different plant fuel sources produce distinctive charcoal morphotypes? Holocene 17: 907-915.

Kelly RF, Higuera PE, Barrett CM, Hu FS (2011) A signal-to-noise-index to quantify the potential for peak detections in sediment-charcoal records. Quaternary Research 75:11-17.

Meidinger DV and Pojar J (eds.) (1991) Ecosystems of British Columbia. Special Report Series (SRS) 6. Victoria, BC: BC Ministry of Forests. 
Mooney SD and Tinner W (2011) The analysis of charcoal in peat and organic sediments. Mires and Peat 7: Article 9: 1-18.

Moos MT and Cumming BF (2012) Climate-fire interactions during the Holocene: a test of the utility of charcoal morphotypes in a sediment core from the boreal region of north-western Ontario (Canada). International Journal of Wildland Fire 21: 640-652.

Nesbitt, J. 2010. Quantifying Forest Fire Variability Using Tree Rings, Nelson, British Columbia, 1700-Present. Masters thesis, University of British Columbia, Canada.

Parish R, Coupé R, and Lloyd D (1996) Plants of southern interior British Columbia. Vancouver, BC: Lone Pine. 463pp.

Pisaric MFJ (2002) Long-distance transport of terrestrial plant material by convection resulting from forest fires. Journal of Paleolimnology 28: 349-354.

Pojar J, Klinka K, and Meidinger DV (1987) Biogeoclimatic classification in British Columbia. Forest Ecology and Management 22: 119-154.

Scott AC (1974) The earliest conifer. Nature 251: 707-708.

Scott AC (2010) Charcoal recognition, taphonomy and uses in palaeoenvironmental analysis. Palaeogeography, Palaeoclimatology, Palaeoecology 291: 11-39.

Scott AC and Damblon F (2010) Charcoal: Taphonomy and significance in geology, botany and archaeology. Palaeogeography, Palaeoclimatology, Palaeoecology 291:1-10

Tinner, W, Hofstetter S, Zeugin F, Conedera M, Wohlgemuth T, Zimmermann L, and Zweifel R (2006) Long-distance transport of macroscopic charcoal by an intensive crown fire in the Swiss Alps - implications for fire history reconstruction. Holocene 16: 287-292.

Umbanhowar CE and McGrath MJ (1998) Experimental production and analysis of microscopic charcoal from wood, leaves and grasses. Holocene 8: 341-346.

Walsh MK, Whitlock C, Bartlein PJ (2008) A 14,300-year-long record of fire-vegetationclimate linkages at Battle Ground Lake, southwestern Washington. Quaternary Research 70: 251-264. 
Walsh, MK, Pearl CA, Whitlock C, Bartlein PJ, and Worona MA (2010a) An 11 000-year-long record of fire and vegetation history at Beaver Lake, Oregon, central Willamette Valley.

Quaternary Science Reviews 29: 1093-1106.

Walsh, MK, Whitlock C, and Bartlein PJ (2010b) 1200 years of fire and vegetation history in the Willamette Valley, Oregon and Washington, reconstructed using high-resolution macroscopic charcoal and pollen analysis. Palaeogeography, Palaeoclimatology, Palaeoecology 297: 273289.

Whitlock C and Larsen C (2001) Charcoal as a fire proxy. In: Smol JP, Birks HJ, and Last WM (eds.) Tracking Environmental Change Using Lake Sediments - Vol 3: Terrestrial, algal, and siliceous indicators. Dordrecht: Kluwer Academic Publishers, 75-95.

Whitlock C and Millspaugh SH (1996) Testing the assumptions of fire history studies: an examination of modern charcoal accumulation in Yellowstone National Park, USA. Holocene 6: 7-15. 
Table 5.1: Vegetation cover at each lake site where sediment cores were recovered for macroscopic charcoal analysis and morphotypes established.

\begin{tabular}{|c|c|c|c|}
\hline Site & Dominant & Common & Uncommon \\
\hline NEL01 & $\begin{array}{l}\text { Engelmann spruce } \\
\text { (Picea engelmannii) } \\
\text { subalpine fir (Abies } \\
\text { lasiocarpa) }\end{array}$ & $\begin{array}{l}\text { lodgepole pine (Pinus } \\
\text { contorta) } \\
\text { western Larch (Larix } \\
\text { occidentalis) }\end{array}$ & $\begin{array}{l}\text { western hemlock (Tsuga } \\
\text { occidentalis) } \\
\text { western redcedar (Thuja } \\
\text { plicata) } \\
\text { mountain ash (Sorbus) }\end{array}$ \\
\hline NEL02 & $\begin{array}{l}\text { western hemlock (Tsuga } \\
\text { occidentalis) } \\
\text { western redcedar (Thuja } \\
\text { plicata) }\end{array}$ & $\begin{array}{l}\text { Engelmann spruce } \\
\text { (Picea engelmannii) } \\
\text { subalpine fir (Abies } \\
\text { lasiocarpa) upslope }\end{array}$ & grass (Poaceae) \\
\hline NEL03 & $\begin{array}{l}\text { Engelmann spruce } \\
\text { (Picea engelmannii) } \\
\text { subalpine larch (Larix } \\
\text { lyallii) } \\
\text { subalpine fir (Abies } \\
\text { lasiocarpa) }\end{array}$ & & $\begin{array}{l}\text { whitebark pine (Pinus } \\
\text { albicaulis) } \\
\text { various shrubs } \\
\text { sedges (Cyperaceae) }\end{array}$ \\
\hline CRN1 & $\begin{array}{l}\text { ponderosa pine (Pinus } \\
\text { ponderosa), Douglas-fir } \\
(\text { Pseudotsuga menziesii) }\end{array}$ & & \\
\hline CRN2 & $\begin{array}{l}\text { ponderosa pine (Pinus } \\
\text { ponderosa) }\end{array}$ & grass (Poaceae) & various shrubs \\
\hline CRN3 & $\begin{array}{l}\text { ponderosa pine (Pinus } \\
\text { ponderosa), Douglas-fir } \\
\text { (Pseudotsuga menziesii) }\end{array}$ & & \\
\hline CRN4 & $\begin{array}{l}\text { Douglas-fir } \\
\text { (Pseudotsuga menziesii) }\end{array}$ & $\begin{array}{l}\text { grass (Poaceae) } \\
\text { sedges (Cyperaceae) }\end{array}$ & $\begin{array}{l}\text { black cottonwood } \\
\text { (Populus trichocarpa) } \\
\text { various shrubs }\end{array}$ \\
\hline
\end{tabular}


Table 5.2: Decision process using diagnostic properties easily observed under stereomicroscopy of deflocculated and sieved lake sediments for macroscopic charcoal analysis. This decision process allows a user do identify charcoal and determine a morphotype. Note that some properties of charcoal are shared by sample contaminants and other naturally-occurring organic and inorganic materials. Listed are some common features encountered. Fragments of freshly fractured charcoal are almost always jet black and morphology classification should be based on the original object.

\begin{tabular}{|l|l|l|}
\hline Property & Charcoal & Organic, mineral, or clastic \\
\hline Chemical stability & Inert, stable & $\begin{array}{l}\text { May react with acids, oxidizers, } \\
\text { bleach }\end{array}$ \\
\hline Colour & Black & Various colours \\
\hline Lustre & Bright, shiny, dull & Various colours \\
\hline Fracture & $\begin{array}{l}\text { Splintery, powdery, dry woody } \\
\text { feel }\end{array}$ & $\begin{array}{l}\text { Various; tearing, flexible, } \\
\text { supple, energetic }\end{array}$ \\
\hline $\begin{array}{l}\text { Colour of } \\
\text { Fragments }\end{array}$ & Black, opaque & $\begin{array}{l}\text { Any; brown, green, orange, } \\
\text { yellow; translucent }\end{array}$ \\
\hline Conclusion & Count and classify morphology & Not charcoal \\
\hline
\end{tabular}




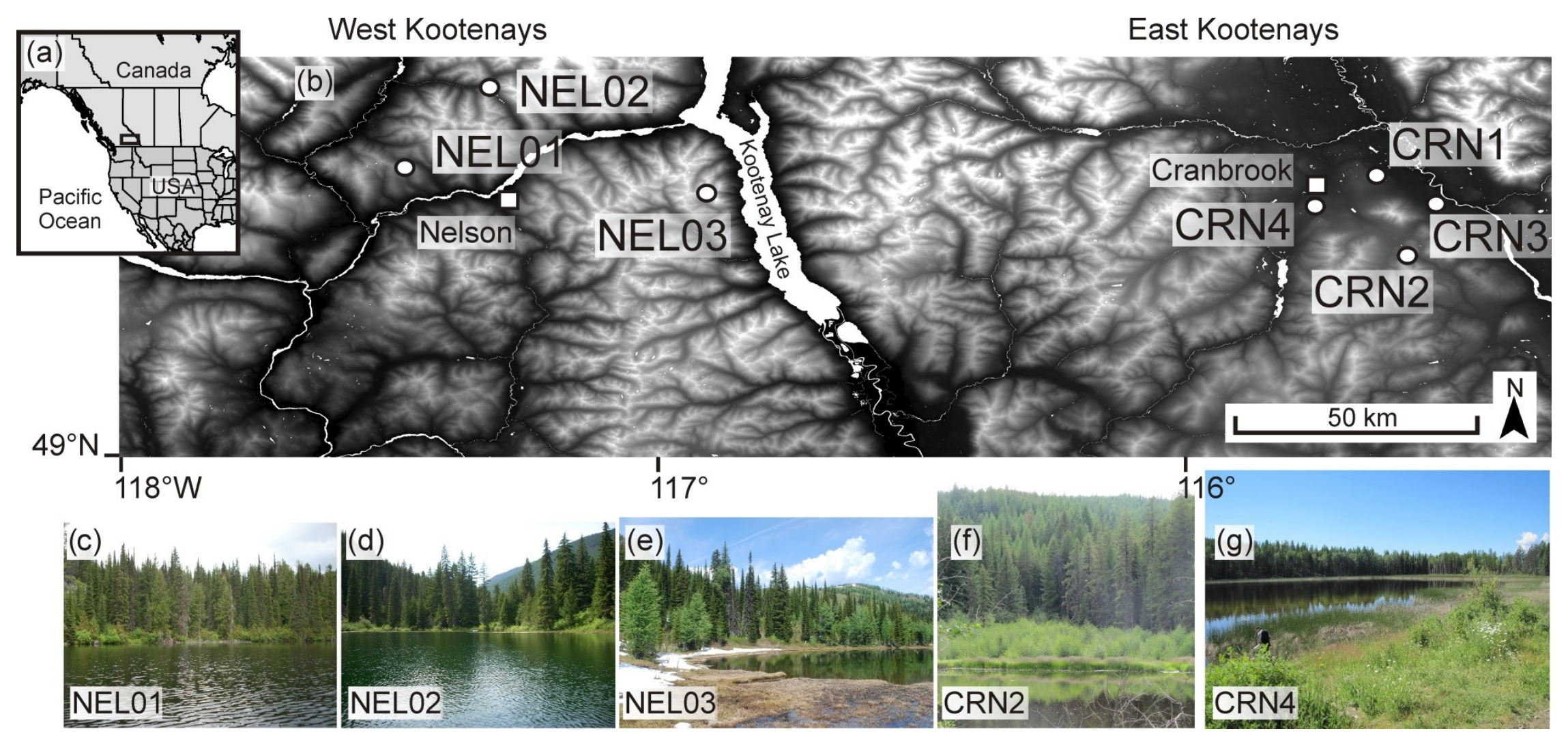

Figure 5.1: Location of study sites, (a) and (b), where Holocene-aged sedimentary charcoal fragments were examined to establish the morphological classification presented here. Photographs of forest vegetation near the study sites: (c) Engelmann spruce-subalpine fir at NEL01, (d) interior cedar-hemlock near NEL02, (e) Engelmann spruce-subalpine fir with abundant subalpine larch at NEL03 (photo credit: Ze'ev Gedalof), (f) ponderosa pine and bushes near CRN2, and (g) interior Douglas-fir, shrubs and Carex at CRN4 (photo credit $\mathrm{f}$ and g: Joelle T. Perreault). 
Morphotype

A Irregular polygons

A1

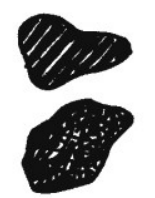

A3

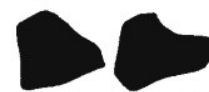

A4

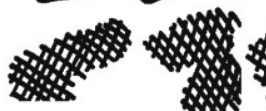

A5

A6

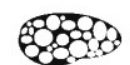

Key Features

Sources

Related Types

2D polygons, few $90^{\circ}$ angles

Textured surfaces exhibit planar foliations or are lignified

Fine dotting of small translucent features

Uniform plain surfaces

Reticulate, mesh pattern

Reticulate, mesh pattern, with venation

Thin framework around a significant amount of oval void spaces.
B2

B3

leaves

B5

Figure 5.2: Type A morphotypes: irregular polygons. 
Morphotype

B Blocky polygons and polyhedra

B1
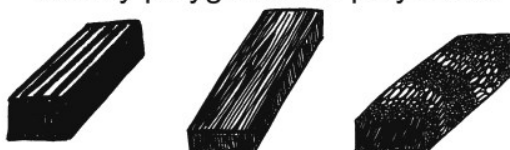

‥

B3

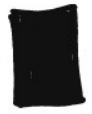

B4

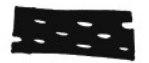

B5

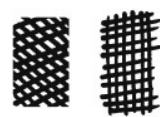

B6

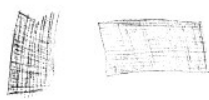

Key Features

Sources

Related Types

Quadrilateral face(s)

3D, textured surfaces exhibit planar wood foliations, or cellularity;

Lignified or earlywood/latewood.

2D, textured surfaces exhibit planar wood

B1 foliations, are lignified.

2D, texture is plain and uniform. wood, leaves?

A3, B4 Completely opaque.

2D opaque with oval voids.

leaves

Rarely with fine parallel venation. Graminoid leaves?

B3, D3

$2 \mathrm{D}$ or $3 \mathrm{D}$, reticulate, mesh pattern. wood?, needles

A4, B6

2D, very fine, translucent, cellular. wood?, needles? Easily broken. Some cell features.

Figure 5.3: Type B morphotypes: blocky polygons and polyhedra. 
Morphotype

C Long (Complex)

C1

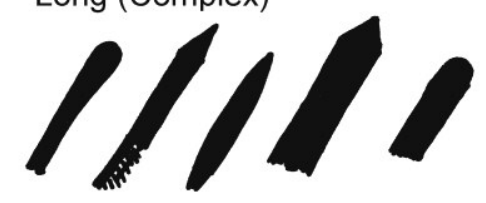

C2

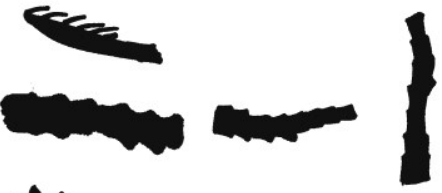

C3
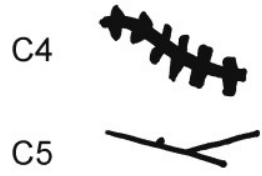

66
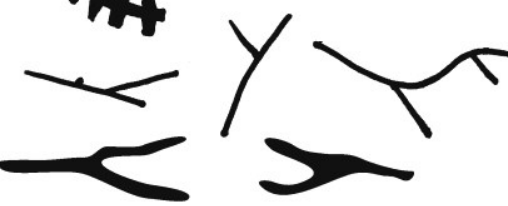

C7

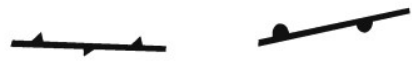

Key Features

Sources

Related Types

Elongated with distinctive features

3D, surfaces show structure: like cellularity and venation.

Internal structure is reticulated.

Elongated with ramifications. needles

Built of repetitive pieces.

twigs, Thuja needles

Multiple short embranchments on

$>1$ side

Very thin and embranched.

leaf veinlets

C6

Thick and embranched.

leaf veins, fine twigs

C5
C1

C2

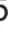

Figure 5.4: Type C morphotypes: long with complex features.

Elongated with short ramifications. fine twigs 
Morphotype

D Long (Simple)

D1 ||

D2

D3<smiles>C=CC=C</smiles>

E Spheroidal

E1

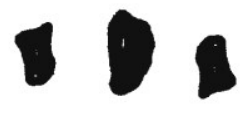

E2

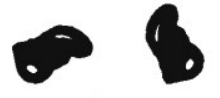

E3

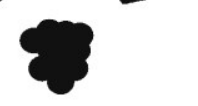

F Irregular

F1

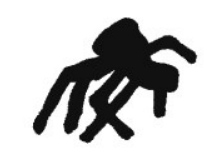

G

Glassy

G1

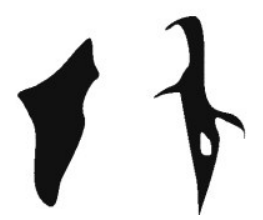

Key Features

Sources

Related Types

Elongated with few features. 2D.

Very thin and long.

D2

Thin, long, and flat.

D1

Thin, long, flat, with oval voids. Graminoid leaves

B4

Spheroidal, ellipsoidal, or ovoid, with an irregular surface.

$3 \mathrm{D}$, rounded.

ossil fuels,

accretion of volatiles,

sap/resin?

E2, E3

3D, rounded, with void spaces.

E1

3D, rounded, agglomerate, raspberry shaped or asymmetric.

E1

Complex shapes. 3D.

3D, bulky with tangled tubes. $\quad$ roots?

2D or 3D, complex shapes,

resin, seeds,

vitreous, resinous, dark, reflective, grasses

dense, sharp corners.

(Jensen et al., 2007)

Occasional voids, and sometimes

dendritic.

Figure 5.5: Type D, E, F and G morphotypes: long and simple, spheroidal, irregular, and glassy. 


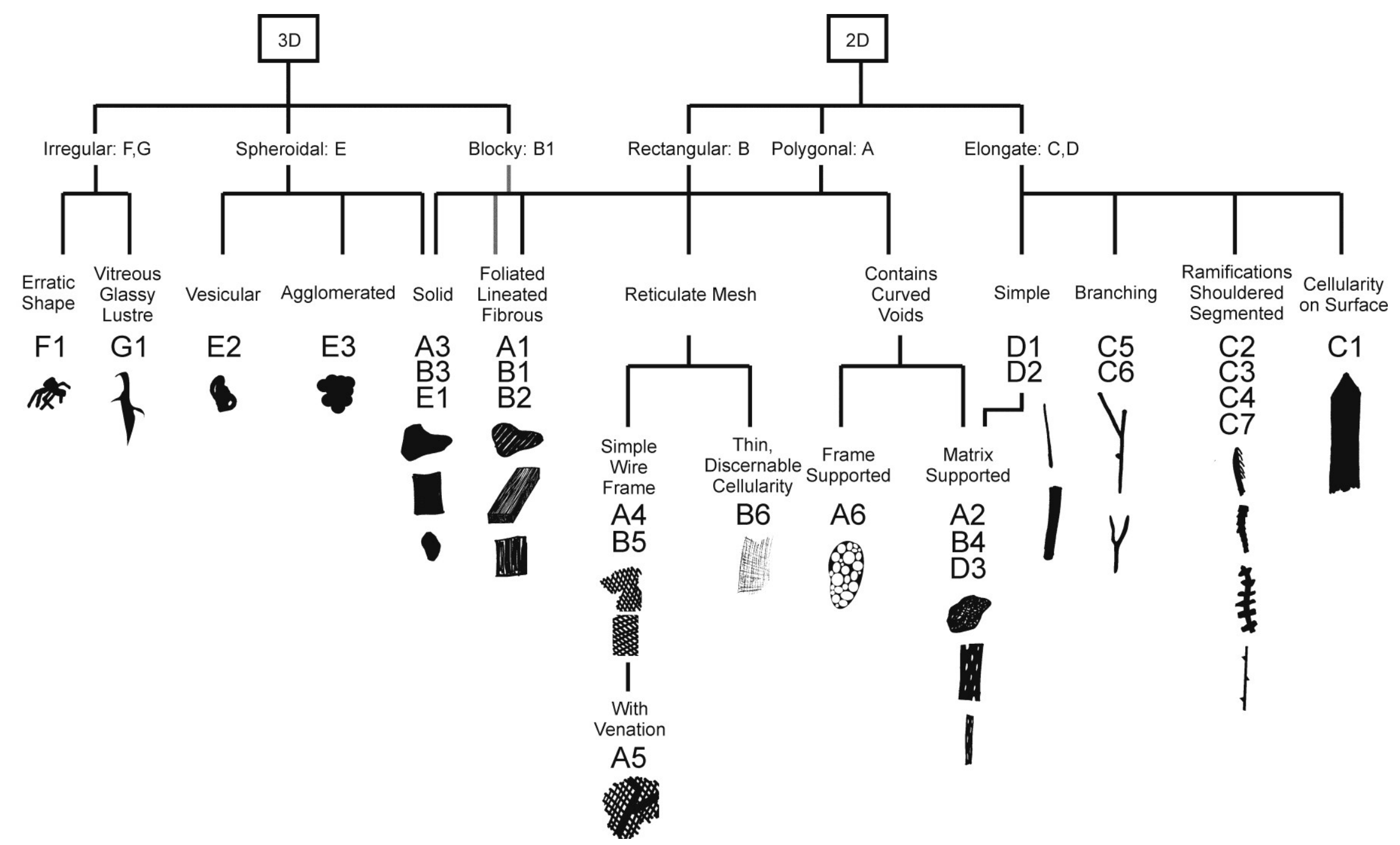

Figure 5.6: Classification key for sedimentary macroscopic charcoal morphology analysis. Note that the blocky (B1) pathway follows the grey lines and the D3 morphotype follows from the elongated-simple to the matrix supported curved features pathway. 
(a)

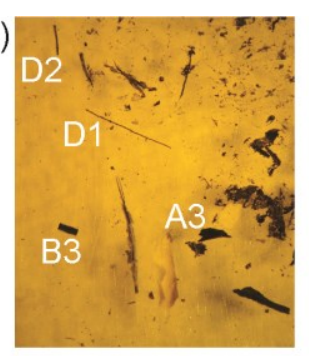

(b)

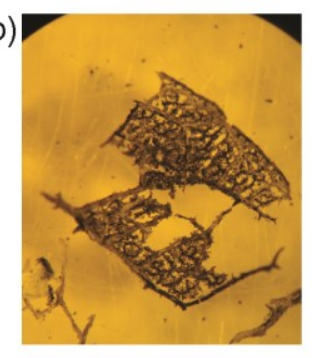

(c)

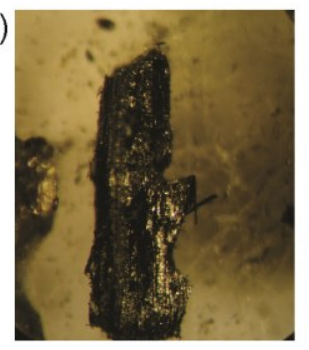

(d)

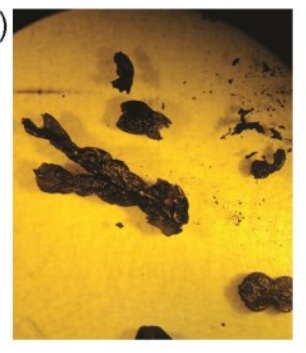

Monocot leaf

A3, B3, D1, D2

$5 X$ mag.

Deciduous leaf

A5

30X mag.

Wood

B1

30X mag.

Thuja needle

C3

5X mag.

(e)
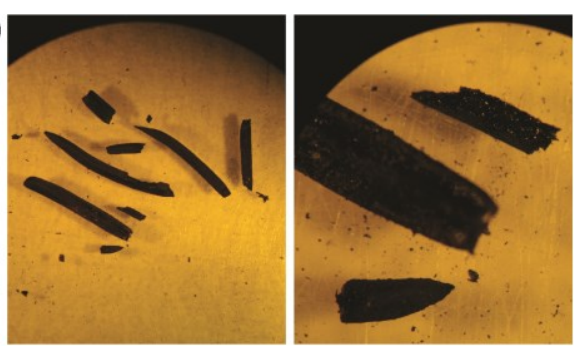

Picea needles

C1

5X, 20X mag.

(f)

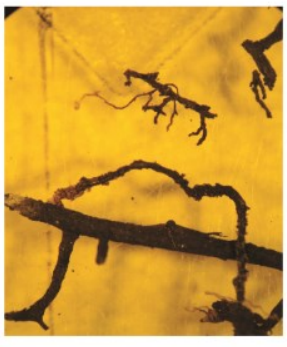

(g)

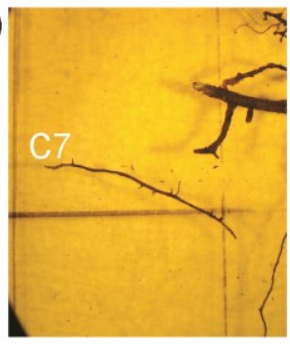

(h)

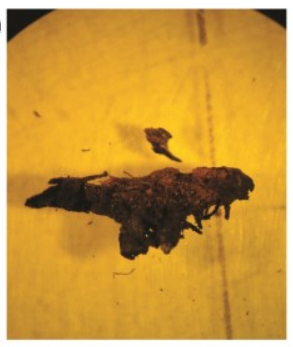

Poaceae roots, stolons

C6

10X mag.

Poaceae roots

C7

5X mag.

\section{Roots and soil}

F1

10X mag.

Figure 5.7: Stereomicroscope photographs of charcoal produced from open flame burning of known fuels.

Figure 5.8 (following page): Stereomicroscope photographs of charcoal found preserved in the Holocene sediments of lakes sampled near Nelson and Cranbrook, British Columbia. Black scale bars $(\mathrm{a}, \mathrm{g})$ represent $250 \mu \mathrm{m}$ and white scale bars (all others) show $500 \mu \mathrm{m}$. 
(a)

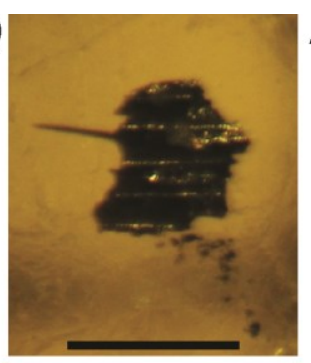

A1

(b)

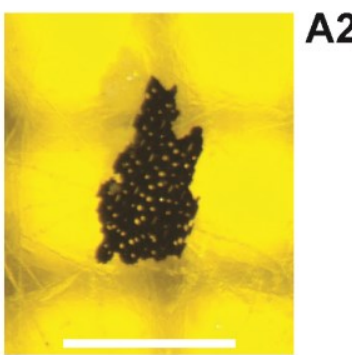

(c)

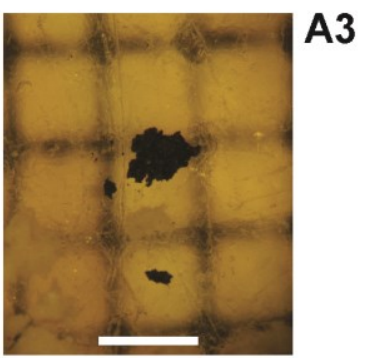

(d)

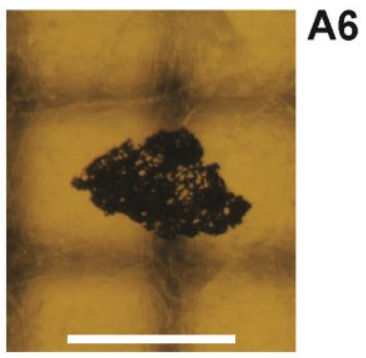

(e)

A6

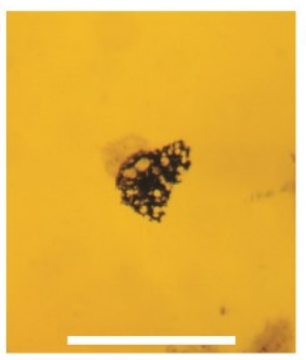

(f)

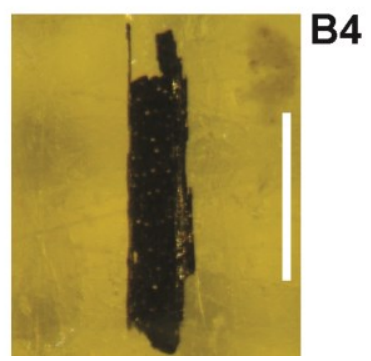

(g)

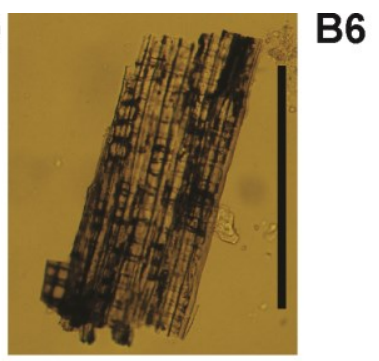

(h)

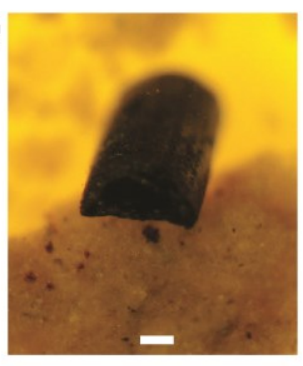

C1

Charred Pinus contorta needle

(i)

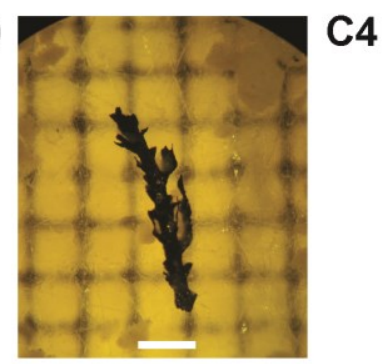

(j)

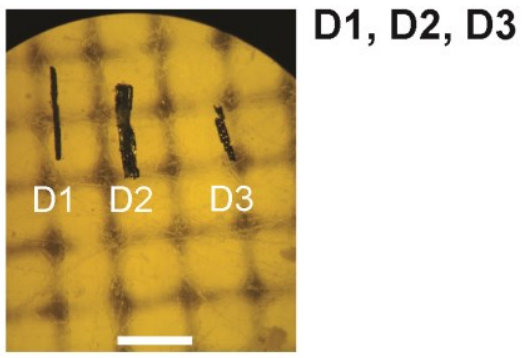

(k)

E1

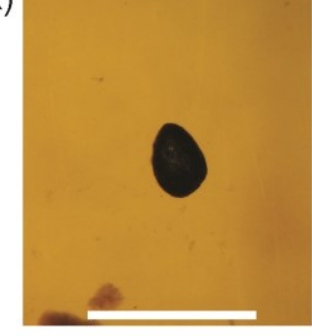

(l)

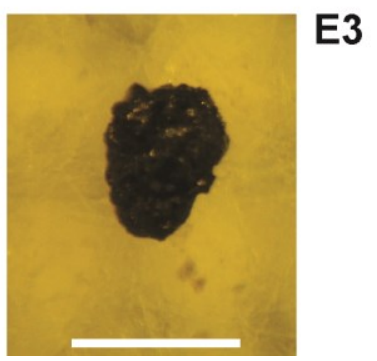




\section{Future Work}

Future work in the region should focus on three main areas: 1) the development of additional long-term paleoecological records, 2) multi-site comparative analyses and the incorporation of data into broad-scale syntheses, and 3) the advancement of paleoecological techniques related to disturbance regimes. This multi-pronged approach would lead to new insights into the fire control mechanisms in operation at various temporal and spatial scales and would be useful for establishing sustainable management strategies for the region as climate change and human influences continue to alter ecosystems.

The development of additional records would contribute to a more complete understanding of the variability of climate-vegetation-fire interactions, multiple disturbance interactions, and terrestrial-aquatic dynamics. Knowledge of the interrelated mechanisms operating at multiple temporal and spatial scales is crucial to public policy planning and sustainable practices in the region. The development of additional and longer records that can be used to analyse these interactions through major climate and human-environment changes during the Holocene has been identified as an important research direction in southeastern British Columbia (Gavin et al., 2006; Courtney Mustaphi and Pisaric, 2013). New records should be developed to provide a greater coverage across the large elevational, topographic, and vegetation gradients present in the region. Blending remote sensing, historical, dendrochronological, and sedimentological records of vegetation and disturbance histories would produce robust records for understanding the evolution of forests and fire regimes and improve our understanding of complex human-environment interactions. Lake sediment records can also provide details about stand- and catchment-scale interactions between the terrestrial and aquatic environments. Forest 
development and disturbance regimes have physical, chemical, and biological effects on aquatic systems and these can be investigated using sedimentological and paleoecological techniques. Physical sedimentology, isotope geochemistry, carbon-nitrogen ratios and planktonic assemblages can provide insight into terrestrial-aquatic interactions as well as how these systems have responded to environmental changes. Additional data collected during the preceding studies suggested a relationship between macroscopic charcoal accumulation rates and Daphnia populations in NEL01 and NEL03, which suggests a possible feedback between biomass accumulation, fire activity and a trophic cascade within the lake system. Additionally, ecological responses to abrupt events such as the large Cascadian volcanic ash deposits can provide information about ecosystem responses to major perturbations. Once records are established, analytical work should concentrate on interregional comparisons (ex. East versus West Kootenays) and should be incorporated in synthesis studies at regional, continental and global scales (ex. Global Charcoal Database; International Multiproxy Paleofire Database; PAGES Global Paleofire Working Group). Synthesis studies identify broad-scale trends in biomass burning and are useful for examining controls of fire at large spatial scales (Marlon et al., 2006; 2012; 2013; Power et al., 2008; 2012; 2013).

A number of methods can be used to reconstruct past fire activity, and generally, these methods are centered on the quantification of burn products, such as ash, charcoal, polycyclic aromatic hydrocarbons, and levoglucosan (Conedera et al., 2009). Additional details of past fire severity and fuel sources can be discerned through quantitative analyses of the morphology of the charcoal pieces preserved in sediments (Scott, 1974; Umbanhowar and McGrath, 1998; Enache and Cumming, 2006; 2007; 2009; Jensen et al., 2007; Walsh et al., 2008; 2010a; 2010b; Franzén and Malmgren, 2012; Moos and Cumming, 2012). Throughout data collection for this 
dissertation, a new classification system for subfossil macroscopic $(150 \mu \mathrm{m}-1 \mathrm{~cm}$ diameter $)$ charcoal was developed based on all of the morphologies observed. Future work should use this classification on deposits from known fires with known parameters (fire weather, fuel types, severity, distance to site of deposition) to examine the relationships between fire variables and the quantitative charcoal morphology assemblages. Experimental work on fuel burning and charcoal deposition could help understand linkages between fuels and fire type with deposited charcoal morphologies.

Research across all of the areas described above would generate useful data and knowledge about the variability of disturbance regimes in the Holocene forests of the region, the controls of disturbances and interactions between multiple types of disturbance. The knowledge gained through this work would improve our understanding of the mechanisms involved in the development of heterogeneous forests and would elucidate how these systems may respond to future climate and anthropogenic influences.

\section{Conclusions}

The development of multiple Holocene records of forest fire has allowed for the analysis of the relative importance of various spatial controls of fire as well as how those controls have varied through time. The results from this study highlight the usefulness of establishing multiple dendrochronological and sediment-based fire histories in a distinct region to examine the spatial controls of fire over long time periods. By quantifying how fire regimes have responded to past environmental change, this information can be used to better constrain models of the response of forests and fire regimes to global climate change and intensifying anthropogenic influences. The results of this research will be increasingly useful for advising environmental policy and achieving sustainable management goals as human activities in remote areas increases at the wildland-urban interface, and as conservation efforts become more concerted and the value of natural environmental services acknowledged. 


\section{References cited in the Introduction and Conclusion chapters}

Agee, JK. 1997. The severe weather wildfire: too hot to handle? Northwestern Science 71: 153156.

Appleby, PG. 2001. Chronostratigraphic techniques in recent sediments. In: WM Last JP Smol (eds.) Tracking Environmental Change Using Lake Sediments - DPER Volume 1: Basin Analysis, Coring, and Chronological Techniques. Dordrecht, The Netherlands: Kluwer Academic Publishers. p171-203.

Bennett, KD, Willis, KJ. 2001. Pollen. In: JP Smol, HJB Birks, WM Last, RS Bradley, and K Alverson (eds.) Tracking environmental change using lake sediments. Volume 3: Terrestrial, Algal, and Siliceous Indicators. Dordrecht: Kluwer Academic Publishers. p5-32.

Birks, HH. 2001. Plant Macrofossils. In: JP Smol, HJB Birks, WM Last, RS Bradley, and K Alverson (eds.) Tracking environmental change using lake sediments. Volume 3: Terrestrial, Algal, and Siliceous Indicators. Dordrecht: Kluwer Academic Publishers. p49-74.

Blaauw, M, Christen, JA. 2011. Flexible paleoclimate age-depth models using an autoregressive gamma process. Bayesian Analysis 6, 457-474.

Bowman, DMJS, Balch, J, Artaxo, P, Bond, WJ, Cochrane, MA, D’Antonio, CM, DeFries, R, Johnston, FH, Keeley, JE, Krawchuk, MA, Kull, CA, Mack, M, Moritz, MA, Pyne, S, Roos, CI, Scott, AC, Sodhi, NS, Swetnam, TW. 2011. The human dimension of fire regimes on Earth. Journal of Biogeography 38: 2223-2236.

Clark, JS. 1988. Particle motion and the theory of charcoal analysis: source area, transport, deposition, and sampling. Quaternary Research 30: 67-80.

Conedera, M, Tinner, W, Neff, C, Meurer, M, Dickens, AF, Krebs, P. 2009. Reconstructing past fire regimes: methods, applications, and relevance to fire management and conservation. Quaternary Science Reviews 28: 555-576.

Courtney Mustaphi, CJ, Pisaric, MFJ. 2013. Synchronous forest fire regimes between watersheds with similar aspect during the late Holocene, southeastern British Columbia, Canada. Journal of Biogeography 40: 1983-1996.

Enache, MD, Cumming, BF. 2006. Tracking recorded fires using charcoal morphology from the sedimentary sequence of Prosser Lake, British Columbia (Canada). Quaternary Research 65: 282-292.

Enache, MD, Cumming, BF. 2007. Charcoal morphotypes in lake sediments from British Columbia (Canada): an assessment of their utility for the reconstruction of past fire and precipitation. Journal of Paleolimnology 38: 347-363. 
Enache, MD, Cumming, BF. 2009. Extreme fires under warmer and drier conditions inferred from sedimentary charcoal morphotypes from Opatcho Lake, central British Columbia, Canada. The Holocene 19: 835-846.

Fægri, K, Iversen, J. 1989. Textbook of pollen analysis. New York, NY: John Wiley and Sons, Inc.

Foit, FF, Gavin, DG, Hu, FS. 2004. The tephra stratigraphy of two lakes in south-central British Columbia, Canada and its implications for mid-late Holocene volcanic activity at Glacier Peak and Mount St. Helens, Washington, USA. Canadian Journal of Earth Sciences 41, 1401-1410.

Franzén, LG, Malmgren, BA. 2012. Microscopic charcoal and tar (CHAT) particles in peat: a 6500-year record of palaeo-fires in southern Sweden. Mires and Peat 10: 1-25.

Gavin, DG, Brubaker, LB, Lertzman, KP. 2003. Holocene fire history of a coastal temperate rain forest based on soil charcoal radiocarbon dates. Ecology 84: 186-201.

Gavin, DG, Hu, FS, Lertzmen, KP, Corbett, P. 2006. Weak climatic control of stand-scale fire history during the late Holocene. Ecology 87: 1722-1732.

Gavin, DG, Hallett, DJ, Hu, FS, Lertzman, KP, Prichard, SJ, Brown, KJ, Lynch, JA, Bartlein, P, Peterson, DL. 2007. Forest fire and climate change in western North America: insights from sediment charcoal records. Frontiers in Ecology and the Environment 5: 499-506.

Gedalof, Z. 2011. Climate and Spatial Patterns of Wildfire. In: McKenzie, D., Miller, C., Falk, D. (Eds.), The Landscape Ecology of Fire. Springer, pp. 89-116.

Hallett, DJ, Anderson, RS. 2010. Paleofire reconstruction for high-elevation forests in the Sierra Nevada, California, with implications for wildfire synchrony and climate variability in the late Holocene. Quaternary Research 73, 180-190.

Hessl, AE. 2011. Pathways for climate change effects on fire: Models, data, and uncertainties. Progress in Physical Geography 35: 393-407.

Heyerdahl, EK, Brubaker, LB, Agee, JK. 2001. Spatial controls of historical fire regimes: A multiscale example from the interior west, USA. Ecology 82: 660-678.

Heyerdahl, EK, Lertzman, K, Karpuk, S. 2007. Local-scale controls of a low-severity fire regime (1750-1950), southern British Columbia, Canada. Écoscience 14: 40-47.

Higuera, PE. (2009) CharAnalysis 0.9: Diagnostic and analytical tools for sediment-charcoal analysis [User's Guide]. Available from http://CharAnalysis.googlepages.com

Higuera, PE, Brubaker, LB, Sprugel, DG. 2005. Reconstructing fire regimes with charcoal from small hollows: a calibration with tree-ring records of fire. The Holocene 15: 238-251 
Higuera, PE, Brubaker, LB, Anderson, PM, Hu, FS, Brown, TA. 2009. Vegetation mediated the impacts of postglacial climatic change on fire regimes in the south-central Brooks Range, Alaska. Ecological Monographs 79: 201-219.

Higuera, PE, Peters, ME, Brubaker, LB, Gavin, DG. 2007. Understanding the origin and analysis of sediment charcoal records with a simulation model. Quaternary Science Reviews 26: 17901809.

Higuera, PE, Gavin, DG, Bartlein, PJ, Hallett, DJ. 2010. Peak detection in sediment-charcoal records: impacts of alternative data analysis methods on fire-history interpretations. International Journal of Wildland Fire 19: 996-1014.

Higuera, PE, Whitlock, C., Gage, J. 2011. Linking tree-ring and sediment-charcoal records to reconstruct fire occurrence and area burned in subalpine forests of Yellowstone National Park, U.S.A. The Holocene 21: 327-341.

James, SR. 1989. Hominid use of fire in the Lower and Middle Pleistocene: a review of the evidence. Current Anthropology 30: 1-26.

Jensen K, Lynch, EA, Calcote, R, Hotchkiss, SC. 2007. Interpretation of charcoal morphotypes in sediments from Ferry Lake, Wisconsin, USA: do different plant fuel sources produce distinctive charcoal morphotypes? The Holocene 17: 907-915.

Kelly, RF, Higuera, PE, Barrett, CM, Hu, FS. 2011. A signal-to-noise index to quantify the potential for peak detection in sediment-charcoal records. Quaternary Research 75: 11-17.

Lynch, JA, Clark, JS, Stocks, BJ. 2004. Charcoal production, dispersal and deposition from the Fort Providence experimental fire: interpreting fire regimes from charcoal records in boreal forests. Canadian Journal of Forest Research 34, 1642-1656.

MacDonald, G. 2001. Conifer Stomata. In: JP Smol, HJB Birks, WM Last, RS Bradley, and K Alverson (eds.) Tracking environmental change using lake sediments. Volume 3: Terrestrial, Algal, and Siliceous Indicators. Dordrecht: Kluwer Academic Publishers. p33-47.

Marlon, J., Bartlein, P.J., Whitlock, C., 2006. Fire-fuel-climate linkages in the northwestern U.S. during the Holocene. Holocene 16, 1059-1071.

Marlon, JR, Bartlein, PJ, Gavin, DG, Long, CJ, Anderson, RS, Brilese, CE, Brown, KJ, Colombaroli, D, Hallett, DJ, Power, MJ, Scharf, EA, Walsh, MK. 2012. Long-term perspective on wildfires in the western USA. Proceedings of the National Academy of Sciences of the USA 109: E535-E543.

Marlon, JR, Bartlein, PJ, Daniau, A-L, Harrison, SP, Maezumi, SY, Power, MJ, Tinner, W, Vannière, B. 2013. Global biomass burning: a synthesis and review of Holocene paleofire records and their controls. Quaternary Science Reviews 65: 5-25. 
Moos, MT, Cumming, BF. 2012. Climate-fire interactions during the Holocene: a test of the utility of charcoal morphotypes in a sediment core from the boreal region of north-western Ontario (Canada). International Journal of Wildland Fire 21: 640-652.

Moritz, MA, Morais, ME, Summerell, LA, Carlson, JM, Doyle, J. 2005. Wildfires, complexity, and highly optimized tolerance. Proceedings of the National Academy of Science of the USA 102: 17912-17917.

Peters, ME, Higuera, PE. 2007. Quantifying the source area of macroscopic charcoal with a particle dispersal model. Quaternary Research 67: 304-310.

Pisaric, MFJ. 2002. Long-distance transport of terrestrial plant material by convection resulting from forest fires. Journal of Paleolimnology 28: 349-354.

Power, MJ, Marlon, J, Ortiz, N, Bartlein, PJ, Harrison, SP, Mayle, FE, Ballouche, A, Bradshaw, RHW, Carcaillet, C, Cordova, C, Mooney, S, Moreno, PI, Prentice, IC, Thonicke, K, Tinner, W, Whitlock, C, Zhang, Y, Zhao, Y, Ali, AA, Anderson, RS, et al. 2008. Changes in fire regimes since the Last Glacial Maximum: an assessment based on a global synthesis and analysis of charcoal data. Climate Dynamics 30: 887-907.

Power, MJ, Mayle, FE, Bartlein, PJ, Marlon, JR, Anderson, RS, Behling, H, Brown, KJ, Carcaillet, C, Colombaroli, D, Gavin, DG, Hallett, DJ, Horn, SP, Kennedy, LM, Lane, CS, Long, CJ, Moreno, PI, Paitre, C, Robinson, G, Taylor, Z, Walsh, M. 2012. Climatic control of the biomass-burning decline in the Americas After AD 1500. The Holocene 23: 3-13.

Power MJ, Mayle, FE, Bartlein, PJ, et al. 2013. $16^{\text {th }}$ Century burning decline in the Americas: population collapse or climate change? The Holocene 23: 3-13.

Pyne, SJ, Andrews, PL, Laven, RD. 1996. Introduction to Wildland Fire. New York: Wiley. 769pp.

Reimer, PJ, Baillie, MGL, Bard, E, Bayliss, A, Beck, JW, Blackwell, PG, Bronk Ramsey, C, Buck, CE, Burr, GS, Edwards, RL, et al. 2009. IntCal09 and Marine09 radiocarbon age calibration curves, 0-50,000 years cal BP. Radiocarbon 51: 1111-1150.

Rolland, N. 2004. Was the emergence of home bases and domestic fire a punctuated event? A review of the Middle Pleistocene record in Eurasia. Asian Perspectives 43: 248-280.

Scott, AC. 1974. The earliest conifer. Nature 251: 707-708.

Scott, AC. 2000. The pre-Quaternary history of fire. Palaeogeography, Palaeoclimatology, Palaeoecology 164: 281-329.

Scott, AC. 2009. Forest fire in the fossil record. In: A Cerdà and PR Robichaud (Eds.), Fire effects on soils and restoration strategies. Enfield, NH, USA: Science Publishers. p1-37. 
Scott, AC. 2010. Charcoal recognition, taphonomy and uses in palaeoenvironmental analysis. Palaeogeography, Palaeoclimatology, Palaeoecology 291: 11-39.

Scott, AC, Glasspool, IJ. 2006. The diversification of Paleozoic fire systems and fluctuations in atmospheric oxygen concentration. Proceedings of the National Academy of Sciences of the United States of America 103: 10861-10865.

Smol, JP. 2008. Pollution of Lakes and Rivers - A Paleoenvironmental Perspective. 2nd ed. Malden, MA: Blackwell Publishing. 383pp.

Solomon, AM, Silkworth, AB. 1986. Spatial patterns of atmospheric pollen transport in a montane region. Quaternary Research 25: 150-162.

Tinner, W, Hofstetter, S, Zeugin, F, Conedera, M, Wohlgemuth, T, Zimmermann, L, Zweifel, R. 2006. Long-distance transport of macroscopic charcoal by an intensive crown fire in the Swiss Alps - implications for fire history reconstruction. The Holocene 16: 287-292.

Umbanhowar, CE, McGrath, MJ. 1998. Experimental production and analysis of microscopic charcoal from wood, leaves and grasses. The Holocene 8: 341-346.

Walsh, MK, Whitlock, C, Bartlein, PJ. 2008. A 14,300-year-long record of fire-vegetationclimate linkages at Battle Ground Lake, southwestern Washington. Quaternary Research 70: 251-264.

Walsh, MK, Pearl, CA, Whitlock, C, Bartlein, PJ, Worona, MA. 2010a. An 11 000-year-long record of fire and vegetation history at Beaver Lake, Oregon, central Willamette Valley. Quaternary Science Reviews 29: 1093-1106.

Walsh, MK, Whitlock, C, Bartlein, PJ. 2010b. 1200 years of fire and vegetation history in the Willamette Valley, Oregon and Washington, reconstructed using high-resolution macroscopic charcoal and pollen analysis. Palaeogeography, Palaeoclimatology, Palaeoecology 297: 273-289.

Whitlock, C, Larsen, CPS. 2001. Charcoal as a Fire Proxy. In: J.P. Smol, H.J.B. Birks, W.M. Last, R.S. Bradley, and K. Alverson (eds.) Tracking environmental change using lake sediments. Volume 3: Terrestrial, Algal, and Siliceous Indicators. Dordrecht: Kluwer Academic Publishers. p75-97.

Whitlock, C., Higuera, PE, McWethy, DB, Briles, CE. 2010. Paleoecological Perspectives on Fire Ecology: Revisiting the Fire-Regime Concept. The Open Ecology Journal 3: 6-23. 


\section{Appendix}

\section{Appendix 1: Copyright License (Chapter 2)}

\section{JOHN WILEY AND SONS LICENSE TERMS AND CONDITIONS}

Jun 30, 2013

This is a License Agreement between Colin J Courtney Mustaphi ("You") and John Wiley and Sons ("John Wiley and Sons") provided by Copyright Clearance Center ("CCC"). The license consists of your order details, the terms and conditions provided by John Wiley and Sons, and the payment terms and conditions.

$\begin{array}{ll}\text { License Number } & 3178920368037 \\ \text { License date } & \text { Jun 30, } 2013 \\ \text { Licensed content publisher } & \text { John Wiley and Sons } \\ \text { Licensed content } & \text { Journal of Biogeography } \\ \text { publication } & \\ \text { Licensed content title } & \begin{array}{l}\text { Varying influence of clima } \\ \text { montane forest fire regim }\end{array} \\ & \text { south-eastern British Col } \\ \text { Licensed copyright line } & \text { C 2013 John Wiley \& Sons } \\ \text { Licensed content author } & \text { Colin J. Courtney Mustaphi } \\ \text { Licensed content date } & \text { Jun 3, 2013 } \\ \text { Start page } & \text { n/a } \\ \text { End page } & \text { n/a } \\ \text { Type of use } & \text { Dissertation/Thesis } \\ \text { Requestor type } & \text { Author of this Wiley article } \\ \text { Format } & \text { Print and electronic } \\ \text { Portion } & \text { Full article } \\ \text { Will you be translating? } & \text { No } \\ \text { Total } & 0.00 \text { USD } \\ \text { Terms and Conditions } & \text { None } \\ & \end{array}$




\section{Appendix 2: NEL03 spline and BACON age-depth models}

Age modelled depths developed for NEL03 using a cubic spline (Chapter 2) and iterative random walks using BACON (Chapter 3).

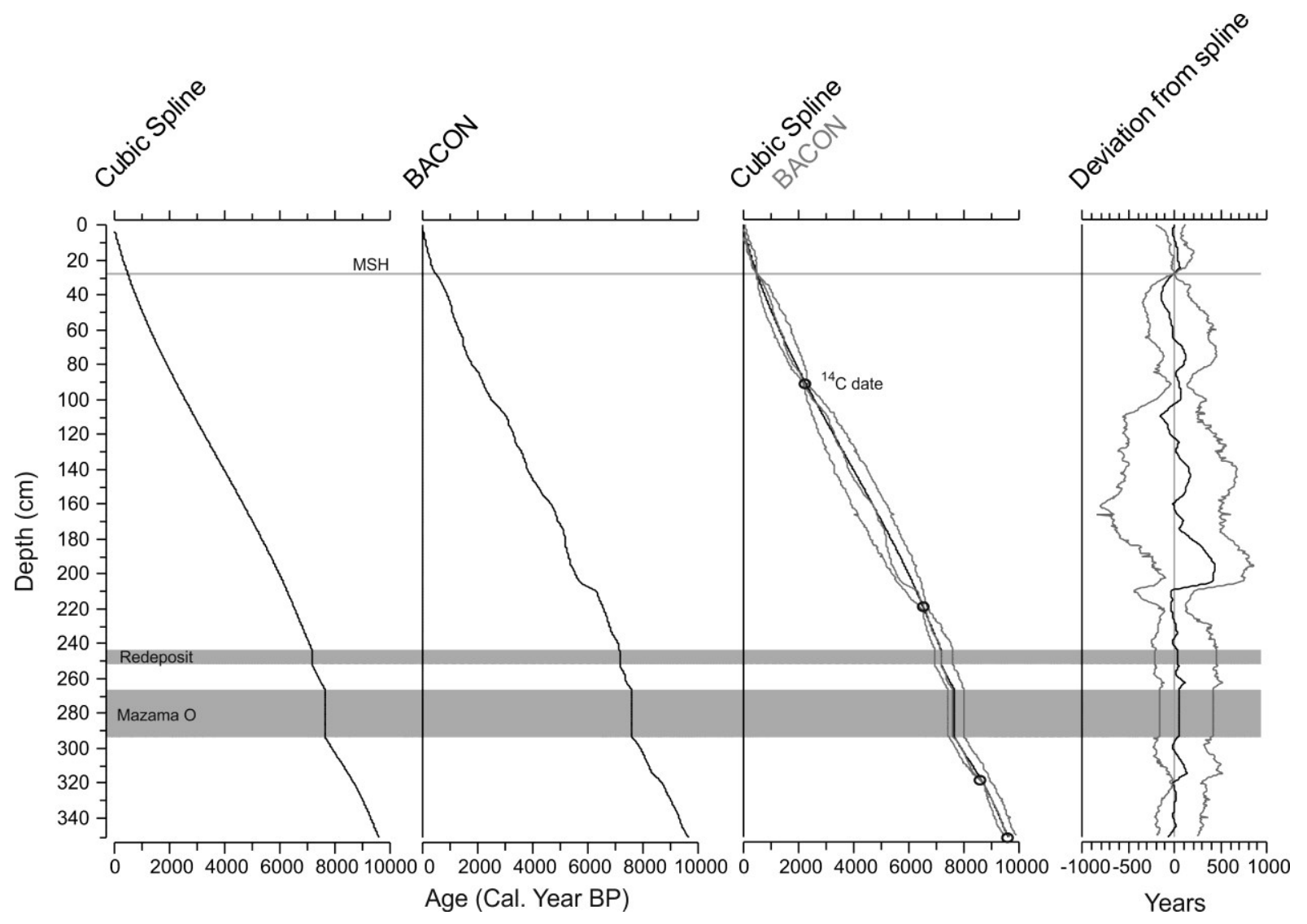

This figure shows the cubic spline interpolated dates (black line; see section 2.3.2) and the mean probable density of iterative random walks (grey line; see section 3.3.2) through the radiocarbon and tephra dates (Table 2.2) of NEL03. The 95\% confidence envelope is also shown by light grey lines. The deviation of the random walk chronology with the spline chronology is shown at right with the BACON derived 95\% confidence envelope deviation from the mean BACON ages (Blaauw and Christen, 2011). Tephra dates are shown in grey and radiocarbon dates locations in the stratigraphy are shown by open circles.

\section{Reference:}

Blaauw, M., Christen, J.A., 2011. Flexible paleoclimate age-depth models using an autoregressive gamma process. Bayesian Analysis 6, 457-474. 